\title{
PRE-SCHOOL CHILD MORTALITY IN THE NETHERLANDS BY
}

H. H. VAN GELDEREN M.D.

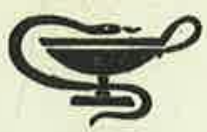

H. E. STENFERT KROESE N.V. - LEIDEN 
In de serie

\section{VERHANDELINGEN VAN HET NEDERLANDS INSTITUUT VOOR PRAEVENTIEVE GENEESKUNDE}

zijn de volgende delen verschenen :

I. Dr L. Bijlmer, Aetiologie der influenza. . . . . . . . ing. $f \quad 4.40$

II. L. A. M. vAN DER Spex, Serologische diagnostiek van kwaadaardige gezwellen. . . . . . . . . . . , , , 3.50

III. Prof. Dr S. T. Bor, De gedachtengang van de statistica, 2e druk . . . . . . . . . . . . . . . " , , 5. -

IV. Dr A. W. J. H. Horrink, Vitamine $\mathrm{C}$ en arbeid . . . . , , 6.-

V. De bestrijding van de thans heersende epidemie van geslachtsziekten . . . . . . . . . . . .

VI. Dr J. D. VenLINDE, De vergelijkende histopathologie van de niet-etterige ontstekingen van het centrale zenuwstelsel

VII. J. A. R. van Bruggen, Studies on the influenza A-epidemic of Januari-March 1941 at Groningen (Holland) .

VIII. De geestelijke volksgezondheid. . . . . . . . . . . .

IX. Selectie, scholing en omscholing . . . . . . . . . .

X. Dr Ir M. G. YDo, Plezier in het werk . . . . . . . .

XI. Dr D. Hoogendoons, Over de diphtherie in Nederland .

XII. De betekenis van de dierziekten voor de volksgezondheid

XIII. De hygiene van de volkshuisvesting . . . . . . . . .

XIV. Dr A. E. H. M. KamerbeEk, Het rubellaprobleem in het licht van Nederlandse ervaringen.

XV. L. M. DE Sonnaville, Een epidemie van mononucleosis infectiosa in de algemene practijk . . . . . . . .

XVI. Dr A. A. Botrer, Over de aetiologie van de strophulus infantum . . . . . . . . . . . . .

XVII. Dr P. DE BAAN, Haemagglutinatie door neurotrope virussoorten . . . . . . . . . . . . . . .

XVIII. Dr W. Winsemius, De psychologie van het ongevalsgebeuren . . . . . . . . . . . .

XIX. Dr H. A. E. van Tongeren, Een experimenteel onderzoek over influenza en secundaire micrococcus bij de muis . .

, , 8.-

,, $4 .-$

, , $5 .--$

,, 3.-

uitverkocht

uitverkocht

ing. $f$ 7.--

, , $3 .-$

, , 3.-

$,, 7,-$

,, $7 .-$

, , $5 .-$

,,$\quad 5 .-$

, , 6.-

,, , 7.50

XX. Dr A. H. Hutre, De invloed van moeilijk te verdragen situaties op groepsverhoudingen . . . . . . . . .

, , 8.50

XXI. Dr B. Hofman, Over een virusreceptorvernietigende eigenschap van speeksel en haar mogelijke betekenis voor de infectie met poliomyelitisvirus. . . . . . . . . , , ,6.50

XXII. Voeding en voedingstoestand van schoolkinderen en een groep jonge arbeiders te Leiden $(1950-1951)$. . . . . 
PRE-SCHOOL CHILD MORTALITY IN THE NETHERLANDS 
VERHANDELINGEN VAN HET

EK. $38 \%$

925

NEDERLANDS. INSTITUUT VOOR PRAEVENTIEVE ' GENEESKUNDE

XXVIII

\section{PRE-SCHOOL CHILD MORTALITY \\ IN THE NETHERLANDS}

BY

H. H. VAN GELDEREN M.D.

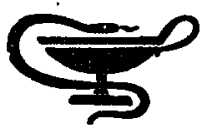

translated by

Ph. Vuysje and W. Mulhall Corbet, M.D.

I955

H. E. STENFERT KROESE N.V. - LEIDEN

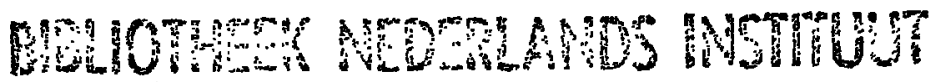




\section{FOREWORD}

When the Department of Health of the Netherlands Institute of Preventivc Medicine was established in 1952, the analysis of child mortality in its historical trend and present state was considered to be one of our first and main duties.

The Netherlands Central Bureau of Statistics has accumulated a wealth of data on child mortality. In the past two years part of this material has been explored.

An analysis of child mortality in western countries reveals five main facts: I - a similar trend in the different age groups of childhood

2 - a decreasing importance of classical causes of death, such as tuberculosis, infectious diseases and respiratory infections

3 - an increasing relative importance of accidents

4 - a tremendous post-war decline

$s-a$ quantitative predominance of perinatal mortality.

In the Netherlands perinatal mortality has been analysed recently in an impressive historical statistical study.

A modern analysis of post-natal infant mortality has been postponed, because it may be more or less understood from the literature on this classical subject of child mortality.

The interest of Dr VAN GRLDEREN soon turned to pre-school child mortality His thesis, which is now published as a monograph, bears witness to his keen work and thorough study.

Pre-school child mortality has aroused but little interest in this country; foreign literature gives more information. It became obvious that more light would be thrown on child mortality in general by an analysis of pre-school child mortality than by a similar study of any other age group in childhood.

The decline in (pre-school) child mortality has been achieved much more by the relatively slow process of increasing social consciousness and improvement of social conditions than by the apparently more spectacular results of curative medicine.

An important aspect of this study may be that pre-school child mortality can be used as a sensitive indicator of health conditions, with special reference to the social and economic background.

Pre-school child mortality should be considered together with school child mortality and mortality in adolescence. An analysis of the figures of these age groups is being published separately. An atlas will give a general survey of child mortality in the Netherlands. Most fascinating was an analysis of the recent dramatic decline of tuberculosis mortality in childhood, described partly in this monograph.

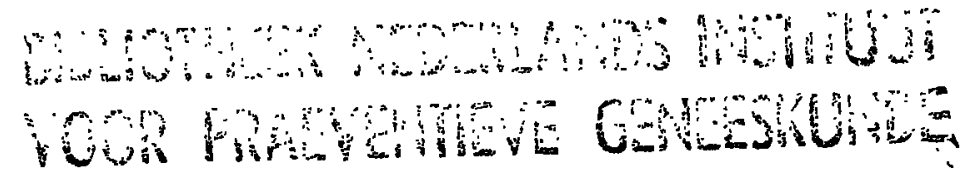


In general, analysis of mortality figures in childhood, especially in pre-school children, gives the impression that a dream of social pediatrics is being realised.

We should never forget, however, that childhood in the greater part of the world still shows igth century European mortality figures.

A study of child mortality is not an aim in itself, but has the purpose of placing child mortality against the background of social medicine, bringing to life seemingly dead and dry statistical data. This purpose seems to bc realised in this monograph: it reveals psychological differences between very young boys and girls, a different mental attitude in different areas, interesting sociological facts and the influence of economic conditions on child life. Moreover this study shows gaps in the medical organisation, thus making an important contribution to the evaluation of public health work.

May this monograph give a stimulus to the further development of social pediatrics in the modern and humane sense of the word, so as to establish a policy in maternal and child health services which has as its only purpose the promotion of health and happincss of families, mothers and children in a welfare state.

Leyden, March I95s

J. H. De HaAs 


\section{CONTENTS}

Foreword by Dr. J. H. de Haas . . . . . . . . v

Introduction. . . . . . . . . . . I

Chapter I The proportion of children of pre-school age to the general population of the Netherlands. . . . . . 3

Chapter Il Total pre-school age mortality. . . . . . . . . 7

Chapter III Comparison of child mortality and total mortality : . Is

Chapter IV Mortality of pre-school children according to sex. . . I8

Chapter V Seasonal influence on the mortality of children of preschool age. . . . . . . . . . . . 22

Chapter VI Pre-school age mortality according to provinces . . . 25

Chapter VII . Mortality of children of pre-school age in rural areas and in towns ............. 37

Chapter VIII Causes of death and nomenclature ........ 40

Chapter IX Mortality of children of pre-school age according to cause of death . . . . . . . . . . . 43

Chapter $\mathrm{X}$ Violent deaths (accidents) . . . . . . . . . 66

Chapter XI Causes of death in children of pre-school age in the various provinces. . . . . . . . . . : . : . 79

Chapter XII Causes of death in rural and urban areas. . . . . . 83

Chapter XIII Mortality of children of pre-school age, economic conditions and size of the family . . . . . . 86

Chapter XIV Number of pre-school children dying in hospital. . . IOI

Chapter XV Literature................ I06

Chapter XVI Pre-school age mortality in various countries..... II3

Chapter XVII A glance into the future. . . . . . . . . . . I22

Summary . . . . . . . . . . . I25

References ............. $\mathrm{I} 34$ 


\section{LIST OF FIGURES}

I Population pyramid . . . . . . . . . . . . . . 4

2 Changes of population by age under 5 years. . . . . . . 5

3 Child mortality in the Nctherlands, 1840-1953. . . . . . . 7

4 Percentage distribution of deaths in pre-school children by age, 1900-r909 and 1950-1952 ............ I3

5 Death ratc of infants and pre-school children, 1933-1953. . . I4

6 Deaths by age in childhood in percent of total deaths (standardized), 1908-1952 . . . . . . . . . . . . . . r6

7 Mortality in prc-school age according to seasons, 1900-1952. . 22

8 Deaths in pre-school age according to seasons and population of boroughs, 1950-1952 ............. 23

9 Infant mortality in the provinces, 1900-1953 . . . . . 28

Io Main causes of death in pre-school age, 1908-1952 . . . . 46

I $a$ Death rates from common infcctious diseases by age, 1950-1952 47

II $b$ Deaths from diphtheria, measles and whooping cough in childhood in percent of total mortality from these diseases, 1908-1952 . .

12 Dcath rates from some infectious diseases and pneumonia in preschool age, 1930-1953. . . . . . . . . . . $4^{8}$

I3 Total mortality and deaths from tuberculosis in pre-school age, I9Io-1953 . . . . . . . . . . . . . sI

I4 Death rate from tuberculosis in childhood, I9I0-I9S3 . . . SI

I5 Decrease of tuberculosis indices by age, 1949-1953. . . . 52

16 Death ratc from tuberculosis and tuberculous meningitis, $1923-\mathrm{r} 953 \quad 53$

17 Death rate from congenital malformations in infants and pre-school children, 1908-1952................. ss

I8 Main causes of death in pcrcent of total deaths in pre-school age, 1908-1952 . . . . . . . . . . . 6 60

19 Percentage distribution of deaths in pre-school children by causc and sex, 1950-1952 .................. 6I

20 Percentage distribution of deaths in pre-school age by cause and age, I950-I952 . . . . . . . . . . . .

2I Deaths from violence in percent of total deaths at pre-school age, I908-I952 . . . . . . . . . . . . .

22 Mortality of I-4-ycar-old children in some European countries, I900-r9s2 . . . . . . . . . . . . . . 


\section{INTRODUCTION}

Efficient preventive medical work can only be done if the best picture possible is previously obtained of the social and hygienic conditions of the people, i.e., the general state of health, incidence and spread of diseases, and the social and economic relationships. The future direction of development of the public health services is not only determined by the present situation, but also by the conditions of the past and the changes that have occurred in them.

A detailed analysis of the death statistics is still one of the most important means of studying the morbidity conditions of a large part of the population over a long period. This is particularly true for the changes in the death rate in the course of years, these changes reflecting the improvement of the general state of health. A direct measurement of the disease factors by means of general morbidity statistics has only rarely been successful and even then it has not been fully adequate.

Mortality statistics form a seemingly dry subject, but they contain an unexpectedly rich source of data, enabling us to trace phenomena that are not to be deduced from separate observations. The apparent contrast between the dry figures and the wealth of material hidden by them, is strikingly expressed in the following quotation from an editorial article in the Journal of the American medical Association (1953, 153: 1177).

'When persons speak of the dryness of statistics they are, of course, generally expressing their boredom rather than voicing the conclusions from a well-considered appraisal. In reality, the amount of human success, suffering, failure and happiness that is packed in some statistical reports is, in the literal sense of the word, tremendous'.

Study of the child mortality may also yield this wealth of facts, which constitute an indispensable basis for preventive paediatrics. Child mortality is usually only regarded, in a limited sense, as a synonym of infant mortality. The relatively high infant death rate has always attracted interest to such an extent that the study of the mortality of older children has been perfunctory.

- The mortality of children of pre-school age has always been high in comparison with that of schoolchildren, adolescents and young adults. The changes in the mortality and morbidity rates of pre-school children have most 
certainly bcen as great and significant as those in infants, but less is known of them. The Child Health Services in the Netherlands have paid less attention to pre-school children than to infants and schoolchildren, so that the social and medical care of the first group is badly in arrears. There are cvidently reasons enough to study the development of the mortality of children of pre-school age.

An analysis of child mortality according to age up to the present time has been carried out in the new Department of Maternal and Child Health of the Netherlands Institute of Preventive Medicine at Leyden. The important changes in the pre-school age mortality and their significance for child hygienc, and the scanty knowledge of this subject, induced me to carry out a more extensive investigation into the trend of the pre-school age death rate.

The prescnt study is an attempt to analyse this trend and thus to contribute to the acquisition of a better understanding of the interplay of forces deterunining the morbidity and mortality rates in children of pre-school age, and of its significance for 'positive' public health, i.e. promoting the health of the young child. 
THE PROPORTION OF CHILDREN OF

\section{PRE-SCHOOL AGE TO THE GENERAL POPULATION OF THE NETHERLANDS}

In our population we have nearly $10 \%$ children of pre-school age. This term denotes the group of children from I-4 years old inclusive, a definition used by the international mortality statistics. This definition is well suitable for our purpose, but it lacks a biological basis. In the study of child development, the pre-school age also comprises older children, up to 6-7 years, and it forms the transition period from infant to schoolchild.

The percentage of pre-school children to the whole population is not constant. This figure has risen since the middle of the Igth century, reached its culmination point in about $\mathrm{I} 880$, and then again fell slowly. The lowest point was reached in 1940.

\section{TABLE I}

Proportion of the children of pre-school age to the whole population of the Netherlands since 1849 *

\begin{tabular}{c|c|c}
\hline year & $\begin{array}{c}\text { number of children } \\
\text { from I-4 years }\end{array}$ & $\begin{array}{c}\text { in of the } \\
\text { population }\end{array}$ \\
\hline & & \\
1849 & 265,121 & 8.7 \\
1859 & 304,121 & 9.2 \\
1869 & 360,260 & 10.1 \\
1879 & 420,038 & 10.5 \\
1889 & 459,893 & 10.2 \\
1899 & 516,392 & 10.1 \\
1909 & 577,544 & 9.9 \\
1920 & 594,026 & 8.7 \\
1930 & 661,172 & 8.4 \\
1940 & 669,789 & 7.5 \\
1950 & 978,962 & 9.7 \\
1952 & 929,443 & 9.0 \\
\hline
\end{tabular}

* In this and all other tables the term pre-school denotes the I-4 jears age group. 
The marked relative increase of the number of pre-school children in the post-war years was soon followed by a fall (table I). The absolute number has nearly doubled since I900: from over 500,000 to over 900,000 . The relative decrease of the number of pre-school children after about 1880 is the result of the decline of the birth and death rates. The percentage of this group to our population has decreased less (by $30 \%$ ) between 1880 and 1940 than the birth rate during the same period (about $40 \%$ ).

Because the average length of life of the population is also increasing (which in itself causes a fall in the relative number of children of pre-school age), the tendency to reduction resulting from the falling birth rate is further increased.

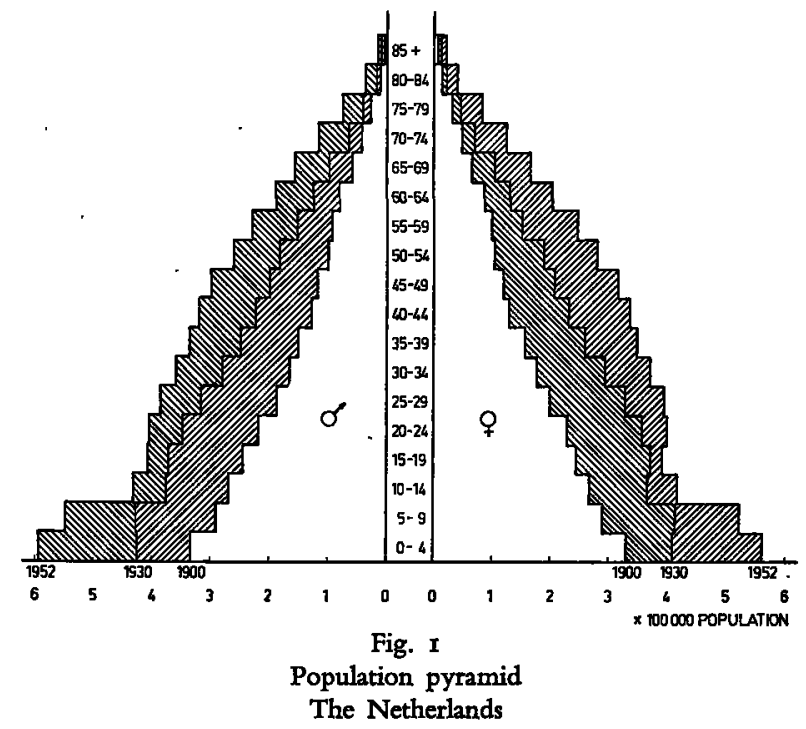

The fact that in spite of this, the relative decline of the number of pre-school children is less than that of the births, is mainly due to the very great reduction of mortality in the early years of life. This is one of the reasons why the percentage of children of pre-school age in the Netherlands is about the same as it was a century ago, notwithstanding the considerable increase in age of the population as a whole (see fig. 1).

Fig. 2, a 'population pyramid' of the children under six years clearly shows the marked fluctuation in the number of pre-school children during recent years, owing to the low birth rate in 1945 and the considerable rise in the number of births after that year.

There are more boys than girls in the I-4 age group. In the first half of the present century the number of boys has increased from ror.6 to I05.6 per Ioo girls. 
The ratio of newborn boys to newborn girls has remained practically unchanged since 1924 (when the Central Bureau for Statistics recorded for the first time the liveborn children who died before their birth was notified, as born alive). This may readily be explained by the relatively slight fall of the stillbirth rate. Because far more boys than girls are born dead, a marked decrease of the stillbirth rate.would have led to an increase in the number of boys born alive. The ratio of liveborn boys to liveborn girls in 1926-1930 was $106.4: 100$, and in 1951-1952 106.5: 100.
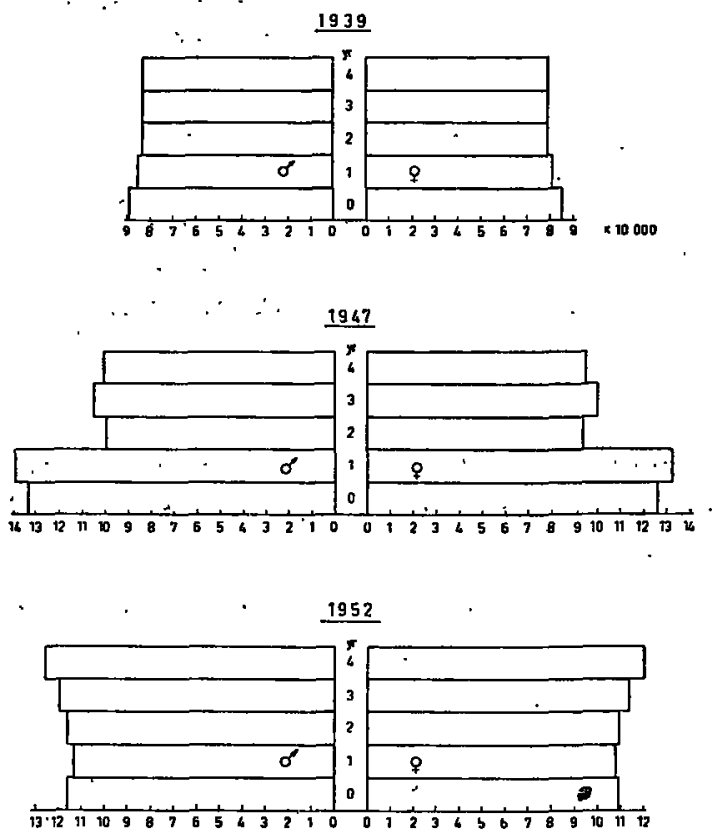

- Fig. 2

Changes of population by age under 5 -years The Netherlands

The rise in the number of boys as compared to the number of girls of preschool age is not due to a relative increase of boys among the newborn, and its cause must therefore be sought in reduced mortality in the first years of life, especially infant mortality. As the death rate of male infants always considerably exceeds that of female ones, and this ratio shows little change, a fall in infant mortality leads to a greater increase of the number of male survivors than of female.

It is remarkable that the decline of infant mortality since I924 has not been accompanied by any marked change in the proportion between deceased boys and girls. In other words; the reduction of the mortality in the first year 
of life has been the same for boys and girls, and so far there is no question of a levelling. out of the difference in mortality figures for both sexes. The male. sex remains the weaker at the beginning of life.

Both the number of boys born alive and the number of boys who die in the first year of life always exceed the corresponding figures for girls. The male birth surplus is reduced by this greater number of deaths among boys, but this reduction becomes less and less with the further fall of the infant mortality. This results in a greater surplus of boys of pre-school age. The present infant mortality has become so low that a further reduction can only have a very slight influence on the male birth surplus.

It is therefore to be expected that, even if the difference in infant mortality between the two sexes disappears, the male surplus among pre-school children will change only little. This can also be concluded from a study published by the Central Bureau for Statistics on the future trend of the population structure: it is expected that in 1980 there will be about 852,000 children aged from I-4 years. This forecast is reproduced in table II.

TABLE II

Forecast of the number of children from 1-4 years in the Netherlands (given average matrimonial fertility and average number of married women $*$ )

\begin{tabular}{c|c|c|c|c|c}
\hline \hline year & boys & gitls & total & b/g $\times$ I00 & $\begin{array}{c}\% \text { of the } \\
\text { population }\end{array}$ \\
\hline & & & & & \\
1950 & 503,000 & 476,000 & 979,000 & 105.6 & 9.7 \\
1960 & 398,000 & 377,000 & 775,000 & 105.5 & 6.9 \\
1970 & 401,000 & 380,000 & 781,000 & 105.5 & 6.4 \\
1980 & 437,000 & 415,000 & 852,000 & 105.5 & 6.5 \\
\hline
\end{tabular}

* numbers taken to the nearest thousand.

Table II shows that the number of pre-school children will probably fall in the following decades. If the emigration of young people takes on large proportions, this decrease of the number of pre-school children will even be considerably greater. The present proportion of the I-4 age group to the total population of nearly 10\% will probably fall to $6.5-7 \%$. Although these figures are based on assumption ${ }^{1}$, those whose task it is to take measures in the interest of the pre-school group will do well to realize to some extent the future number of these children in our country.

1 In a revised edition (1954) the Central Bureau for Statistics gives as estimates of the future preschool age population in the Netherlands figures that are fồ-15 \% higher than those mentioned in table II. 
The mortality figures classified according to age have been regularly recorded in the Netherlands since I840. It is possible that in the early years of the recording of these figures not all the deaths were included in them, which may make these very early data somewhat too optimistic.

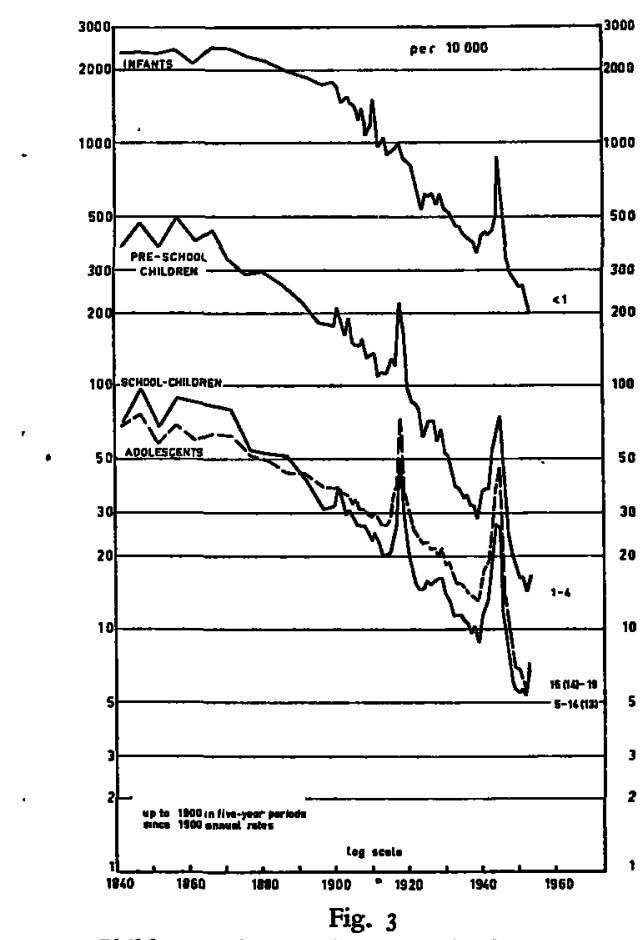

Child mortality in the Netherlands $1840-1953$

Graph 3 and table III show the course of child mortality per I0,000 of each age group ${ }^{1}$, in 5-year periods from I840 to I900, and subsequently per year. The marked decline for all juvenile age groups is clearly visible, but, in

1 The censuses of 1839,1849 etc. were used for the composition of the age groups up to I900; it is assumed that the increase of the population between two censuses has always been rectilinear. 
addition to this general tendency to decrease, there are a number of other remarkable features. The mortality of the pre-school children initially remained at a high level, just as that of the schoolchildren, but as early as about the year I875 a sharp fall began which has continued up to now, interrupted during the two world wars.

TABLE III

Child mortality rate according to age in the Netherlands (1840-1953)

\begin{tabular}{|c|c|c|c|c|c|}
\hline \multirow{2}{*}{ period } & \multicolumn{5}{|c|}{ death rate per 10,000} \\
\hline & $<\mathrm{I}$ & $I-4$ & $5-14 x$ & & Is $-19{ }^{\star}$ \\
\hline I840-'44 & 2332 & 375 & 70 & & 69 \\
\hline I $845-' 49$ & 2354 & 464 & 96 & & 76 \\
\hline I 850-'54 & 2308 & 371 & 66 & & $5^{8}$ \\
\hline I855-'59 & 2400 & 489 & 89 & & 68 \\
\hline I 860-'64 & 2116 & 399 & 85 & & 59 \\
\hline $1865-70$ & 2434 & 432 & $8 \mathrm{I}$ & & 63 \\
\hline I870-'74 & 2428 & 331 *ᄎ & 79 & & 62 \\
\hline I 875-'79 & 2254 & $288 \star \star$ & 54 & & 52 \\
\hline I880-'84 & 2128 & $292 \star \star$ & 52 & & $4^{8}$ \\
\hline I $885-' 89$ & I980 & 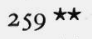 & 50 & & 44 \\
\hline I 890-'94 & I 856 & $220 \star \star \star$ & $4 \mathrm{I}$ & & 44 \\
\hline I 895-'99 & I7I 4 & I79 & $3 I$ & & 38 \\
\hline I900 & I73I & I74 & 32 & & 37 \\
\hline I9OI & 1696 & 207 & 37 & , & 38 \\
\hline I902 & I 435 & 185 & 34 & & 36 \\
\hline 1903 & I490 & 160 & 29 & & 35 \\
\hline 1904 & I5I6 & I 87 & 30 & & 35 \\
\hline I905 & I 437 & I5O & 28 & & 33 \\
\hline I906 & I396 & I 45 & 27 & & 34 \\
\hline 1907 & I22I & I 44 & 26 & & $3 I$ \\
\hline r9o8 & 1355 & I 54 & 26 & & 30 \\
\hline 1909 & 1066 & I 28 & 24 & & 29 \\
\hline I9IO & I I 49 & I3 I & 23. & & 28 \\
\hline I9I I & $\mathrm{I} 482$ & I 34 & 24 & & 29 \\
\hline I9I2 & 948 & IO8 & 23 & & 28 \\
\hline I9I3 & 977 & II 2 & 20 & & 27 \\
\hline I9I4 & IOI6 & IIO & 20 & & 26 \\
\hline I9IS & 893 & II 7 & 20 & & 28 \\
\hline I9I6 & 906 & I26 & 23 & & 35 \\
\hline I9I7 & 923 & I $2 \mathrm{I}$ & 26 & & $38 \ldots$ \\
\hline I9I 8 & 973 & 225 & 48 & & 68 \\
\hline I9I9 & 885 & I6I & 28 & & 36 \\
\hline I920 & 827 & 96 & $2 I$ & & 33 \\
\hline I92I & 795 & 85 & I7 & & $25, \ldots$ \\
\hline 1922 & 690 & 84 & Is & & 25 \\
\hline
\end{tabular}




\begin{tabular}{|c|c|c|c|c|c|}
\hline & \multirow{2}{*}{ period } & \multicolumn{4}{|c|}{ death rate per I0,000 } \\
\hline & & $<\mathrm{I}$ & $\mathbf{I}-$ & $5-14$ * & I5-19 * \\
\hline & I.923 & 596 & 79 & I4 & 23 \\
\hline & 1924 & 522 & $6 c$ & Is & 22 \\
\hline & 1925 & 602 & 6 & I6 & 23 \\
\hline & 1926 & 598 & $7 C$ & IS & $2 I$ \\
\hline & 1927 & 607 & 7 & IS & $2 \mathrm{I}$ \\
\hline & 1928 & 549 & 58 & 16 & 20 \\
\hline & 1929 & 608 & 6 & I6 & $2 I$ \\
\hline & 1930 & 537 & 52 & I4 & I 8 \\
\hline & 1931 & 509 & 5 & I3 & 19 \\
\hline & I932 & $48 \mathrm{I}$ & 44 & II & 17 \\
\hline & I933 & 444 & 38 & II & I5 \\
\hline & I934 & $44 \mathrm{I}$ & 37 & II & I5 \\
\hline & 1935 & 410 & 34 & II & I5 \\
\hline & 1936 & 402 & 35 & 10 & 14 \\
\hline & 1937 & 390 & 32 & 10 & 13 \\
\hline & 1938 & 384 & 32 & 10 & 13 \\
\hline & 1939 & 349 & 28 & 9 & I3 \\
\hline & 1940 & 406 & $3 c$ & II & 17 \\
\hline & I94I & 446 & 37 & 12 & 18 \\
\hline & 1942 & 416 & 37 & I3 & .. $\quad 18$ \\
\hline & I943 & 434 & 54 & 19 & 24 \\
\hline & I944 & $49 I$ & 63 & 27 & 38 \\
\hline & I945 & 815 & 74 & 25 & 45 \\
\hline & I946 & 465 & 45 & 12 & 14 \\
\hline & I947 & 334 & 24 & 8 & II \\
\hline & I948 & 289 & $2 c$ & 6 & 8 \\
\hline & I949 & 268 & IS & 6 & 7 \\
\hline & I950 & 253 & IC & 5 & 7 \\
\hline & I95I & 255 & IC & 6 & 6 \\
\hline & 1952 & $23 \mathrm{I}$ & Is & 5 & 6 \\
\hline & 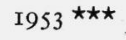 & 219 & Is & 5 & 6 \\
\hline & & & & & \\
\hline
\end{tabular}

rounded off in table, not in curve,

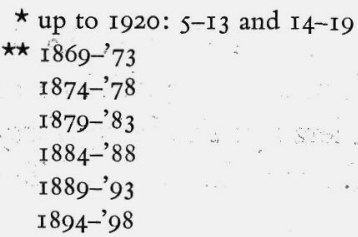

$\star \star \star$ excl. victims of the Febr. I953 floods 
The infant mortality, on the other hand, also showed a fall after 1875 , but this was relatively of only minor importance. It was not until about 1900 that the infant mortality began to fall markedly, and this has continued to the present day except for the two war periods.

It can safely be assumed that the decline of the total juvenile mortality in the second half of the roth century is the result of the improvement of social and hygienic conditions: improvements which needed to be only relatively slight to effect a considerable fall in the very high number of deaths. The impression is gained from the Dutch statistics that the infant mortality did not show a manifest reaction to this improvement until later.

Is the mortality of pre-school children a more sensitive criterion for social and hygienic conditions than infant mortality?

It is generally assumed that infant mortality is the most important criterion, even though Stocks is of the opinion that the second year of life is a better one in many respects. A disturbing factor is, bowever, that infant mortality is to a considerable extent determined by the form of nutrition: breast feeding or bottle feeding. Only in the most developed countries has artificial feeding been refined to such a degree of late years, that the difference is no longer important. The method of feeding is in general not dependent on the social conditions. The fashion of the times and female labour are important factors in this respect (WICKEs); hence infant mortality was lower in areas where breast feeding was customary (provided that the mothers were not too much underfed) than in regions where bottle feeding was usual (for example because the mother worked on the land), even if the social and hygienic conditions in the second case were better than in an area where breast feeding was the rule. Examples of this in the Netherlands are given by DE Vooys.

The general state of health, and hence the death rate, of children of preschool age, are markedly influenced by both social and domestic circumstances. The nutritional factor does not disturb this relationship, since child nutrition after infant age is directly related to socio-hygienic conditions.

The pre-school age mortality is therefore a better standard of measurement of the socio-bygienic statc of the people than is the infant death rate. This is confirmed by Dutch statistics.

GArE, in an analysis of the juvenile mortality in England, showed that in the second half of the nineteenth century the death rate among children of pre-school and school age was already falling considerably: this being forcy years before a fall in the infant death rate, which did not make itself manifest before I910 or thereabouts.

KüGLE, in his study on the death rate of pre-school children in Germany round the 1914-1918 wat years, also arrived at the conclusion that social and 
hygienic conditions were of far greater importance as regards this age group than as regards that of the infants.

Reviewing the matter, it does not seem entirely fortuitous that the fall in the pre-school age death rate began about 1875. That was about the period at which the social consciousness of somewhat larger parts of the population became awakened, and the first improvements in social and hygienic conditions were made, this leading inter alia to the disappearance of famines and of widespread epidemics, such as of cholera.

The influence of better medical care was not yet directly manifest-apart from "vaccination against smallpox-although the alarmingly high child mortality began to be borne in upon medical men as well as upon philanthropists in the second half of the I9th century (KNAPPER).

After about.1875, the pre-school age death ratc continued to fall at a remarkably constant rate. The first world war caused a considerable rise, but.a fall soon set in again. The second world war caused another sharp rise, but this has been followed by a continuous fall. It is striking how a whole complex of factors, responsible for this decline, has led to a steady reduction, - as if we were dealing with some physical law.

An analysis of the curve since 1900 shows that after about 1925 the fall has been slightly. more rapid than in the previous 25 years.

The curve shows that modern methods of treatment have had no demonstrable influence on the course of the pre-school age mortality in recent years. This will be reverted to several times later in this study.

In the years around 1900, of every I00,000 children of exactly one year old, 7,200 did not reach their fifth birthday. About 1925, this number had been reduced by more than half, namely to 3,100, while around 1950 only 690 of every 100,000 children aged one did not reach their fifth birthday.

Compared with the mortality of infants and schoolchildren, the pre-school age mortality shows the greatest reduction. In the middle of the Igth century the pre-school age mortality was still about 5 times that of children of school age, but at present it is only about 3 times as great, while the corresponding figures for the ratio between pre-school age mortality and infant mortality are $1 / 6$ and $1 / 15$, respectively!

Table IV shows the decline of the death rates for four juvenile age groups since 1900, the mortality in 1900-1905 always being taken as roo for the calculation of the index figure for 1950-1952.

This method of representation proves clearly that the fall in mortality was greatest in pre-school children, in spite of the fact that there has been no real soció-medical care-for pte-school children; in contrast to infants and schoolchildren. 
'TABLE IV'

Index of the juvenile mortality 1900/1905-1950/1952

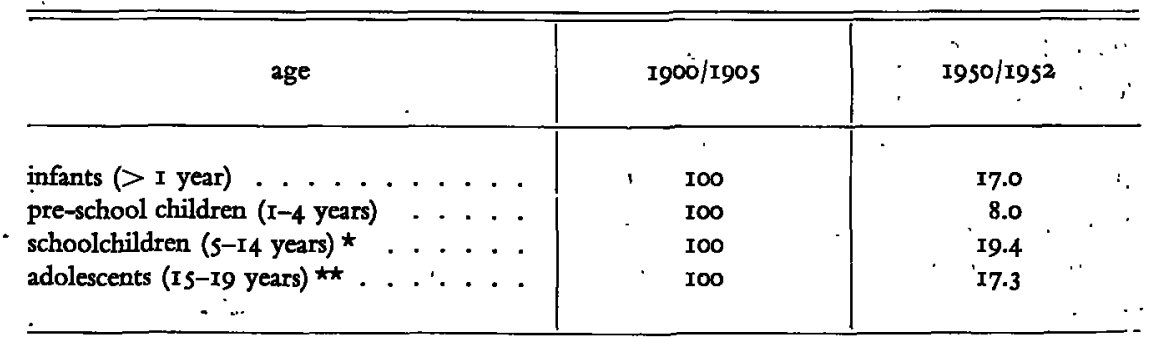

* 1900-1905: 5-13 years

* 1900-1905: 14-19 years

GORTER drew attention to this remarkable fact at the Third Pre-school Child Care Congress in 1938. :

The complex of socio-hygienic factors underlying the decline in mortality has evidently exerted the greatest influence in the pre-school age group. It is not easy to explain this fact.

The influence of better nutrition of the population had doubtlessly a great effect on the decline in mortality. This is a different matter for the first year of life, because a baby requires special care in regard to its feeding, and in former days the question of breast feeding or bottle feeding was of paramount importance. The general improvement in nutrition had therefore only an indirect influence on the infant mortality. For the general state of health of the pre-school child the composition of the diet is of special importance, even more so than for the older child.

. While the latter may, to a certain extent, make up for the qualitative inadequacy of the diet by increase of its quantity, the pre-school child is bound: to a relatively small quantum. (De HAAs). It is probable that the $\mathrm{I}-\mathbf{4}$-agc group have benefited more, and more directly, from the qualitative improvement of the general nutrition than the other children, which may be an important factor in the explanation of the greater reduction of the pre-school age mortality as compared with that of the other age groups.

Up to now we have dealt with the mortality of pre-school children!'(i.e., those from ' I-4 years old) as an entity, but within this group there are also differences; the child's chance of dying becomes less as his age increases.

A distinction has been made between I-ycar-olds and 2-4-year-olds in the mortality statistics since 1933. Graph 5 shows the course of the mortality of these two age groups. Apart from the rise during the war years, the mortality has fallen regularly in both groups, but to a greater degree in the I-year-olds than in the 2-4-year-olds. 
In the period 1933-1952 the mortality for the first group decreased from 70 per I0,000 to 23 per 10,000; for the second group from 27 per 10,000 to I2.5 per ro,000, i.e., by 67 and $54 \%$, respectively.

- This shows the tendency for the diffe- ${ }_{10} 0$ rence in mortality between I-year-olds and 2-4-year-olds to level out, as can ${ }^{\circ 0}$ also be seen in table $V$ and fig. 4. Here . the mortality figures for the I-, 2-, 3and 4-year-olds are compared for the years I900-I909 and I950-I952.

As said before, the pre-school age mortality has shown a greater fall than the infant mortality, and the I-year-olds have benefited most among the preschool age group.

The infant mortality consists of two 20 components with a widely diverging share in it: the neonatal mortality, which "o falls only slowly, and the mortality after of the first months, showing a far greater decline. Graph 5 shows that in the past twenty years the mortality in the 2-I2th

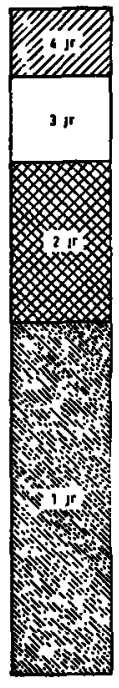

$1900-1909$

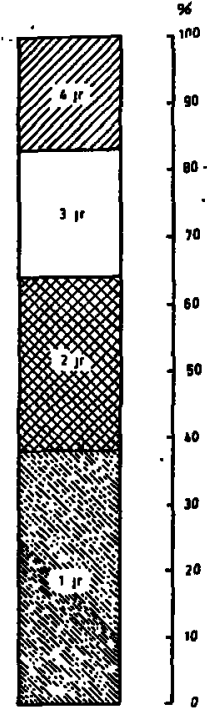

1950- 1952

Fig. 4

Percentage distribution of deaths in preschool children by age

month has decreased nearly to the same. The Netherlands 1900-1909 and 1950-1952 degree as that of the I-year-olds and even somewhat more than that of the 2-4-year-olds. The rapidity of the reduction in the mortality of infants and I-year-olds in the past two decades, which has seemed to vary so much, proves therefore to be based completely

TABLE V

Mortality of pre-school children according to age, as a percentage of the total 1-4 age group mortality in 1900-1909 and 1950-1952

\begin{tabular}{|c|c|c|}
\hline age & 1900-1909 & $1950-1952$ \\
\hline 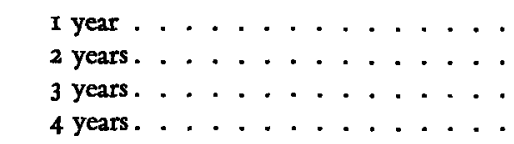 & $\begin{array}{l}53 \\
24 \\
13 \\
10\end{array}$ & $\begin{array}{l}38 \\
26 \\
19 \\
17\end{array}$ \\
\hline I-4 years . . . . . . . . . & 100 & 100 \\
\hline
\end{tabular}


on the persistent mortality shortly after birth, which has diminished only slowly. The older infants and younger pre-school children, although still presenting important differences in death rate, show about the same decline.

The second world war caused a marked general rise in the mortality of

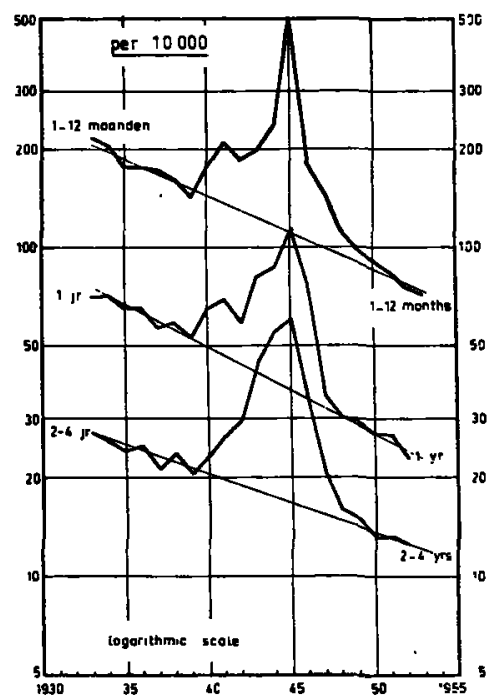

Fig. 5

Death rate of infants and pre-school children

The Netherlands I933-I953

children as a whole, but this has not been the same for all groups. Graph 3 shows that the mortality of pre-school children and older children rose more and during a longer period than that of infants, so that therc was relatively a considerably greater number of "war victims" among the older children. KüGLE made the same observation in the first world war in Germany. The many factors that have been of importance will be analysed later. 
III

\section{COMPARISON OF CHILD MORTALITY AND TOTAL MORTALITY}

The juvenile mortality has not only been markedly reduced during this century, but this decline has even been considerably greater than that of the total mortality. The proportion of child mortality to the total mortality has thus become smaller. The decrease of the percentage of juvenile mortality to total mortality is not only a historical phenomenon, but it has also its counterpart in various countries with different juvenile death rates: see table VI.

TABLE VI

Child mortality as a percentage of the total mortality (not standardized ${ }^{\star}$ )

\begin{tabular}{|c|c|c|c|c|}
\hline countries I950 & $<$ I year & $\mathrm{I}-4$ years & 5-I4 years & $<$ Is years \\
\hline Ceylon...... & 26.I & 20.2 & 5.7 & 52.0 \\
\hline Japan ..... & 15.5 & 9.I & 3.3 & 27.9 \\
\hline Spain . . . . & II.9 & 5.2 & 2.5 & 19.6 \\
\hline Italy. . . . . & $\mathrm{I2.8}$ & 3.7 & I. 5 & 18.0 \\
\hline Netherlands . . & 7.6 & 2.I & I.3 & II.O \\
\hline
\end{tabular}

* adapted from Annual Epid. \& Vital Stat. 1950 W.H.O., Gencva 1953

The decreasing proportion of childhood mortality to general mortality is even demonstrable in one town and in one period of time by comparison of population groups with varying juvenile death rates, as was done by De HaAs in pre-war Batavia (at present Djakarta) in Indonesia. The following table is borrowed from his study; it gives, as it were, a historical cross-section.

\section{TABLE VII}

Child mortality as a percentage of the general mortality in certain populationgroups Djakarta (Batavia) 1935-1937

\begin{tabular}{|c|c|c|c|c|}
\hline $\begin{array}{l}\text { population } \\
\text { groups }\end{array}$ & $<$ I year & $\mathrm{I}-4$ years & $s-14$ years & $<15$ years \\
\hline Indonesians. . . . & 36.4 & 21.8 & 5.0 & 63.2 \\
\hline Chinese . . . & 32.9 & 14.6 & 4.9 & $\$ 2.4$ \\
\hline Europeans . . . & $\times 4.4$ & 7.0 & 3.6 & 25.0 \\
\hline
\end{tabular}


A correct comparison of the share of the childhood mortality in the total mortality in various years requires standardization of the death figures on a certain population structure. When the proportion of children to the whole population decreases owing to ageing of the latter, this fact in itself will cause a decrease of the relative juvenile mortality. This influence is eliminated by standardization, so that changes in the proportion of the mortality are only based on the real decline of mortality. With this object, the population of a number of three-year-periods was standardized on the population structure of 1900 , and the share the juvenile mortality would have had in the general mortality if the total age structure had remained the same, is calculated.

TABLE VIII

Child mortality as a percentage of the total mortality (standardized).

The Netherlands 1908/1910-1950/1952

\begin{tabular}{|c|c|c|c|c|c|}
\hline period & $<\mathrm{r}$ & $I-4$ & $5-14$ & $15-19$ & $<20$ \\
\hline 1908-19ro & 23.3 & 9.8 & 3.4 & 2.4 & 38.9 \\
\hline $1920-1922$ & $\mathrm{x} 8.4$ & 7.6 & 3.3 & 2.2 & 31.5 \\
\hline I929-193I & I5.7 & 5.7 & 3.I & 1.8 & 26.3 \\
\hline r937-1939 & $\mathrm{T} 2.8$ & 3.8 & 2.5 & I.5 & 20.6 \\
\hline $1943-1945$ & $x_{4.1} \mathrm{I}$ & 5.6 & 4.5 & 2.9 & 27.1 \\
\hline $1946-1948$ & I 4.4 & 4.3 & 2.7 & I.5 & 22.9 \\
\hline $1950-1952$ & 7.8 & I. 8 & $\mathrm{I.4}$ & 0.7 & II.7 \\
\hline
\end{tabular}

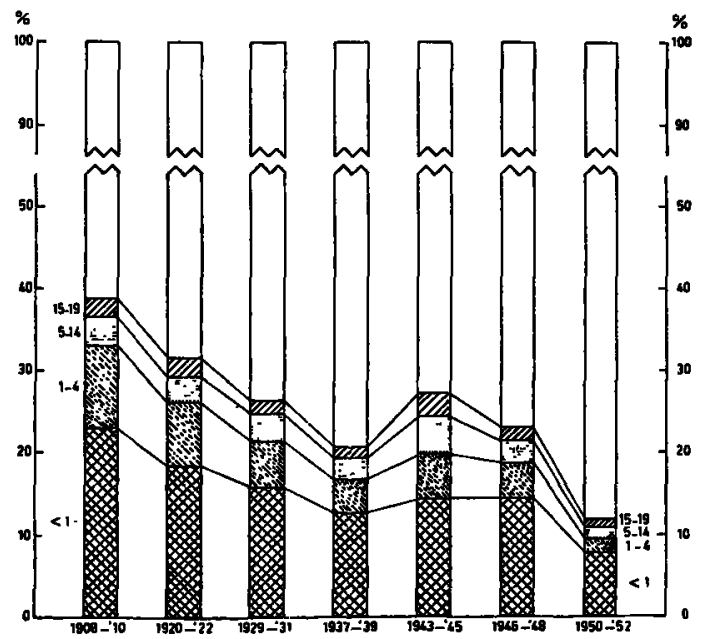

Fig. 6

Deaths by age in childhood in percent of total deaths (standardized) The Netherlands 1908-1952 
Table VIII and Graph 6 show that the proportion of the juvenile mortality to the total mortality has declined considerably since 1908/1910, a fall from $38.9 \%$ to II.7\% for the 0-I9 age group. This decline in the relative mortality has been the greatest as regards pre-school age children, because the mortality of this group has also fallen to the greatest degree.

The gradual decline of the proportion of child mortality to the total mortality was interrupted by the war. The rise in the death-rate figures during the war and shortly afterwards involved children more than adults, not only infants, but more especially pre-school children and older children. The relative mortality of schoolchildren and adolescents during the war years was even higher than' 40 years ago. Although these older children constitute a group with usually the lowest death rates of all age groups, they reacted exceptionally strongly to the bad conditions of the war years, more than the infants, who were better protected and who benefited most from the maternal care.

In these chapters we have compared the course of the mortality of pre-school children with that of infants and older children.

In spite of the fact that there is practically no organized care for pre-school children and this group forms an 'underdeveloped' one in our child hygiene, their mortality has declined more than that of infants and older children. The mortality of pre-school children is still relatively high, however: the death sate of the 1-4-year-olds is still as high as that of the 35-40-year-olds, though fifty years ago it was at the level of that of the $50-55$ years-olds. The recent war ycars have shown that, under very unfavourable conditions, the mortality of the pre-school age group is more difficult to keep under control than that of the infants. 
The mortality of males exceeds that of females at practically all ages. This is also the case in the pre-school age group.

The number of $\mathrm{r}-4$-year-old boys is greater than that of the girls. A correct idea of the mortality per sex can therefore only be obtained after elimination of this difference. Hence the mortality of boys and girls is always compared per 100,000 of each sex in this chapter, and the mortality per 100,000 boys is always expressed as a percentage of the mortality per roo,000 girls. If the mortality of boys and girls per 100,000 of each sex is the same, the proportional figure is roo:

TABLE IX

Masculinity of the death rates in the 1-4 age group (1908-1952)

\begin{tabular}{|c|c|c|}
\hline \multirow{2}{*}{ period } & \multicolumn{2}{|c|}{ mortality rate of boys in $\%$ of the mortality rate of girls } \\
\hline & accidents included & accidents excluded \\
\hline igo8-'10 & I07 & ros \\
\hline 1920-'2I & 112 & III \\
\hline $1929-30$ & $12 \mathrm{I}$ & 117 \\
\hline $1938-40$ & I2I & 112 \\
\hline $1943-45$ & 117 & 112 \\
\hline $1947-$ - $^{\prime} 49$ & I2I & I09 \\
\hline I950-'52 & 118 & 104 \\
\hline
\end{tabular}

Table IX gives this percentage for various years of this century. The excess mortality of the boys increases up to 1930 , after which it remains practically constant.

The increase of this excess mortality in the years 1900-1930 implies thai the mortality of the girls, which was already lower than that of the boys, declined even more rapidly in this period. This is partly due to the markedly decreasing importance of diseases of the respiratory tract, which had more victims among girls than among boys. 
In the first 30 years of the present century, the mortality due to accidents was a factor of relatively only minor importance. Subsequently, however, with the continuous decline of the mortality of the pre-school age group, accidents became of growing importance as a cause of death $(p .66, f g .21)$. Because it is especially boys who are increasingly involved in fatal accidents, this cause of death becomes more and more the determining factor. for the boy/girl ratio' in the mortality of the I-4 age group.

If the pre-school age mortality is considered leaving out deaths due to accidents, (table $I X)$, the remarkable. fact emerges that the excess mortality of boys decreases again after about 1930, and that at present this figure is even lower than at.the beginning of the century. The excess mortality of boys is therefore not so constant a figure as is sometimes contended.

There is a manifest difference in excess mortality of boys between the youngest and the older pre-school children (table $X$ ). This figure decreases especially among the I-year-olds, and disregarding deaths due to accidents, there is at present even an excess mortality of girls.

TABLE $\mathbf{X}$

Masculinity of death rates in 1-year-olds and 2-4-year-olds (1934-1952)

\begin{tabular}{|c|c|c|c|c|c|}
\hline \multirow{3}{*}{ period } & \multicolumn{4}{|c|}{ mortality rate of boys in $\%$ of the mortality rate of girls } & $\because$ \\
\hline & \multicolumn{2}{|c|}{ I year } & \multicolumn{3}{|c|}{$2-4$ years } \\
\hline & $\begin{array}{l}\text { accidents } \\
\text { included }\end{array}$ & $\begin{array}{l}\text { accidents } \\
\text { excluded }\end{array}$ & $\begin{array}{l}\text { accidents } \\
\text { included }\end{array}$ & $\begin{array}{l}\text { accidents } \\
\text { excluded }\end{array}$ & \\
\hline I934-'36 & II2 & 106 & 121 & IIO & ; \\
\hline I937-'39 & II6 & II2 & 122 & $\mathrm{II}_{4}$ & \\
\hline $1940-42$ & 120 & II6 & II9 & 108 & \\
\hline I943-'45 & II 4 & 107 & II & I Io & \\
\hline I946-'48 & III & 107 & 126 & 108 & : \\
\hline I949-'so & II6 & 107 & 127 & 109 & : \\
\hline I9SI-'52 & 97 & 89 & 129 & 112 & \\
\hline
\end{tabular}

The excess mortality of older boys keeps on increasing to some extent, but; leaving out violent deaths, the number of 2-4-year-old boys who die remains constantly at about $110 \%$ of that of the girls.

The mortality of boys of pre-school age remains greater than that of girls, even :disregarding the mortality due to accidents. What is the cause of this excess mortality of boys and why.has it decreased among the younger members of this group in recent years? 
The mortality statistics show that by far the greatest number of causes of death involve more boys than girls, and only a few, more girls than boys. The greater chance of dying of the male pre-school child is therefore not due to one single cause.

The youngest pre-school children have a lower excess mortality of boys, partially because the diseases of the respiratory tract (from which girls suffer more than boys) are relatively of more importance in the second year of life than among older members of this group, but partially also because various causes of death, such as diphtheria and forms of meningitis, at present strike relatively less at boys of one year old than at a later age.

The rise of the excess mortality of boys, which accompanied the fall of the pre-school age mortality in the Netherlands during the first decades of the present century, finds its counterpart in various countries with a varying preschool age mortality. Countries with a high pre-school age mortality showed, after deduction of fatal accidents, no excess mortality of boys in I950. Countries with a low pre-school age mortality still have an excess mortality of boys after deduction of violent deaths. In Japan and Italy, for example, about the same number of I-4-year-old boys as girls died; but in France, England and the U.S.A., countries with a relatively low pre-school age mortality, I07-I09 boys of I-4 years old died as compared with every Ioo girls, disregarding deaths due to fatal accidents.

The increase of the excess mortality of boys that has accompanied the decline of the pre-school age mortality, is therefore a general phenomenon, not only based on a growing importance of the mortality due to fatal accidents.

The study of the mortality according to sex shows that there is indeed an excess mortality of boys among the pre-school age children, but that this is not so constant as is generally contended.

In recent years there is a manifest tendency of this figure to fall, especially among the younger pre-school children, but this tendency is masked by the growing importance of accidents as causes of death.

The excess mortality of boys holds true for the majority of causes of death at the pre-school age, but it is not constantly observed for each of these causes. The excess mortality of boys shows a trend to diminish or to disappear for various causes of death, especially among the younger pre-school children; this is one of the factors leading to the recent fall of the excess mortality of boys among the pre-school age group The lower excess mortality of boys among the younger members of this group as compared with the older ones, is also explained by the relatively greater importance of diseases killing more girls (pneumonia, meningitis) in the first group.

A considerable improvement in the social conditions probably not only 
results in a decline of the pre-school age mortality, but, in the beginning, also in an increase of the excess mortality of boys. The latter value falls again, coinciding with a further decrease of the pre-school age mortality (deaths due to accidents excluded). All this constitutes an argument in favour of the conception that boys form the weak sex, explaining why more girls than boys benefit initially from a fall in the pre-school age mortality. The boys begin to make up for their arrears only later, when the pre-school age mortality has reached low figures. The high mortality due to accidents is however the main cause of the persistence of an excess mortality of boys. 


\section{SEASONAL INFLUENCE ON THE MORTALITY OF CHILDREN OF PRE-SCHOOL AGE}

The pre-school age mortality has always been considerably lower in summer than in winter (fig. 7). In the course of years the difference between the two seasons has neither constantly increased nor decreased. A summer peak, as still existed for infants at the beginning of the century, has not been observed for pre-school children, at any rate after 1900 . The months with the highest mortality for the latter group are January, February and March; those with the lowest mortality, September and October.

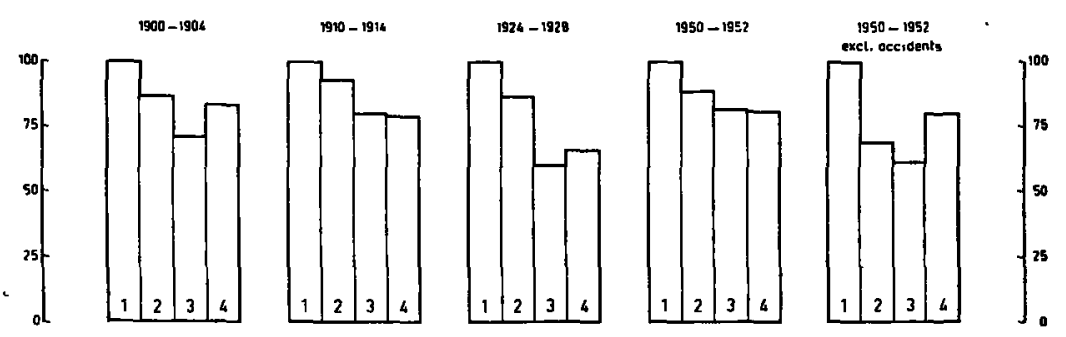

Fig. 7

Mortality in pre-school age according to seasons The Netherlands $x 900-$ I952

$$
\begin{aligned}
& \text { I = January-March } \\
& 2 \text { = April-June }
\end{aligned}
$$

The relatively low death rate in summer is at present partially masked by the many fatal accidents in spring and summer. If the mortality due to accidents is deducted from the total pre-school age mortality, the difference between summer and winter, i.e., the winter peak, proves to be even greater. The winter peak is relatively even higher than in the beginning of the present century, and, although it is impossible to eliminate the mortality due to accidents from the statistics of former years, it is quite certain that in the beginning of this century fatal accidents did not exert any great influence on the pre-school age mortality in the various'seasons, because the number of deaths due to accidents formed only a small percentage of the total preschool age mortality. 
The sharp fall of the pre-school child mortality did not eliminate the winter peak; ; on the contrary, it bas become even more marked. This is the more remarkable because the causes of death that are of special frequency in the winter months, such as infectious diseases and diseases of the respiratory tract, have become less important in relation to the total mortality of pre-school age children ( $p .59)$.

The diseases causing the winter peak are largely those affections which might be expected to be most influenced by modern chemotherapeutics and antibiotics. The persistence of the winter peak therefore shows that in this way no definite effect of modern therapeutic methods on the death. rate of pre-school children can be observed any morc than when we were dealing with the course of the total pre-school age mortality.

(a)! :
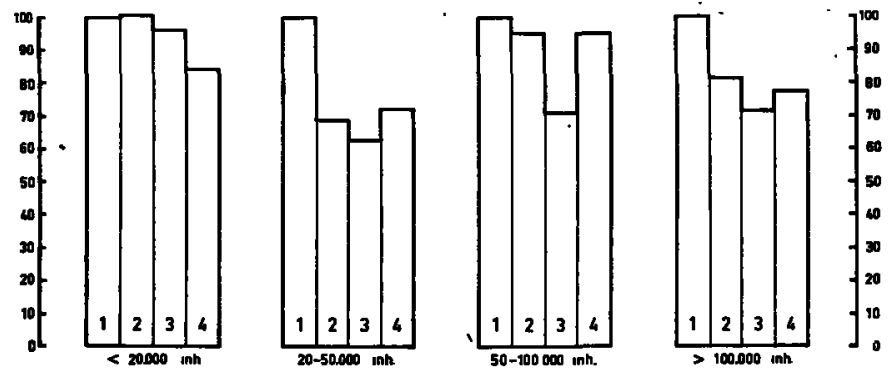

Fig. 8

Deaths in pre-school age according to seasons and population of boroughs The Netherlands 1950-1952

$$
\begin{array}{ll}
\text { I }=\text { January-March } & 3=\text { July-September } \\
2=\text { April-June } & 4=\text { October-December }
\end{array}
$$

Deaths in the first three months $=100$

It was possible to differentiate the seasonal pre-school age mortality according to size of the communities only for recent years. Fig. 8 gives the preschool age mortality per three months, expressed as a percentage of the mortality of this category in the first quarter, for every group of communities. The seasonal influences are not very notable in rural districts, but, on the contrary, they are clear enough in the towns.

The data available do not allow of a detailed analysis of this difference. There is, however, one important factor: in the country the death rate from accidents is higher and that due to infectious diseases is lower ( $p .83)$ than in the towns, which results in a rise of the summer mortality and a fall of the winter mortality, respectively. Hence the pre-school age death rates of summer and winter vary less in rural areas than in the towns.

It is a remarkable fact that the winter peak in the pre-school age mortality has persisted unchanged, in spite of the improved methods of treatment of 
the diseases which cause this peak. The increasing urbanization of our population may be of significance in this respect, because the winter peak is higher in towns than in the country. It must, however, be assumed that in the course of years the summer mortality has decreased to a greater extent than the winter mortality. It is not impossible that, together with the fall of the death rate, an unfavourable aspecific factor, the winter, becomes relatively more important.

The winter forms a period of a general decrease of resistance, for example due to the relatively deficient nutrition, less sunlight and indoor life. Even though the pattern of the causes of death has completely changed, winter remains the most unfavourable season, so long as there is no planned compensation of these adverse factors, which are as yet insufficiently understood. The complex of factors causing the decline of mortality has a greater effect in summer. 


\section{PRE-SCHOOL AGE MORTALITY ACCORDING TO PROVINCES}

Study and analysis of regional differences in mortality may often lead to a better understanding of its causes. One of the methods is the comparison of the death rates in the various provinces. This is a relatively rough comparison, because our provinces are usually not very homogeneous areas as regards the social and economic structure. A finer differentiation, e.g., according to the existing 'economic-geographic regions', is however not well possible, is at present the number of deaths among pre-school children in smaller, more homogeneous' areas has become too low to allow of conclusions.

Table XI gives the figures of the pre-school age mortality in our provinces for some periods of the 2oth century. This mortality has greatly decreased in all provinces. This reduction has been accompanied by a certain levelling out of the provincial differences, as shown by table XI. About I9ro the pre-school age mortality was relatively high in the provinces of Drenthe, Gelderland, North Brabant and Limburg, and this has since decreased to a greater extent than the relatively lower mortality in North and Western Holland. If the decrease in pre-school age mortality is greater when its original level was high, this means that the differences show a tendency to disappear.

Of late years there are only slight differences in the pre-school age mortality in the various provinces and in general these differences are inconstant. Most provinces have sometimes a relatively low, and then again a relatively high pre-school age mortality. The province of Zeeland alone stands out by its constantly low pre-school child mortality. An analysis in greater detail of the mortality of this group in Zeeland seems therefore warranted.

\section{'Pre-school age mortality in Zeeland}

Zeeland has certain unique features compared with the rest of the Netherlands. It is one of our most sparsely populated provinces (I63 per square kilometre). Due to the low birth rate and to emigration, the population is on the average :older than elsewhere. Zeeland forms part of the fertile clay region along the -Dutch coast, with relatively large agricultural estates (DE Vooys). There are no large towns; the province is mainly agrarian and industrialization lags far 
TABLE XI

Mortality of children of pre-school age in the various provinces from 1895/1904-1948/1952

\begin{tabular}{|c|c|c|c|c|c|}
\hline \multirow{2}{*}{ province } & \multicolumn{5}{|c|}{ death rate $I-4$ years per 10,000} \\
\hline & $1895 / 1904$ & $1905 / 1914$ & $1920 / 1921$ & $1926 / 1936$ * & $1948 /$ I952 \\
\hline Groningen. . . . . . & I67 & II6 & 98 & $5 \mathrm{I}$ & 19 \\
\hline Friesland . . . . & I37 & 93 & 59 & 48 & 20 \\
\hline Drenthe. . . . . . & I92 & IS7 & 93 & 68 & 20 \\
\hline Overijssel .. . . . & 201 & 128 & 96 & 56 & 19 \\
\hline Gelderland. . . & 186 & 133 & 96 & 55 & 19 \\
\hline Utrecht . . . . & I89 & I32 & 92 & 43 & $2 \mathrm{I}$ \\
\hline North Holland. . . . & 194 & 129 & 83 & 43 & 19 \\
\hline South Holland . & 189 & 124 & 88 & 49 & 18 \\
\hline Zeeland.... & 136 & 98 & 61 & 34 . & 14 \\
\hline North Brabant . & 198 & I58 & 112 & 66 & 19 \\
\hline Limburg . . . . . & 185. & I69 & I04 & 66 & $2 \mathrm{I}$ \\
\hline The Netherlands . . & 184 & $\mathrm{I}_{3} \mathrm{I}$ & 9I & 52 & 19 \\
\hline
\end{tabular}

* borrowed from P. MunTendaM, T. v. Soc. Gen. (1938), I6: 234

behind compared with other provinces. The comparatively isolated situation of the greater part of the province is still a characteristic feature.

It is difficult to determine the prosperity of a whole province, but the distribution of the income deduced from the income-tax statistics shows that in recent years Zeeland is a fairly prospcrous province (table XII). At prẹsent it. hạs even the highest average income per inhabitant among the rural districts (apart from the. North-East polder), as can be concluded from the publication of the Central Bureau for Statistics dealing with income distribution according to cconomic-geographic areas. The corresponding statistics dating from before the war show, however, that Zeeland was then far less prosperous.

The discussion on the general level of prosperity in Bouman's book on agriculture in Zeeland also shows that the great mass of the agricultural labourers in this province received low wages until a short time ago. The Zeeland industrial workers also lagged far behind in this respect compared with those in. West Holland (Pluymers). It may be true that the low wages were compensated to some extent by the customary gifts in kind, but this was no reason to regard the population of this province as prosperous in those dàys. 
TABLE XII

Average income according to the income tax statistics (1950)

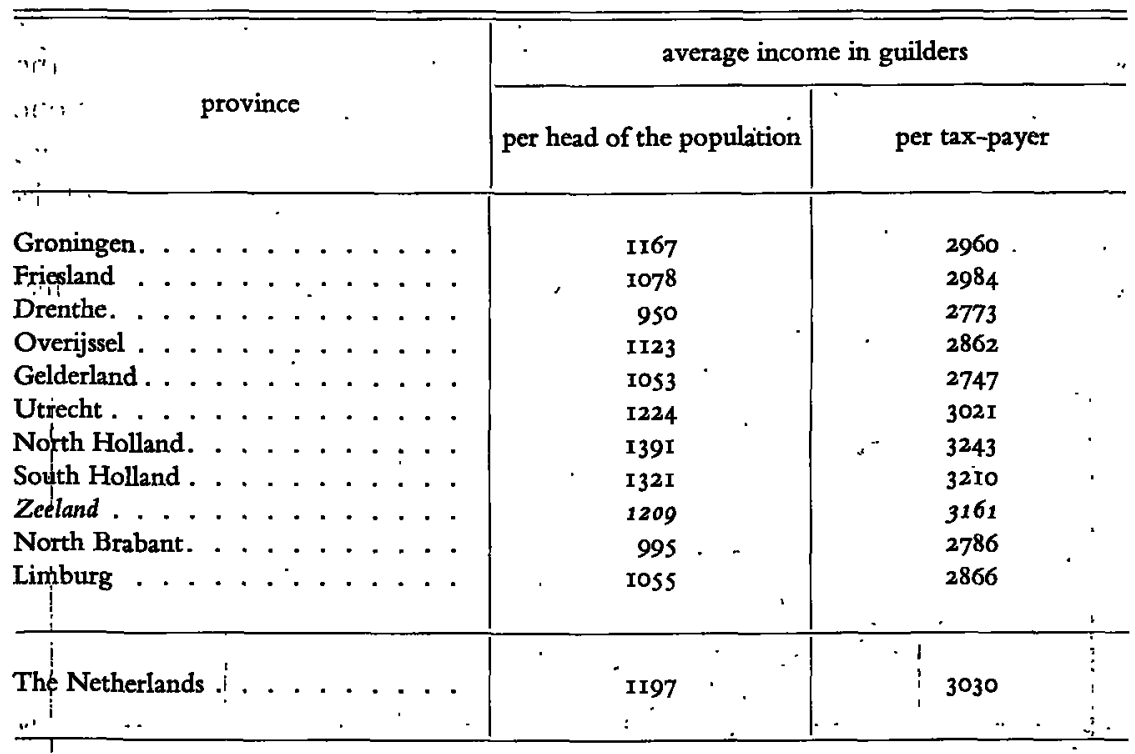

The general mortality has in general always been rather low in Zecland. This is shown by table XIII, which gives the total mortality in our provinces TABLE XIII

Standardized death rates per province as percentages of the total death rate in the

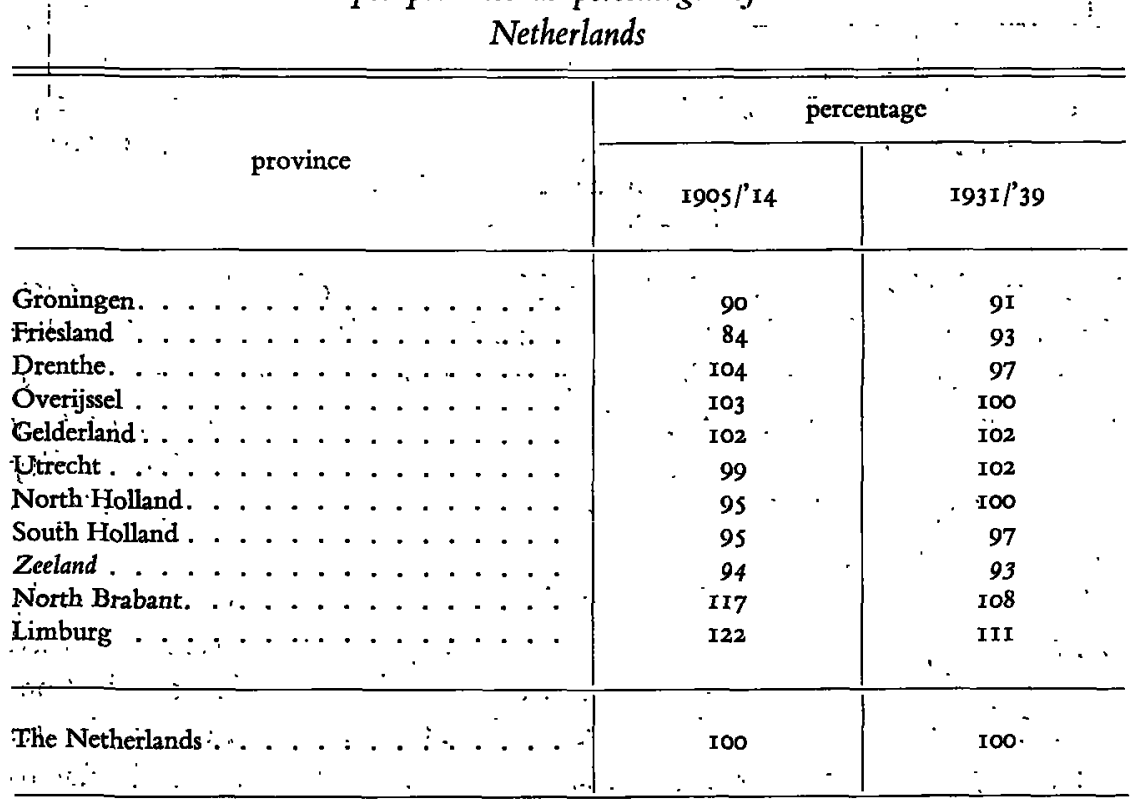


after standardization, climinating the influence of differences in age structurc. The relatively low death rate holds true, since 1900 or further back for all age groups except the infants. The infant mortality in Zeeland ranked among the highest in Holland until about 1920, falling to one of the lowest after the second world war (fig. 9). The mortality in Zeeland for children over one year of age has always been low, however. The low total death rate was especially striking in former times, when the infant mortality, then high in Zeeland, formed such a large proportion of the total mortality. The discrepancy between the former high infant mortality and low total mortality will be dealt with in greater detail later.

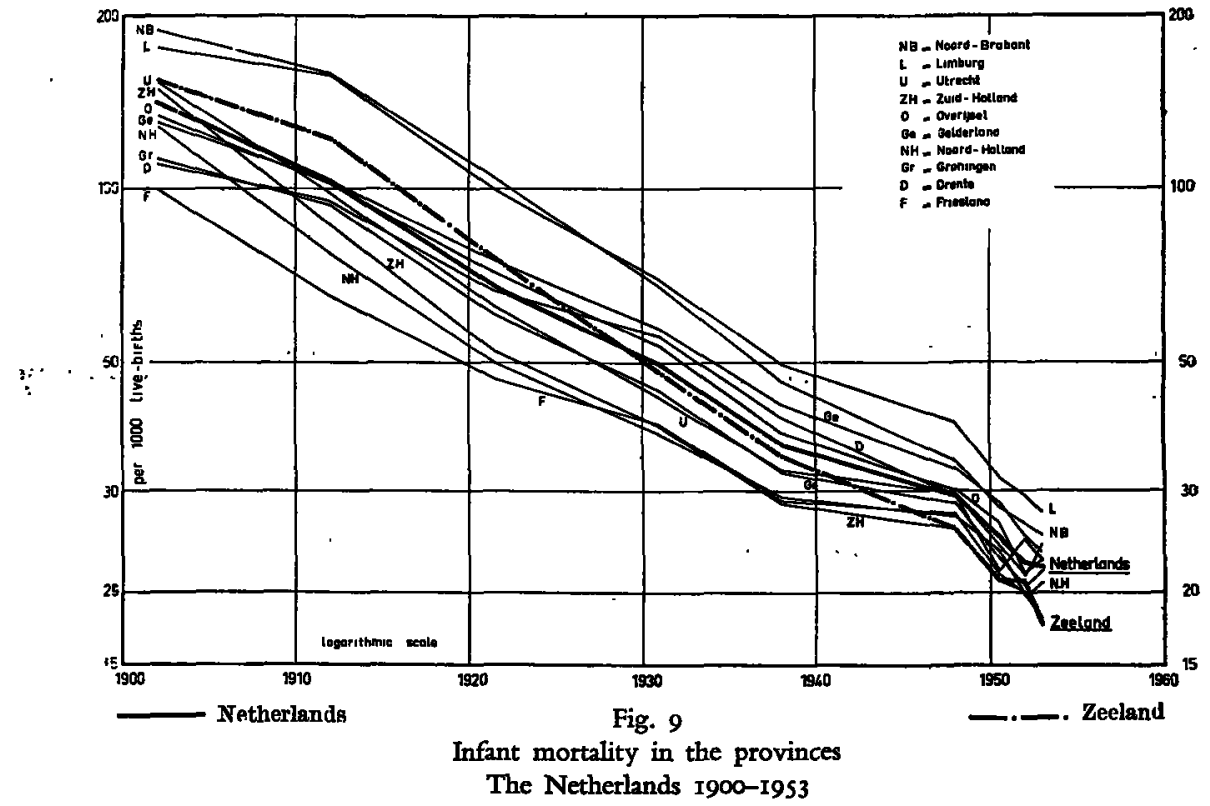

The pre-school age mortality in Zeeland has been one of the lowest, or even the lowest, in Holland for at least 50 years. None of the other provinces has ever shown such a constantly low pre-school age death rate; on the contrary; comparison of the figures of the various provinces in the course of this century actually shows that the sequence of the provinces as regards this mortality has been inconstant. This is the more true the further the death rate of these young children has fallen.

The mortality of a population group is always the resultant of a great many factors, interwoven and interacting to such a degree that they cannot be used separately for an explanation of the death rate, but only in combination. Consideration of only a single factor may lead to a distortion of the picture. De Vooys points out the danger of incomplete demographic analysis, due to 
failure to consider the many interrelating factors in this connection. He cites Soroxin, who expressed this tersely and clearly as 'a causal and meaningful unity of factors'.

Some of the many factors that may influence the death rate of pre-school children will be discussed in the following pages, in an attempt to explain the low figure for Zeeland.

As stated before: Zeeland holds a particular place in The Netherlands in several respects. The typical agrarian character and the absence of large towns are not sufficient for an explanation of the low pre-school age mortality. In former times, this mortality was indeed lower in the country than in the more urban. areas, but at present the reverse is actually the case (p. 37). The pre-school child mortality in Zeeland has always been low, however, both formerly and at present.

The relatively low density of the population formerly exerted a favourable influence on the pre-school age mortality, but this is no longer the case. This factor therefore cannot serve to explain the constantly low death rate. of pre-school children. Zeeland is fairly prosperous at present, and this fact will exert a favourable effect on the mortality of the I-4 age group. In former years, however, the population of Zeeland was certainly not prosperous, although its death rate was already among the lowest in Holland. The prosperity factor.also cannot help us to explain the constantly low mortality of the pre-school children in Zeeland.

We have no exact data on the nutrition in this province, which is of such paramount importance as regards the general state of health of the pre-school child. It is possible that the general nutrition in this fertile. agricultural area is fairly good compared with other parts of the country. Buttermilk pap, a daily meal in Zeeland especially in former days, may be of importance as a source of protein. According to Bouman, green vegetables, fruit and molasses (source of iron) were also frequently used in the poorer families. It.is, however, improbable that the diet of the Zeeland children was so much better than in other parts of the country, that it would have contributed to.any important extent to the low death rates of the pre-school age group. The prosperity was too low to accept this factor.

It is unknown whether the intellectual development of the Zeelanders is much better than in other provinces.. The figures published by the Demological Institute on the average intelligence quotient of Dutch recruits show that the I.Q. of the recruits from Zeeland is on the high side for a rural area. This may suggest that the average intelligence in Zeeland compares favourably 'with that in other agrarian regions, with probably a favourable effect on the care of young children.

Medical care, and in particular specialist paediatric care, was far behind in 
Zeeland in comparison with the greater part of Holland, especially before the second world war. Welfare centres for infants.and pre-school children were fewer and less attended in this province than elsewhere. Until a short time ago there were practically no paediatricians, and even in 1949 the number of beds for children in the Zeeland hospitals was the lowest in the country, as shown by the Reports of the Chief Public Health Officer. Large parts of the province are moreover very isolated, which impedes intensive medical care. The number of deceased pre-school children who were treated in hospital is lower than in other areas of the country; this will be discussed in greater detail in chapter XIV. Many scriously ill children have to go without hospital treatment. The low death rate of pre-school children in Zeeland is therefore not to be attributed to better medical care. This could also be deduced from the fact that the pre-school age death rate was here already relatively low at the beginning of the present century, at a time when medical measures could exert only comparatively little influence on the mortality.

Being a rural province, with a small and isolated population, Zeeland benefited less and later from the progress of technical hygiene. Hygienic measures are moreover not so important for the pre-school age mortality as for that of the infants, as appears from the low mortality due to intestinal disturbances in pre-school children.

The factors mentioned: agrarian and rural character, low density of the population, prosperity, dietary customs, intellectual development and medical and hygienic care, which are usually taken into consideration when analysing the death rate, therefore cannot explain the low pre-school age mortality existing in Zeeland for half a century at least. The socio-economic and hygienic conditions in Zeeland were by no means favourable compared. with other provinces. The search for factors influencing the pre-school age mortality must therefore be continued.

As already mentioned, one of the characteristic features of the Zeeland population is the low birth rate during the past fifty years. Not only was the birth rate low, but also the matrimonial fertility, i.e., the number of children born alive per I,000 married women of $15-49$ years. This is the more remarkable because Zeeland is an agrarian province par excellence, and the birth rate is usually higher in rural areas than in the towns. The matrimonial fertility in Zeeland, about I870 still the highest in the Netherlands, began to fall sharply even before 1900 , more than in any other province. At present the birth rates of rural Zeeland and industrial North Holland are the lowest in the country (VAN DEN BRINK). The census figures show that the women in Zeeland in general do not marry late and taking the low matrimonial fertility into consideration, the conclusion is arrived at that birth control must have been practised in. Zeeland for a considerable. time. As long ago 
as about 1900, ScHouren writes in his report on obstetrics in his practice in the South of Zeeland, that birth control had found ready acceptance there!

This family planning resulted in a relatively low average number of children per family, as demonstrated in table XIV.

TABLE XIV

Number of children per family in the various provinces according to the data of the

1947 census

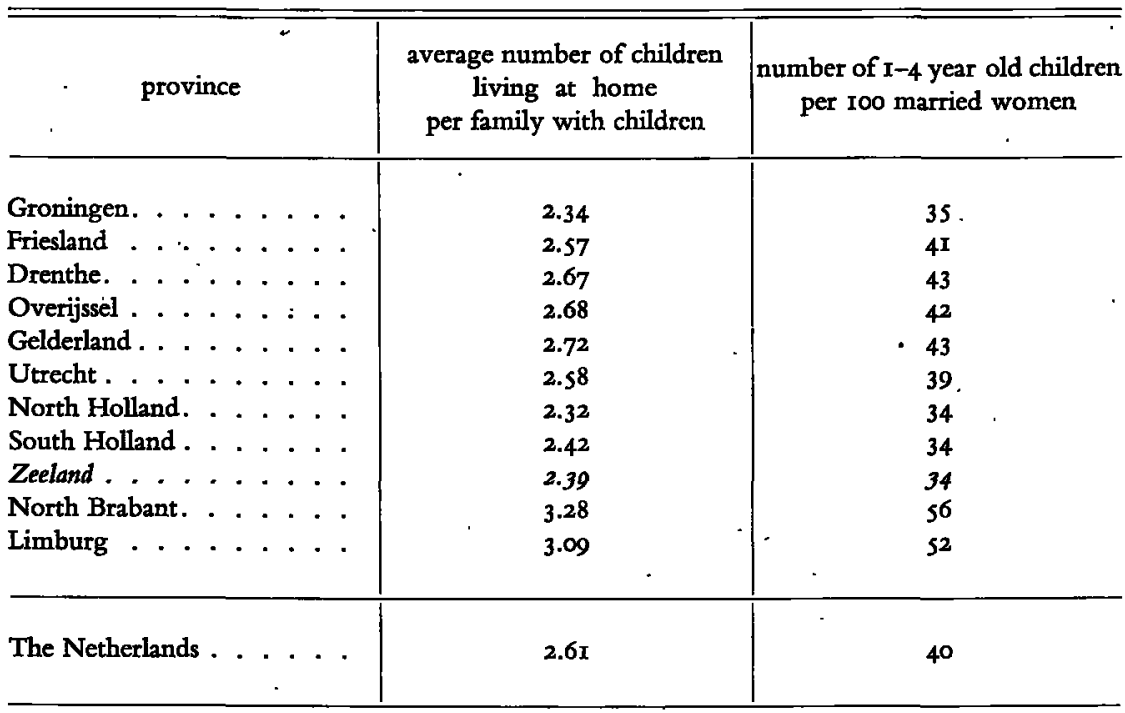

So far it has not yet been completely established whether there is a direct relationship between a large family and a higher child mortality. No doubt the mortality of infants alone has been too much the centre of interest in this respect. The relationship between size of family and mortality is even more intricate in the case of infants than of pre-school children, because the mortality, especially shortly after birth, is markedly influenced by age and parity of the mother. METHORST's study (1935) on the mortality of children under six (infants included) in connection with prosperity and size of the family. proved that there was a direct relationship between mortality under the age of six and number of children, even within the same economic group. As the number of children is itself influenced by economic prosperity, and large families were especially found among the less well-to-do people, elimination of the influence of prosperity is necessary in order to determine the influence of the size of the family.

The investigation of the Medical Statistical Bureau in Amsterdam in 1938 also points strongly into this direction. Recently LOWE et al. proved that during the first three years of life there is a great influence of the size of the 
family (and age of the mother) on the frequency of infectious diseases, pneumonia and intestinal disturbancès, and that this influence is greater-than that _of prosperity as judged from the father's occupation and the housing conditions of the family.

It is also acceptable that a pre-school child from a large family has on an average a greater chance of dying than one from a small family. The risk of contracting an infectious disease at an early age is considerably greater in a large family (with at the same time pre-school children and schoolchildren) than in a small one. The chance of an accident is also greater in a large family, because as a rule less attention can be paid to the younger children. Accidents and infectious diseases are both important causes of death at pre-school age. In chapter XIII an analysis will be given of the association between size of the family and pre-school age mortality.

The relatively low number of children of families in Zeeland is most probably an important factor for the low pre-school age death rate in former times as well as at present.

Still, this factor alone is not sufficient to explain the constantly low death rates. Practically all age groups show favourable mortality rates, so that there must also be factors of a more general nature. It is obvious that the causes of this low mortality should also be sought for in the Zeelanders themselves, in their mentality and way of life. As regards the low pre-school age mortality, this mentality would have to exert a favourable effect in the form of adequate provision for the pre-school children, i.e., good maternal care. This cannot be proved without a direct and comparative sociological investigation. Such an investigation has not been carried out in Zeeland up to now. On the other hand, there are some indirect indications suggesting good child care in the Zeeland families; this will be dealt with later.

The same difficulties encountered in the explanation of the low pre-school age mortality in Zeeland, were also met with in the explanation of the birth control. These difficulties were even greater, as the classical demography justifies the expectation of high birth rates in this rural province with its religious-minded population and a great number of agricultural labourers. Birth control, however, is spread over the whole of Zeeland. It is practised among all denominations, and thus in all parts of the province. The Calvinists in Zeeland have a lower birth rate than those elsewhere, the Roman Catholics in Zeeland have less children than those in other provinces, etc. Within professional groups also the Zeeland family proves to be small; as compared with the same groups elsewhere (Census 1947).

It is true that Zeeland belongs to our clay districts, where in general the families are relatively small, but three classical factors accompanying birth 
control, namely higher prosperity, urbanization and indifference towards the church, are practically absent in Zeeland.

In order to explain the birth control, the character of the Zeelanders must therefore be placed in the foreground. VAN DEN BRINK speaks, in this respect, of the 'couleur locale'. Dв Vooxs even tried to demonstrate this mentality by analysing the relationship between birth rate and the political choice of the religious-minded population, accepting that this choice shows their mental attitude. The correlation between birth rate and the voting or not voting on clerical parties was clearly demonstrable, and greater than the correlation with general religiousness. In this way De Vooys thought this mentality might give a partial explanation for regional differences in birth rate in Żeeland. The opinions on the character of the population of Zeeland diverge, of course, although it is agreed upon that the Zeelander is characterized by a certain deliberateness in his way of life, i.e., that he lets himself be guided more by his reason than by his emotions (MRERTENs). He is usually not light-hearted. Family planning which started among the big farmers for practical reasons, was soon adopted by the mass of the agricultural labourers. This happened in general more rapidly and to a greater extent in Zeeland than in other parts of the Netherlands (STEigenga-KouwE, De Vooys).

It seems acceptable that such a deliberate and rational turn of mind will promote care for the child. NEURDENBURG pointed out that in the course of years the changes in the ideas of the population have led both to a fall of the child mortality and of the birth rate.

It is quite possible that the fall of the birth rate and the lower pre-school child mortality (thanks to better care) are rooted in the same mental attitude.

Here also we are dealing with a combination of factors reinforcing one another. Good care for the children will have a more favourable effect on the mortality, the smaller the family. We cannot prove the assumption that the low pre-school age mortality in Zeeland is also based on a certain mentality of the population, leading to good care for pre-school children. The mortality statistics, however, give some indication that such a good care does exist.

There is primarily the relatively low mortality from accidents in Zeeland, the more striking because this mortality is usually high in the sparsely populated rural areas ( $p .75)$. Even at the beginning of the century, when traffic accidents were still rare everywhere, the number of fatal accidents of preschool children in Zeeland was relatively low. The relatively slight traffic intensity in Zeeland at the present day, therefore, gives no explanation of the low mortality due to accidents. The great significance of the degree of care and attention as regards the frequency of accidents in young children is dealt with in chapter $X$.

SAJET calls the great number of fatal accidents proof of insufficient care for 
the pre-school child. Candiotri, in too accusingly a manner, speaks in this respect even of carelessness and negligence on the part of the mother. The comparatively low pre-school age mortality from accidents in Zeeland, however (also in former times when the mothers often worked on the land) is an indirect indication of relatively good care for the child.

Secondly, the course of the infant mortality in Zeeland also points to a good care of the children. It was high for a long time, and was even among the highest in the country during the first twenty-five years of the century. Until the second world war, it dropped only rarely under the general average for the country, but then a rapid fall followed, and at present the infant mortality in Zeeland is one of the lowest in Holland (fig. g).

The high infant mortality of the first quarter of the century formed a striking contrast with the pre-school age mortality, which was then already low. One of the causes was that the social and medical care in Zceland lagged behind compared with other provinces. This was not very important for the mortality of the pre-school age group, but for that of the infants it was. Technical hygienic measures influence the infant death rates far more than the pre-school age mortality, while, in this respect, Zeeland was also behind in comparison with the greater part of the country. Good dietary habits of the mass of the population have not yet a direct influence on the infant, while, on the other hand, the question of breast feeding or bottle feeding was often of decisive importance until recently.

In Zeeland breast feeding was rather the exception than the rule, partly because the mothers worked on the land. DE Vooys writes that in the last century, breast feeding was relatively rare in Zeeland, and far less frequent than in other provinces.

It is therefore quite understandable why the infant mortality was still alarmingly high in Zeeland in the first few decades of the 2oth century. It started to fall gradually, however. The medical and hygienic backwardness decreased and the social-economic conditions improved, especially after the second world war. An even more important feature is, however, that the whole picture of infant mortality has changed markedly now it has reached such a low level. The method of feeding, medical and social measures and social-economic conditions can hardly be called the determining factors when the infant death rate is less than $3 \%$. If the infant death rate falls, on the other hand, good maternal care becomes of ever increasing importance for the mortality. ANDERSON writes that, once infant mortality has reached a low level, maternal care becomes of greater significance than socio-economic conditions. The morbidity-study of SPENCE et al. also convincingly proves the predominating importance of maternal care, even though this care itself is also influenced by prosperity, size of the family and housing conditions. 
The fact that Zeeland has reached practically the lowest infant mortality in the Netherlands, more rapidly than other provinces and in so short a time, is indicative of the good care of children there. The influence of this adequate care on the death rate became the greater, the lower the values reached. Table XV demonstrates that this is especially true for the mortality after the first week and not for the neonatal mortality, which in Zeeland is by no means the lowest of our country. It is also to be expected that maternal care is especially of paramount importance for the infant mortality after the neonatal period.

TABLE XV

Infant mortality in and after first week of life, differentiated according to province (1950-1952)

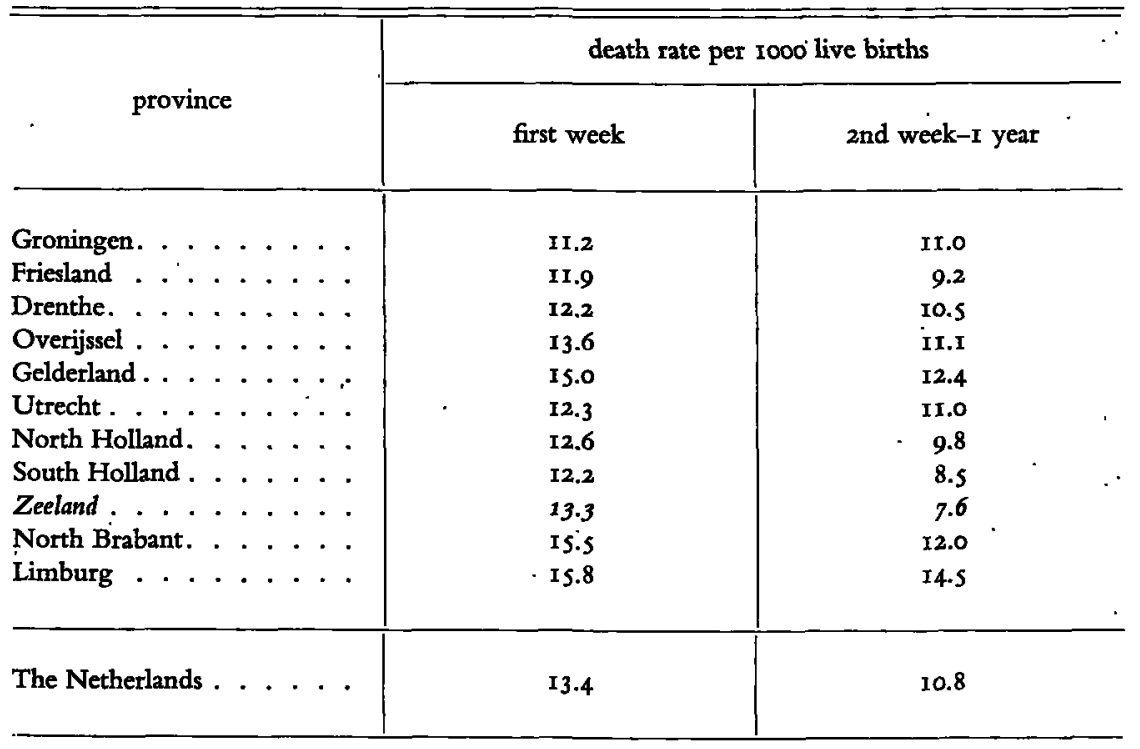

It may be a general truth that a low infant- and prc-school child mortality go hand in hand (SALter, SAJET), it is nevertheless not always so, as shown by analysis of the mortality figures in more sharply delimited areas.

Summarizing, it may be said that Zeeland holds a particular place in our country in demographic and socio-economic respect, but that this does not afford an explanation of the low pre-school age mortality existing in that province for fifty years at least. The small number of children per family as a rule is probably an important factor as regards the favourable death rate. In addition, the population of Zeeland seems to possess character traits and a manner of living leading to a-relatively good care for the child and thus to a lower juvenile mortality. The low mortality from accidents as compared 
with other rural areas, the course of infant mortality and the present very low mortality after the first week, are indirect indications that there is indeed relatively good child care in Zeeland. In the complex of factors that determine the death rate, and which influence each other mutually, the combination of small families and good care for the pre-school child seems the predominating one. This is only true for the infant mortality when it has already reached a low level.

The degree of medical care is of far less importance for the pre-school age mortality, at any rate up to now.

The province of Friesland resembles Zeeland in many respects. During the first decades of this century, Friesland showed the same low pre-school age death rates as Zeeland. Subsequently, however, the fall of the pre-school age mortality was less rapid than in most of the other areas of our country, so that this province had to surrender its favourable place to other provinces. The average low prospcrity (table XII) may be a factor of some importance, even though in the beginning of the century the economic conditions were not favourable either. The greater number of children per family seems to be of higher importance. At the beginning of the century matrimonial fertility was still relatively low in Friesland, just as in Zeeland, but at present it is higher than the average for the whole country and considerably higher than in Zeeland (VAN DEN BRINK). The pre-school age mortality due to accidents is very high in Friesland, so that the care for the young child is probably less good in Friesland than in Zeeland.

Here also' the factors: number of children and care of the pre-school child (though in this case in a negative sense) seem to be of paramount importance for the explanation of the relatively high pre-school age death rate.

The influence of the main causes of death of pre-school children in the various provinces is separately dealt with in chapter XI. We only mention here that the low pre-school age death rate in Zeeland is not due to the very low mortality from certain causes of death, but that it is true for practically all of them. This is to be expected, as in Zeeland the favourable factors are of a general, aspecific nature. A detailed investigation into the care of the pre-school child in the Zeeland family, and into the Zeeland manner of living and the character of the population leading to this good care, may yield valuable practical data for the maternal and child health policy in our country and possibly also in other countries. Up to now very little is known about the causes of the favourable mortality figures and the relatively low birth rate in Zeeland. In this respect this province has not yet drawn sufficient attention. 


\section{VII}

\section{MORTALITY OF CHILDREN OF PRE-SCHOOL AGE IN RURAL AREAS AND IN TOWNS}

Table XVI gives the pre-school age mortality according to size of the municipality in I95I/1952. At present the death rate of I-4-year-old children in the country is higher than in the towns.

TABLE XVI

Pre-school age mortality according to size of municipality, 1951/1952

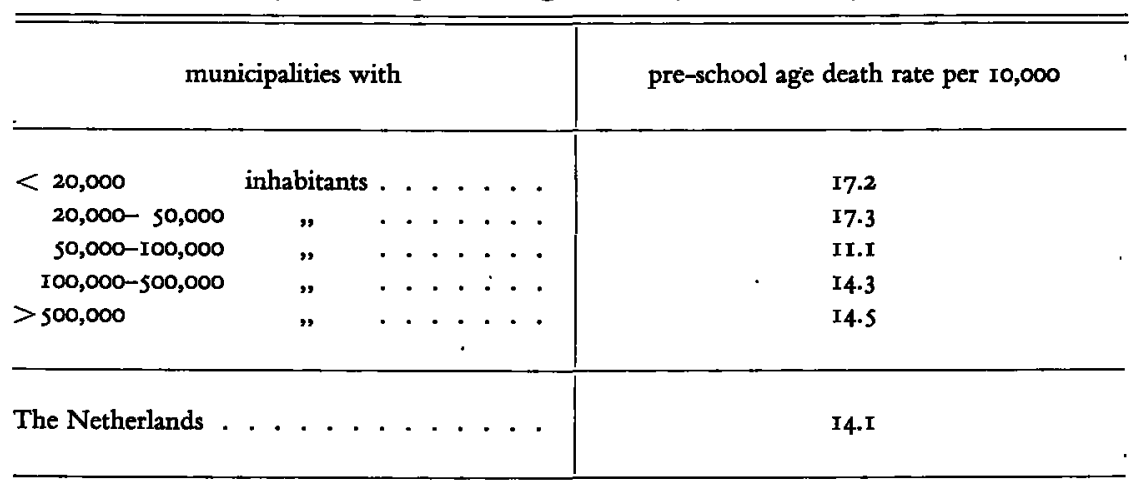

Table XVII shows that the reverse was the case in about I9Io: then the towns had higher death rates than the rural districts.

TABLE XVII

Pre-school age mortality according to size of municipality, 1906/1913 and 1951/1952

\begin{tabular}{|c|c|c|c|c|}
\hline \multirow{2}{*}{\multicolumn{3}{|c|}{ municipalities with }} & \multicolumn{2}{|c|}{ pre-school age death rate per ro,ooc } \\
\hline & & & & \\
\hline$<20,000$ & inhabitants & ..... & 127.4 & I7.2 \\
\hline $20,000-100,000$ & " & $\ldots \ldots$ & I37.2 & I4.6 \\
\hline$>100,000$ & $"$ & $\ldots \ldots$ & 138.0 & 14.3 \\
\hline
\end{tabular}

The fall of the pre-school age mortality in the towns has therefore been even greater than in the country. 
Table XVIII gives, for purposes of comparison, the corresponding figu res for the mortality of infants.

TABLE XVIII

Infant mortality according to size of municipality

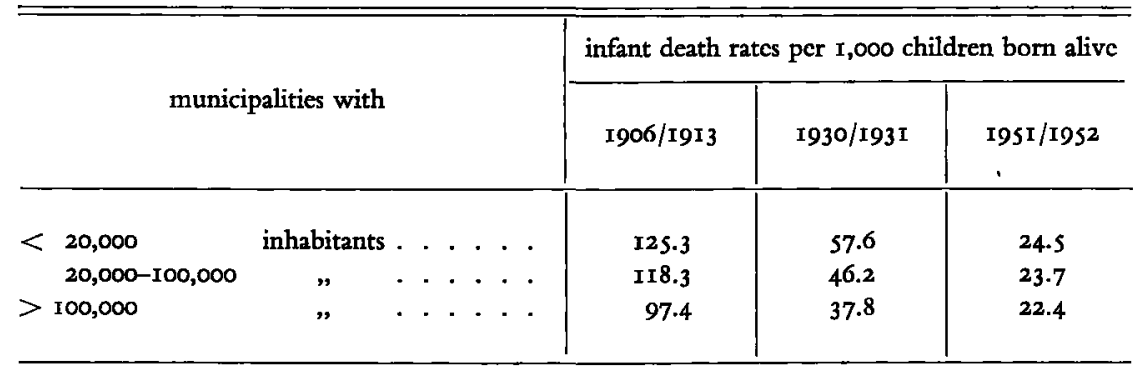

About 1910 the mortality of infants was markedly higher in the country than in the towns, and this has remaincd so up to the present, although the discrepancy is not so high. As regards infants, the mortality has therefore decreased more in the rural areas than in the towns, while exactly the reverse is the case for the pre-school age children: thesc death rates have shown a greater fall in the towns than in the country.

The cause of this diffcrence might perhaps be sought for in the great influence on the infant mortality (especially in former times) of the hygienic and medical supervision (alimentary disturbances and intestinal infections). The rural districts were behind in this respect as compared with the towns, although the arrears are being made up. Technical hygienic measures are less important as regards the pre-school age mortality (as shown by the relatively slight mortality from intestinal affections), while infectious diseases constitute a far greatcr death factor. The fact that infectious diseases had morc victims among young children in densely populated towns than in the country, is one of the causes of the former higher pre-school age death rate in the towns.

At present the mortality from infectious diseases is of less importance as regards the total pre-school age mortality, whilc the differences betwcen town and country have become less marked owing to increasing urbanization, more intensive traffic and less isolation. The main cause of death in pre-school age is at present the fatal accidents. The mortality from accidents is significantly higher in the country than in the towns, probably as a result of the greater number of cases of drowning ( $p .70)$.

The present differences in pre-school age mortality between rural areas and towns are completely based on the difference in deaths from accidents. The pre-school agc mortality, minus violent death, was in 1951/1952 II.6 per I0,000 for the large towns, and in the country, Ir.9 per I0,000.

Disregarding dcaths duc to accidents, the marked fall of the pre-school age 
mortality has therefore bcen accompanied by a levelling out of the differences between town and country, the towns having made up for their arrears. The same levelling tendency is also observed in the mortality of infants, in which the rural areas are catching up, even if these differences between rural and urban areas have not yet disappeared completely. The levelling out of the differences in pre-school age mortality betwcen town and country has also taken place in France (CANDiotTr \& Moine).

When discussing the main causcs of death, the pre-school age mortality according to size of municipality will be dealt with in more detail. 


\section{CAUSES OF DEATH AND NOMENCLATURE}

The basic material of the statistics of the causes of death is provided by the: attending doctor, who, in this respect, bears a grcat responsibility, the significance of which is not always realized. The death certificate signed by the doctor is of course not always completely accurate. The causc of death is only rarely verified by autopsy, and cven then sufficient certainty as regards remote and immediate cause of death is not always obtainable.

Diagnostics have developed in the course of years, partly by expansion of our knowledge, and partly by changes in the conception of 'cause of death', while the fashion of the times was another important factor (LOGAN).

The classification of the data from death certificates is mainly of importance for the distinction between the remote and the immediate causes of death. This classification is most difficult in infants and elderly people; the problem is easicr where pre-school children are concerned.

A third factor influencing the data finally published in the death statistics, is the nomenclature, which has changed several times in the present century.

The three factors mentioncd: diagnostics, classification and nomenclature may cxert an unfavourable influence on the absolute value of the mortality statistics, each to a varying degrec. This is mainly true for the comparison of death rates over long periods, for the study of particular diseases and for particular ages. The mortality duc to convulsions, for example, formerly an important 'cause of death', has disappeared. from the present statistics. Diabetes and cardiovascular diseases are examples of affections in which the distinction between remote and immediate cause of death may be difficult, especially at an advanced age.

The chance of errors is less great when dealing with pre-school children than with infants or clderly people. The differences in diagnosis, classification and nomenclature become of less importance by dividing a number of diseases into groups of causes of death, by which arrangement the reliability is greatly increased. A diffcrence in interprctation between bronchitis and pneumonia as a cause of death is eliminated by considering discases of the respiratory tract as a whole. In this way our group of intestinal diseases also includes dysentcry, etc. 
This study is moreover limited to a number of diseases with rather sharply defined clinical features, and which, in general, do not cause great diagnostic difficulties.

Little value can be attached to small differences over long periods. It is therefore a favourable factor that the differences in mortality, as observed in this investigation, are great, and therefore undeniably of significance, even if a number of mistakes may still be possible. The constancy of the fall and the general trend in the statistics of causes of death are also indubitable facts.

To deny each importance to these statistics because of errors would be an unjustifiable nihilism (PascuA). This does not only hold true for these statistics. Numerous medical and laboratory methods are liable to errors, sometimes serious oncs, without this forming an impediment to their use. It is often impossible to determine the degree of the crrors that may be made in the statistics of causes of death. Recently, however, we have a better conception of the influence of changes in nomenclature.

The World Health Organization considered the latest radical change of nomenclature (introduced into Holland in 1950) a reason for instituting an investigation into the influence a changc of nomenclature exerts on the statistics of causes of death.

An analysis of these differences is possible by recording, for a period of one year, all causes of death both according to the old nomenclature of 1938 and the new one of 1948. This analysis has been carried out at the request of the W.H.O., inter alia in Canada. The corrections applied in our material to study the significance of the change in nomenclature as regards the statistics are borrowed from this analysis.

More than $95 \%$ of deaths recorded as due to one of the four common infectious discases according to the 1938 nomenclaturc, belong also to the same group according to the 1948 nomenclature. The same holds true for the mortality from tuberculosis, tumours and reticuloses and violent death (accidents). As regards diseases of the respiratory system, the new nomenclature gives rise to greater changes in the statistics of causes of death, but, on closer analysis, the diffcrence proves to be slight for pre-school children.

Practically all other cases of death classified differently after introduction of the new nomenclature concern diseases of old age (arteriosclcrosis, prostatic hypertrophy, cardiac asthma, etc.) and diseases of the ncwborn. For intestinal diseases also (gastroenteritis, diarrhoea and dysentery) the new nomenclaturc gives rise to an important change in the classification, on closer inspection almost exclusively affecting infants. $90 \%$ of the mortality from intestinal diseases after the first year of life remains the same after the change of nomenclature, and this percentage might have been greater if our group had been made somewhat wider. 
The introduction of the new nomenclature neither influenced the death rate from congenital abnormalities for children older than one year; more than $90 \%$ of these cases of death are recorded as due to congenital abnormalities.in both nomenclatures.

Conversely, it is possible to start from the classification of the 1948 nomenclature, and then to investigate what changes the use of the 1938 nomenclature would have caused in the statistics. These changes prove to be smaller than those observed in the first method.

Such an analysis of earlier changes of nomenclature is practically impossible. Many data on the older nomenclature can be found in NeurdenburG's academical thesis. The strong impression is gained that changes of nomenclature are only of minor significance for the registration of causes of death important at pre-school age, in contrast to those for infants and elderly pcople. Change of nomenclature has only a slight influcnce on the figures for infants, if the self-chosen grouping is strictly adhered to and only the data of the large, i.e., most detailcd list of causes of death are used (TAYLOR).

Logan studied the extent of the differences in classification of the causes of death, if, according to pre-arrangcd rules remote and immcdiate cause of death are separated or if the doctors' death certificates are accepted as such. This difference is practically nil at pre-school agc, while it may be very great for elderly pcople. As Stocks has it: 'Amongst the young, a single cause of death often suffices to tell the story'; at any rate in a statistical elaboration.

Summarizing, it may be said that the reliability of the statistics of causes of death for pre-school children is more than sufficient to allow of conclusions on not too small changes in mortality from various causes. The reliability becomes considerably greater if we adhere to a self-chosen grouping based on the detailed list of causes of death.

The limitation of the value of these statistics is not, as often thought, caused by a supposed inaccuracy of the death certificate, but should be sought for in the conception of 'cause of death' itself. The state of health of the child before his fatal illness is the main factor deciding whether he will die from a disease or not. This is demonstrated time and again in the analysis of mortality, and most marked in undeveloped areas in which it can almost be called a fortuitous factor whether a chronically underfed and debilitated child will succumb, for example to measles or dysentery (De HAAs).

In spite of this limitation of the conception 'cause of death', the statistics dealing with it give us a detailed version of the general picture already obtained by analysis of the pre-school age mortality as a whole. This picturc at the same time reflects the general state of health, the social milieu and the spread of diseases in pre-school children. 
IX

\section{MORTALITY OF CHILDREN OF PRE-SCHOOL AGE ACCORDING TO CAUSE OF DEATH}

The most important causes of death at pre-school age are taken together in a number of groups, which not only facilitates comparison with former times and other countries, but also increases the reliability of the statistical data.

The groups are:

(1) The common infectious diseases: measles, whooping cough, diphtheria, scarlatina.

(2) Diseases of the respiratory tract. This group always comprises all affections of the respiratory tract, except tuberculosis and the respiratory complications of the infectious diseascs.

(3) Tuberculosis: all forms.

(4) Intestinal disturbances, including gastro-entero-colitis, diarrhoea and dysentery.

(s) Violent deaths.

(6) Congenital abnormalities.

(7) Tumours and reticuloses.

(8) Non-specified or insufficiently specified and unknown causes of death.

(9) All other causes of death.

These groups are composed from the causes of death according to the detailed list. The causes are numbered; each nomenclature has its own numbers. Table XIX gives the numbers of the causes of death of the groups chosen, for cach nomenclature.

The causes of death are always expressed per 100,000 pre-school children. Table XX and fig. 10 give a rough impression of the fall in the mortality from some of the most important causes in I-4-year-old children. This fall has usually becn greatcr than that of the total pre-school age mortality (apart from violent death and congenital abnormalities which have had no part in the decline of the death rates, or only slightly so). The extent to which the main causes of death have contributed to the fall of the pre-school agc mortality has been roughly the same for all of them. If medical care and modern methods of trcatment had been of great influence in the fall of the death rate, this fall would have started later, or at any rate its tempo would have bcen an acceler- 


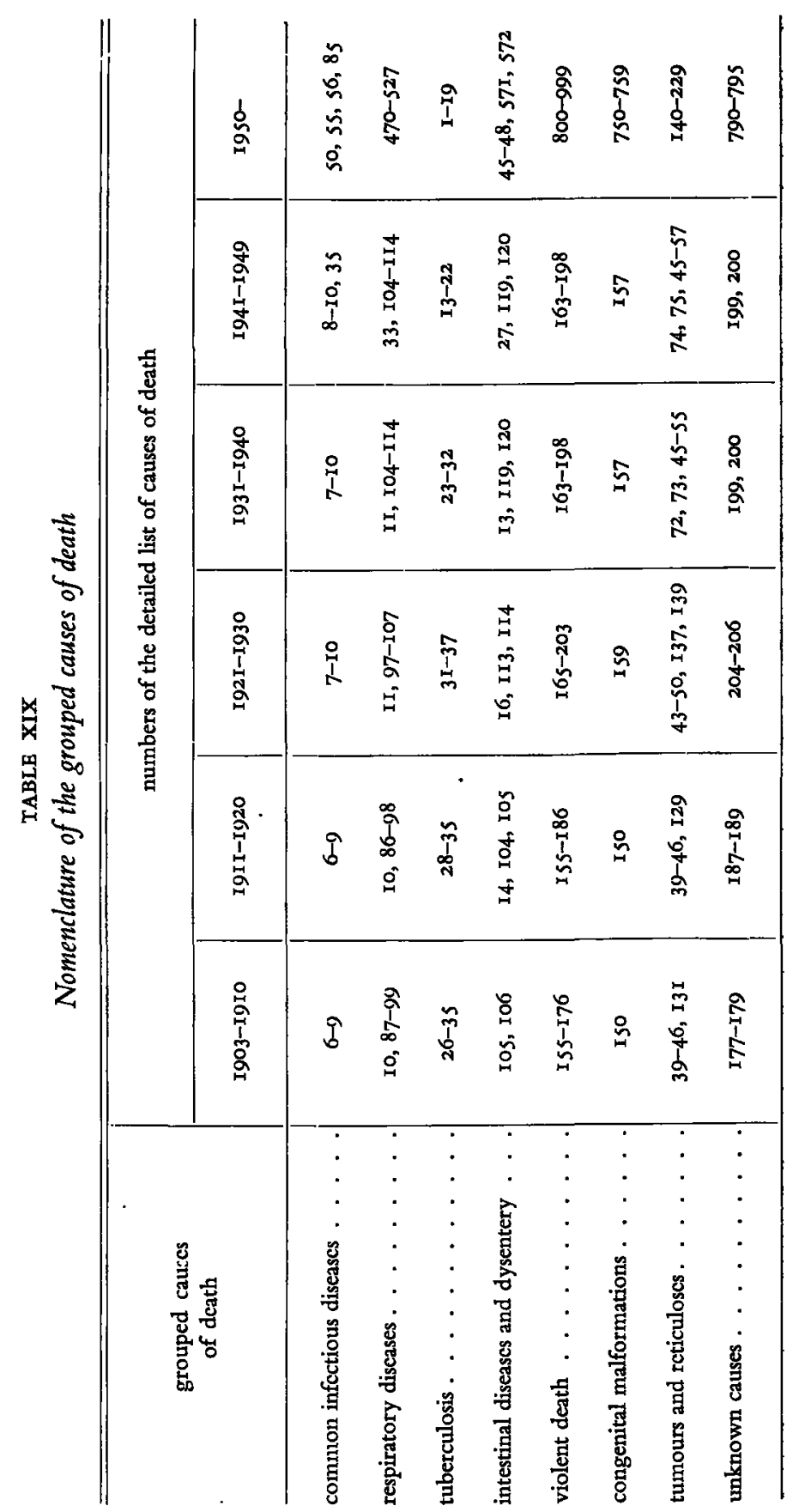




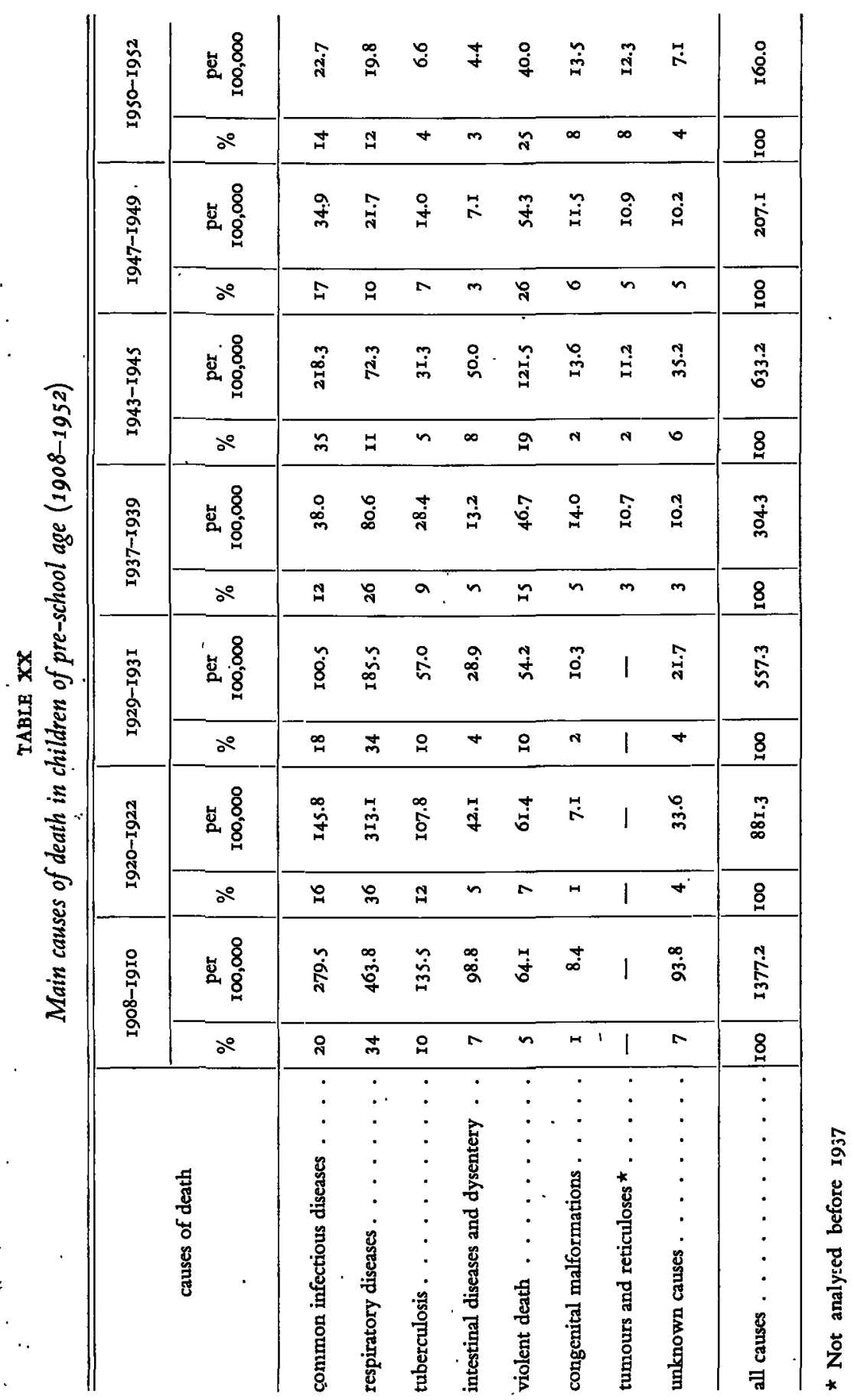


atcd onc, and it would not have bcen so equable for the various causcs of death.

The main causes will be dealt with briefly.

(I) Common infectious diseases

The mortality from this causc has gradually decreased, apart from the very high peak in the second world war.

(a) Scarlatina. The mortality from scarlatina has never been an important factor in pre-school age mortality in the 2oth century, even though about the year I9Io still some hundred J-4-year-old children died from this disease

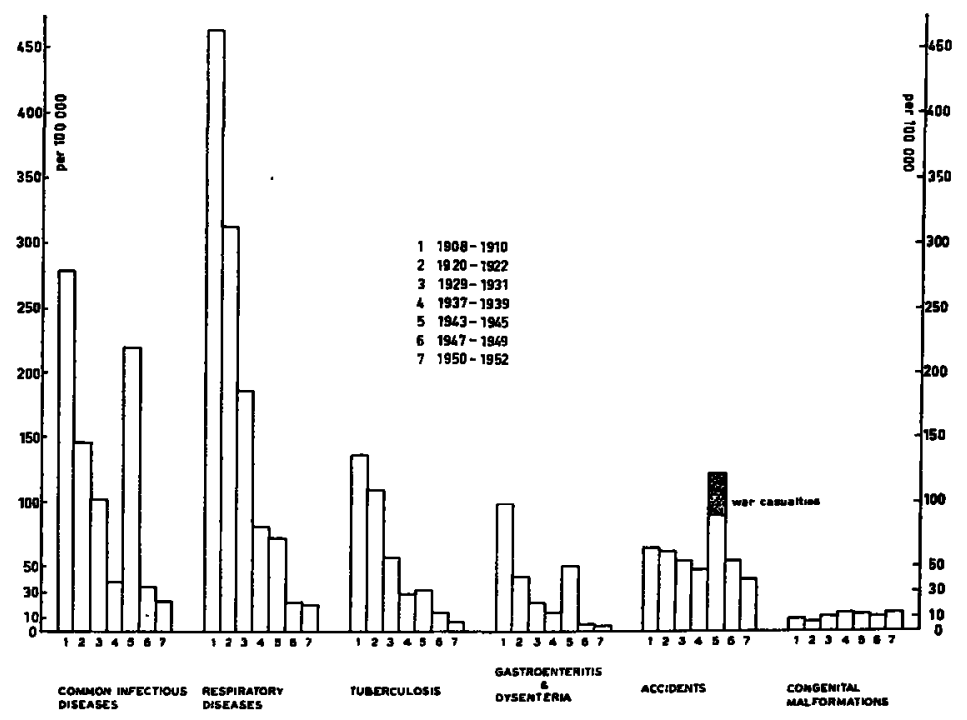

Fig. Io

Main causes of death in pre-school age

The Netherlands I908-1952

annually. Since about 1935 there is practically no longer any mortality from scarlet fever in children of pre-school age.

(b) Measles. Much has been written about the mortality of measles, recently by DegenaAr. Most victims of this disease belong to the pre-school age group (figs. 11a and 11b). It is true that young children of school age also show a high morbidity (SAJET; Dorothy Holland), but the fatality rate is very low among these 5-9-year-old children. It is possible that improvements in housing conditions and the relative decrease in the number of pre-school children have been factors in the decline of measles mortality, just as in the other infectious diseases (this is also assumed by DegenaAR), because thus the 
nfection occurred on an average at a somewhat older age, with less chances of a fatal outcome. On the other hand, increasing urbanization would lead to an increase of the chance of a fatal issue. In any case, the death rate from measles has been reduced markedly, while the incidence of the disease has changed little or not at all.

DegenaAR was unable to demonstrate any influence of the sulphonamides on measles mortality. Fig. 12 shows that since 1930 the fall in measles mortality in pre-school children has continued regularly, without any demonstrable influence of modern drugs. The epidemic increases are no longer important,

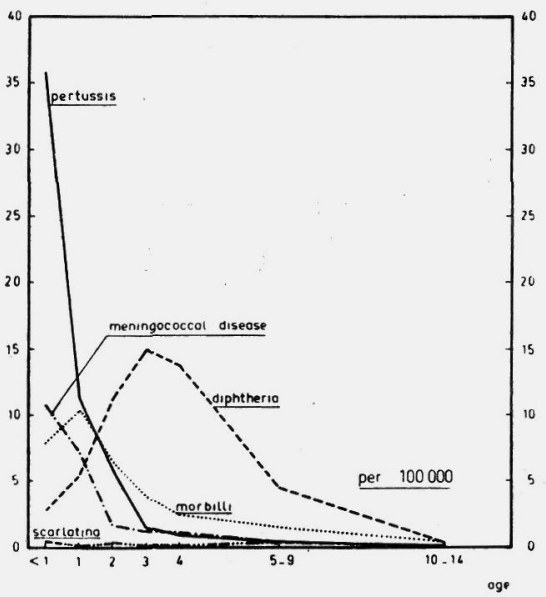

Fig. I I $a$

Death rates from common infectious diseases by age

The Netherlands I950-I952

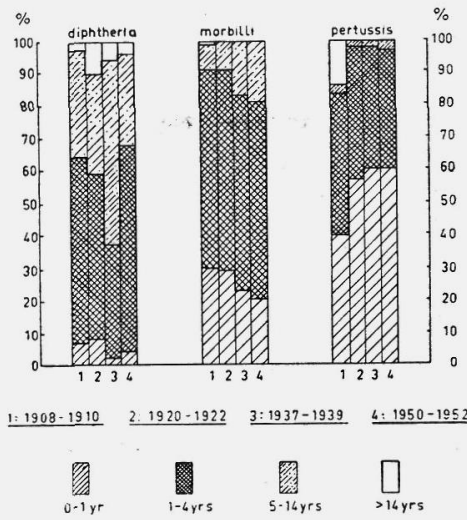

Fig. $1 \mathrm{I} b$

Deaths from diphtheria, measles and whooping cough in childhood in percent of total mortality from these diseases

The Netherlands I908-I952

although the peak in 1946 (repatriates from Indonesia!) still demonstrates the potentially dangerous nature of this disease even at the present time, at any rate under conditions of reduced general resistance.

The age distribution of the mortality of measles has not changed greatly. The fact that the fall of this mortality has been the same for infants and pre-school children, lends support to the contention that improved therapeutic methods have not been of much importance in this decline. A shift to older ages and a decrease of the number of complications through better social conditions are most likely the main reasons for the fall in the mortality of measles.

(c) Whooping cough. Although the mortality due to whooping cough has also markedly declined in pre-school children (fig. 12), this has been to a lesser degree than in measles. Of recent years, however, the pertussis mortality has 
shown a striking decrease, even prior to the general.introduction of the newer . antibiotics and of mass-vaccination. Of all the children dying in the Nether-

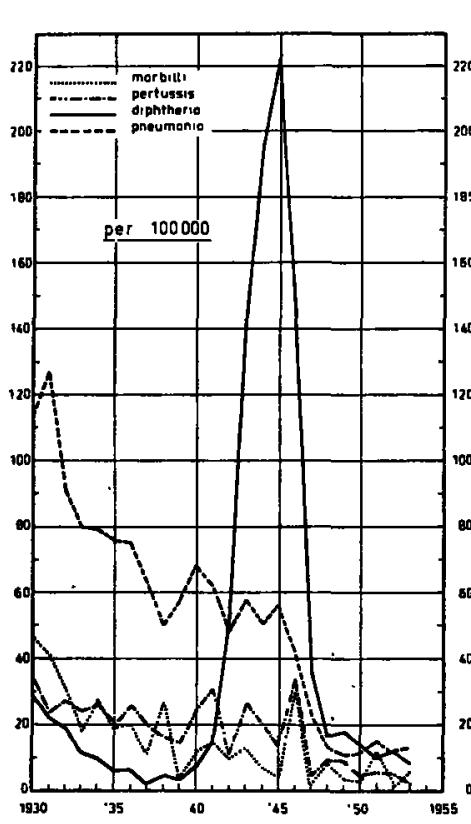

Fig. I2

Death rates from some infectious diseases and pneumonia in pre-school age The Netherlands 1930-1953 lands from whooping cough, $60 \%$ are infants, under $20 \%$ are I-year-olds, and 100 only $10 \%$ 2-year-olds. Forty years ago this age distribution was only found among the more well-to-do people with their so smaller families (SAJET), the other groups of the population also losing many pre${ }^{10}$ school children from this disease. In I930 the increased prosperity and reduced birth rate had already led to the same age distribution in the whole country, and it has a remained so for the past twenty ycars. Just as was the case for the mortality from "measles, this unchanged age distribution “o since 1930 constitutes an argument against any great influence of modern therapeutic ${ }^{20}$ methods, and in favour of a predominant importance of social factors (such as improved state of health, greater prosperity and smaller families). Thomson, who analysed the mortality from pertussis in England, also arrived at this conclusion.

(d) Diphtheria. In recent years the epidemiology of this disease in the Netherlands has been described by HoOgENDOORN, NOORDAM, NIEUWENHUYZE, and other authors. The course of the mortality from diphtheria in pre-school children shows a different picture from that of measles and whooping cough (fig. 12). It is true that the mortality from diphtheria has markedly declined since the beginning of the present century, but, during the second world war, the number of fatal cases in pre-school children rose to no less than 70 times the low figure of the immediate pre-war years. The mortality has fallen considerably since the end of the war, but it has not yet reached the 1939 level again by a long way. The mortality from diphtheria has declined only slowly of late years. The number of pre-school children falling victims to diphtheria in the last three years of the war was about five times the number dying as war casualties. If the expense, energy, and brainwork spent on civil defence on the one hand and diphtheria immunizations on the other, are compared, the question arises spontaneously whether the lessons taught by the second world war in this respect have been taken to heart well enough. The effect 
of a good immunization campaign is no longer a matter of doubt, as has been well shown in England. RuYs et al. (see Noordam's academical thesis), when studying the war epidemic, strongly emphasized the greac frequency of infections with the gravis type of $C$. diphtheria. Apart from the importance of this question for the epidemiology and the clinical picture of the disease, it should serve in no respect as an excuse for the shortcomings in the fight against diphtheria. Adequate immunization of infants and pre-school children is the only satisfactory method of diphtheria prophylaxis, irrespective of the nature of the causative agent.

Diphtheria is still a children's disease. Of all fatal cases of this affection between 1915 and 1945 , more than $50 \%$ were children below the age of five. The shift of the mortality towards older children and adults during the second world war epidemic, gave rise to considerable attention, but it proved to be only transient ( fig. 11b). During the past five years, the number of deaths due to diphtheria in pre-school children and infants has constituted over $70 \%$ of all fatal cases of this disease. The bighest death rate is observed among the 3-4-year-olds. The morbidity is also the highest among the 4-year-old children (HoOgENDOORN).

The number of cases of this disease among schoolchildren is considerably higher than is to be expected from the death rates, because the fatality rate decreases with advancing age.

The morbidity also showed a shift in age distribution during the war epidemic, but this proved to be only temporary: the number of diphtheria cases in pre-school children and infants was $28 \%$ of all cases in the period $1935-1939 ; 20 \%$ in $1940-1946$ and $45 \%$ in $1948-1952$.

The low frequency of diphtheria before the second world war and possibly also a higher virulence of the causative agent, effected a shift towards higher ages during the war years. It is possible tbat, conversely, the high morbidity of the war years and afterwards, resulted again in a shift towards younger ages: Immunization, however, is also of importance in this respect, because this, strangely enough, was mainly carried out in schoolchildren. As children of school age are more readily immunized than younger children, diphtheria will be of relatively greater frequency among the younger ones (TASMAN).

The diphtheria mortality in pre-school children has decreased by more than 40\% since 1923-1934; this fall was nearly $70 \%$ for the schoolchildren.

Diphtheria is also at present still an affection of childhood, finding its victims mainly among infants and pre-school children. This fact is of paramount importance for the fight against the disease (immunization), as recently emphasized again by HOOGENDOORN and RUYs. This fight has been intensified and better organized in the last few years. 
(2) Diseases of the respiratory tract

The fall of the pre-school age mortality from these affections was already manifest at the beginning of the 2oth century, and it is procceding rapidly.

Fig. 12 gives a survey of the mortality from pneumonia in pre-school children during the past twenty ycars. Pneumonia is responsible for by far the greatest number of deaths due to diseases of the respiratory tract. Fig. 12 shows that the pre-school age mortality from pneumonia has been reduced to onc-tenth in only twenty years' time!

Although the large-scale sulphonamide therapy was introduced as carly as 1937, at first no manifest influence was shown on the pneumonia mortality of I-4-year-old children. It is possible, however, that the sulphonamides did prevent an increase in the number of fatal cases during the war. At the same time it is probable that young children have benefited less from modern therapeutic methods than adults, as also appears from the studies of ANDERson and of Vera Norris. The latter analysed an extensive series of hospital cases, and it can be deduced from her data that, since the introduction of sulphonamides and penicillin, the death rate from lobar pneumonia and from bronchopneumonia has decreased considerably less in children younger than to than in adults. The analysis of the mortality in Australia by LANCASTER also demonstrates that not only is a long period required before a modern form of effective therapy can influence the mortality, but also that younger children (and aged people) benefit less from this therapy than older children and adults. Twelve years after the introduction of the sulphonamides, the attention of SPENCE $e t$ al. was drawn to the fact that if an indication to treat infants with these drugs existed, this was carried out to a limited extent only and often in insufficient dosage.

The mortality from pneumonia showed a sudden fall directly after the second world war. This was probably also the result of chemotherapy, even if its contribution to the fall in mortality was not demonstrable until ten years: after its introduction. The low levcl reached in 1948 did not decrease further with the use of penicillin. Will years again have to pass before the pre-school age mortality can be reduced further by the timely and well-judged use of antibiotics?

The fact that not enough I-4-year-old children suffering from serious. pulmonary diseases ( $p .102)$ are admitted to hospital, justifies the idea that, in the present state of our knowledge, a further decrease of the pncumonia mortality in this category is still possible: more children should benefit in time from this knowledgc.

In spite of the marked fall in the mortality of pneumonia, diseases of the respiratory tract (apart from tuberculosis) still constitute an important cause of death of these children, and the winter peak persists $(p .23)$. 
The fall of the pneumonia mortality in pre-school age children has been the same o only slightly more than that from tuberculosis, measles, whooping cough and intestinal diseases, notwithstanding the effective modern drugs used in pneumonia.

\section{(3) Tuberculosis}

Tuberculosis was still an important cause of death at the beginning of the present century, also in pre-school children. In about igro, approximately the same number of I-4-year-old children died from tuberculosis as at present from all causes of death combined.

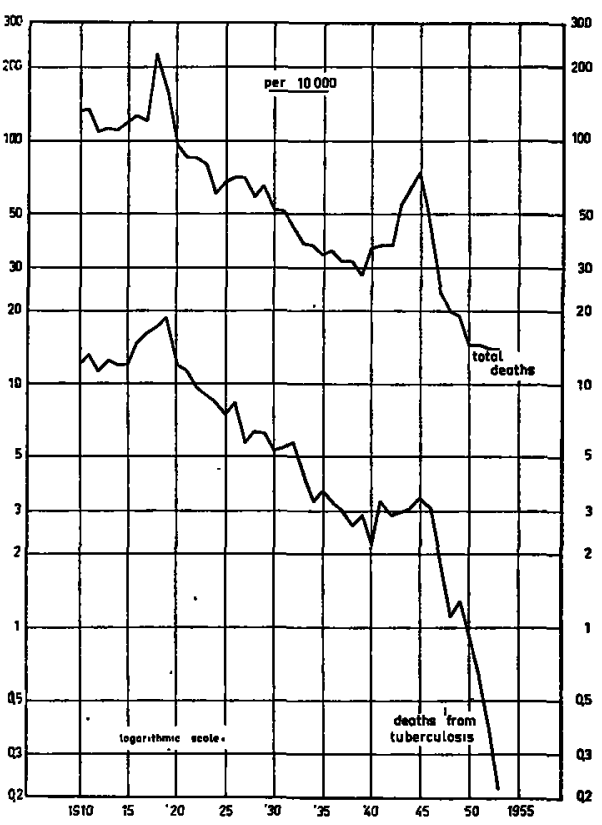

Fig. I3

Total mortality and deaths from tuberculosis in pre-school.age

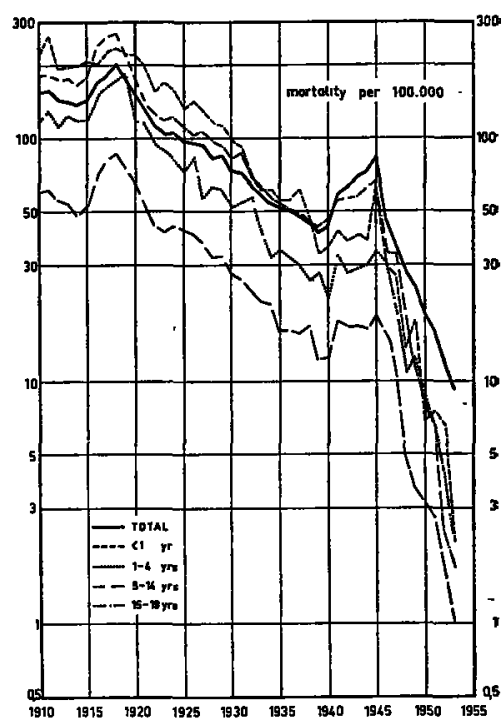

Fig. 14

Death rate from tuberculosis in childhood The Netherlands 1910-1953

The Netherlands I9I0-I953

The fall of the tuberculosis mortality in children has been very rapid, since I945 even amazingly so (figs. 13 and 14), as recently described in detail by De HAAS.

Such a marked decline in so short a time cannot only be explained by improved economic conditions, while housing conditions have deteriorated rather than become better. Streptomycin and PAS were not in general usc until 1948, and therefore they certainly do not constitute the sole cause. The fall must also have resulted from prophylactic measures such as identification of the source, isolation of patients with positive sputum, registration of all 
patients, pasteurization of the milk, in short, the whole fight against tuberculosis that came into full action after the war, coupled with educative propaganda. Later on curative medical care has also been of influence, both by bringing about a decrease of the fatality rate and by reduction of the chances of becoming infected, now that so many patients can be made sputumnegative. The marked decline in the mortality can be explained from the cumulative effect of the various preventive and curative measures. It must be remarked that these results have been obtained without the general adoption
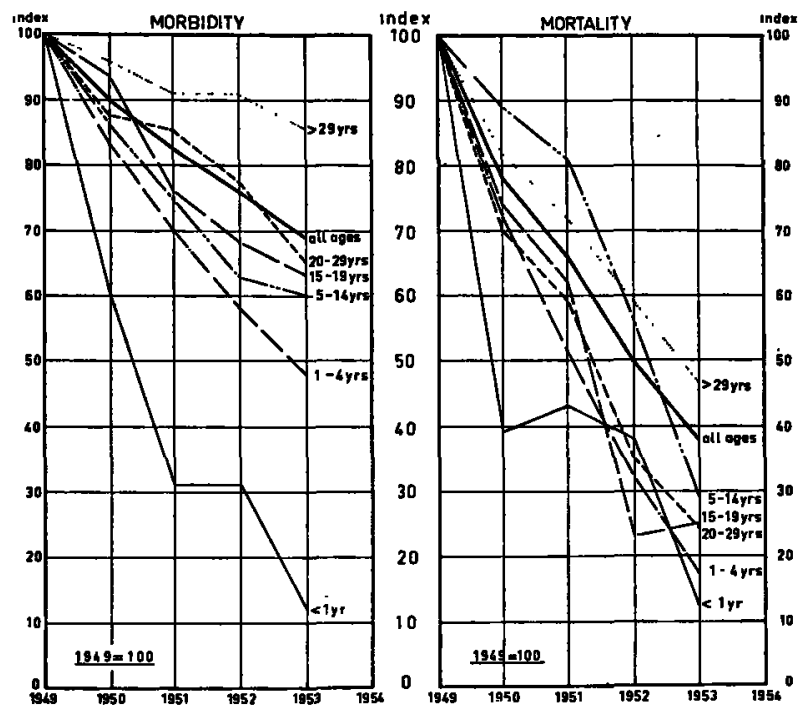

Fig. 15

Decrease of tuberculosis indices by age

The Netherlands I949-r953

of BCG vaccination. The present tuberculosis incidence in children has made BCG vaccination superfluous, apart from selected cases (HoOGENDOoRN; De HAAS ${ }^{1}$.

The great influence of preventive measures is also apparent from the fact that mortality and morbidity rates in children have fallen far more rapidly than in adults (fig. 15). The mortality from tuberculosis in infants has even practically disappeared, notwithstanding that in this group treatment is often too late, the diagnosis relatively more difficult, and the clinical course more serious. The frequently-heard contention that the fall in the tuberculosis death rate is mainly the result of a better prognosis due to improved methods of treatment, is not in agreement with the trend of statistical mortality figures. The statistics of tuberculosis morbidity are of little help in the solution of the

1 BCG report, r95t (not published) 
problem, as a fall of the morbidity may be masked by better methods of tracing cases of active tuberculosis and changes in the diagnostic criteria. Tuberculin index surveys indicate a great decline of morbidity, but nationwide surveys are still lacking in the Netherlands.

HOOGENDOORN used the tuberculous meningitis mortality as a standard of measurement for the morbidity, on the strength of the $100 \%$ death-rate of this affection up to 1947 , and thus it can be demonstrated that the morbidity of

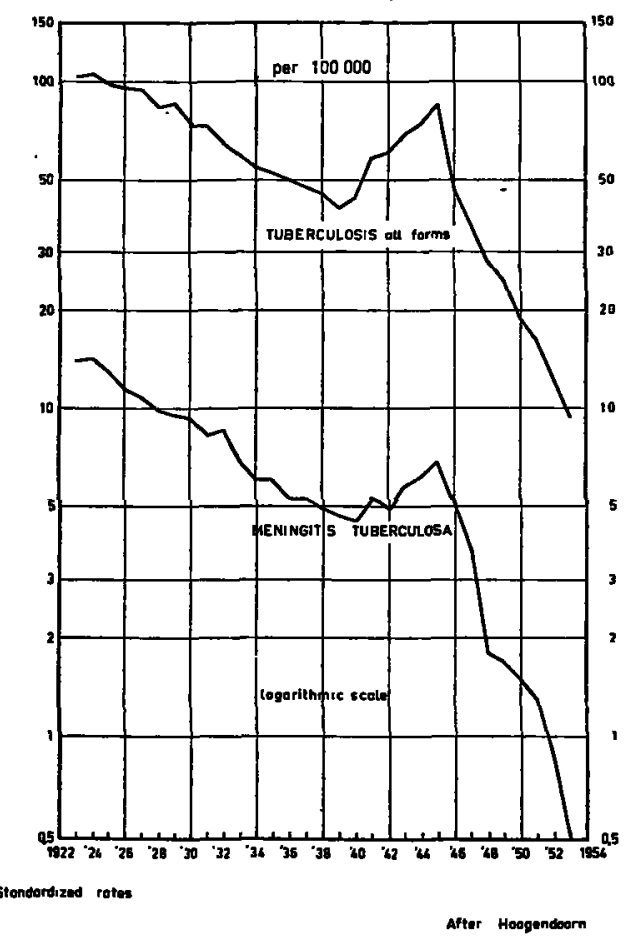

Fig. 16

Death rate from tuberculosis and tuberculous meningitis The Netherlands 1923-1953

tubercalosis falls with the same speed as the mortality from this disease (fig. 16). Even since the introduction of streptomycin, the total mortality from tuberculosis has not decreased more rapidly than that of tuberculous meningitis; in spite of the difference in effectiveness of chemotherapy and antibiotics in the various forms of tuberculosis.

There are no signs that the fall in the death rate from tuberculosis in children has come to a standstill, which is also a result of prophylactic work. This is very different from the course of the pneumonia death rate (fig. 12): The reduction of the mortality from pneumonia in children of pre-school age, due largely to the newer methods of treatment, started in 1945 but was arrested 
again some years later, when evidently a level had been produced by thosc cases which are not saved by the present methods of treaiment. The fall in the tuberculosis death rate, on the other hand, is continuing unintcrruptedly. The effect of preventive measures is greater and less limited than that of curative ones.

The conclusion that the marked fall in the mortality from tuberculosis is primarily due to preventive measures and only secondarily to curative ones, is also reached by LoRBER, who analysed this mortality in children in Sheffield since the second world war.

The remarkable decline in the tuberculosis death rate in all juvenilc age groups is one of the miracles in the social and medical field in the Netherlands.

Within a few years tuberculosis will probably have become a relatively rare disease in children of pre-school age, as is already the case in infants.

\section{(4) Intestinal diseases}

The intestinal affections comprisc gastro-entero-colitis, diarrhoea and dysentery. The mortality from this group of diseases, which were of rather frequent occurrence at the beginning of the century especially among the younger children of the pre-school age group, has steadily decreased. At present these diseases are of minor importance as regards the pre-school age death rate; the general improvement of hygienic and dietary habits has undoubtedly been the most important factor.

Compared with the mortality of infants, the direct influence of the technical hygienic progress on the pre-school age death rate has been only slight, due to the relatively small significance of the intestinal diseases, cren forty years ago.

\section{(5) Violent deaths}

The mortality due to accidents has bccome of great importance as regards the pre-school age death rate, but so far it has been little studjed in the Netherlands. Therefore a special chapter was allocated to this subject (chapter $X$ ).

\section{(6) Congenital malformations}

The mortality from these in I-4-year-old children rose between I9Io and I940, and was then arrested. This was, however, only a sceming increase, as will be explained.

Cardiac malformations occupy an important place among the congenital defects that cause death at pre-school age. Practically all fatal cardiac affections at this age are associated with congenital defects. Deaths from.complicating cardiac diseasc (e.g., in diphtheria) are recorded under the primary cause of death in the mortality statistics. 
By adding the mortality from cardiac disease to that of congenital malformations, a better picture is obtained of the latter. The pre-school age mortality from congenital malformations thus proves to have remained practically constant in the course of the century (fig. 17). In more recent years knowledge of the congenital cardiac malformations has increased, so that at present deaths of I-4-year-old children due to cardiac affections are more frequently recorded as congenital defects than formerly, although this procedure was decided upon in medical statistical circles as early as about I900 (NeURDENBURG).

It must be remarked that the pre-school age mortality from congenital diseases did not show any rise in the years following the second world war, although these children were mainly born during the last years of the war, in a period of bad nutritional conditions.

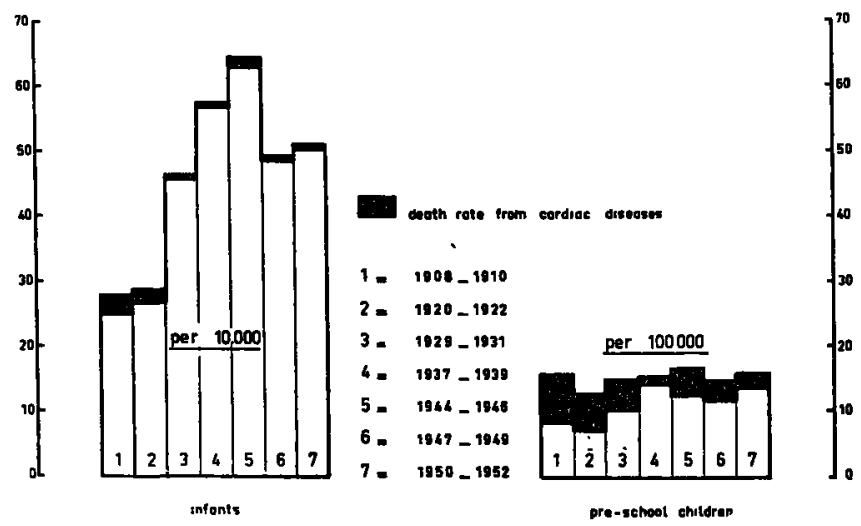

Fig. 17

Death rate from congenital malformations in infants and pre-school children The Netherlands 1908-1952

A result of the better methods of treatment is that in some cases death from congenital malformations in children of pre-school age may be postponed if not prevented. This however, also applies to infants, so that at present a greater number of children with congenital defects may reach pre-school age; this improvement in medical skill is therefore not reflected in a fall of the pre-school age death rate from congenital defects.

The death rate from congenital abnormalities in infants has increased considcrably, also if the mortality from cardiac diseases is added to it (fig. 17, table XXI). One of the causes of this rise is the more accurate definition of the conception "born alive" since 1924. As a large number of children born alive but who dic before notification of their birth succumb to a congenital defect, the inclusion of this group in the death statistics leads to a seeming increase of the mortality from congenital abnormalities. It is also possible that the chances 
of an abnormal foetus being born alive have become greater. Improvements have moreover been made in methods of diagnosis and the statistical classification of congenital malformations, especially in infants, so that extensive illdefined groups in the death statistics, such as congenital debility, prematurity, and unknown cause of death, have become smaller. This also leads to an apparent rise of the infant mortality from congenital malformations.

TABLE XXI

Mortality from congenital malformations in infants and children of pre-school age (1908-1952)

\begin{tabular}{|c|c|c|c|c|}
\hline \multirow[b]{2}{*}{ period } & \multicolumn{2}{|c|}{ death rate $<$ I yr. per 10,000} & \multicolumn{2}{|c|}{$\begin{array}{c}\text { death rate } \mathrm{I}-4 \text { yr. age group } \\
\text { per } 100,000\end{array}$} \\
\hline & $\begin{array}{l}\text { congenital } \\
\text { malformations }\end{array}$ & $\begin{array}{l}\text { congenital } \\
\text { malformations } \\
\text { and } \\
\text { cardiac disease }\end{array}$ & $\begin{array}{l}\text { congenital } \\
\text { malformations }\end{array}$ & $\begin{array}{c}\text { congenital } \\
\text { malformations } \\
\text { and } \\
\text { cardiac disease }\end{array}$ \\
\hline I908-'то & 25.0 & 27.8 & 8.4 & I5.6 \\
\hline I920-'22 & 26.6 & 28.7 & 7.0 & 12.5 \\
\hline 1929-'3I & 45.7 & 46.4 & 10.3 & 14.8 \\
\hline r937-'39 & 56.8 & 57.4 & I4.I & I5.I \\
\hline I944-'46 & 62.7 & 64.4 & 12.4 & 16.5 \\
\hline I947-'49 & 48.5 & 49.3 & II.7 & 14.5 \\
\hline $1950-152$ & 50.4 & 51.0 & 13.5 & I5.7 \\
\hline
\end{tabular}

The death rate due to such defects in the infants born between 1944 and 1945 is somewhat higher than in preceding years, but this does not at all imply that the frequency of congenital affections was also higher, as the whole mortality of infants was higher owing to the bad conditions existing in the last years of the war.

The data of the infant mortality statistics do not help to judge the trend of the frequency of congenital deformitics. The corresponding death rate in children of pre-school age, however, makes it probable that the frequency. has not changed to any great extent, even during the war years. A slight decrease may have been masked by better diagnosis. A significantly lower incidence seems only possible by means of planned pre-natal measures, which brings the problem of these malformations within the field of prophylaxis.

Although the mortality from congenital malformations in I-4-year-old children is low compared with that of infants, it can serve better as a measurement standard for the frequency than the relatively high mortality in infants due to this cause. 


\section{(7) Tumours and reticuloses}

At present these affections have developed into a relatively important cause of death. Table XXII gives some figures. These figures do not show a manifest increase of the incidence of tumours and reticuloses; the differences in mortality from this cause in various periods are not significant.

TABLE XXII

Mortality from tumours and reticuloses per 100,000 children of pre-school age (1937-1952)

\begin{tabular}{r|c|c|c|c}
\hline cause of death & I937-I939 & I943-I945 & I947-1949 & I950-1952. \\
\hline reticuloses . . . & 5.0 & 5.2 & 4.6 & 6.4 \\
tumours. . . . & 5.7 & 6.0 & 6.3 & 5.9 \\
\hline total. . . . . & $\mathrm{I} 0.7$ & $\mathrm{II.2}$ & 10.9 & 12.3 \\
\hline
\end{tabular}

The increase of leukaemia, mentioned in the English-American literature (GAULD and other authors), is not in agreement with our findings.

There are about as many deaths from neoplasms as from reticuloses in the pre-school age group. A further differentiation of the incidence of the various tumours and reticuloses is to be found in the work of BUFKrN $e t$ al.

\section{(8) All other causes of death}

All other causes of death together form only a relatively small part of the mortality of pre-school age children. At present (1950-1952) the most important of them are: purulent forms of meningitis, with 40-50 deaths annually (about half of which are meningococcal infections), and diseases of the central nervous system, excluding tumours and meningitis (table XXIII). If not epidemic, poliomyelitis is not an important cause of death for the child of pre-school age. The greatest number of fatal cases of poliomyelitis among I-4-year-old children of the past fifteen years was in I943, when the death rate was 9.8 per 100,000 in this age group. Other epidemics have yielded much lower figures for the poliomyelitis death rate of thesc children.

There is a great difference as regards the causes of death between the I-year-old and the 2-4-year-old children.

Table XXIV demonstrates this difference. We will only touch on some remarkable features.

The decline of the mortality from infectious diseases during the past fifteen 
'Other' causes of death in children of pre-school age (1950-1952)

\begin{tabular}{|c|c|c|c|}
\hline \multirow[b]{2}{*}{ cause of death } & \multicolumn{3}{|c|}{ average annual mortality } \\
\hline & $\begin{array}{c}\text { number of } \\
\text { dcaths }\end{array}$ & $\begin{array}{l}\text { percentage of total } \\
\text { pre-school age } \\
\text { mortality }\end{array}$ & per 100,000 \\
\hline 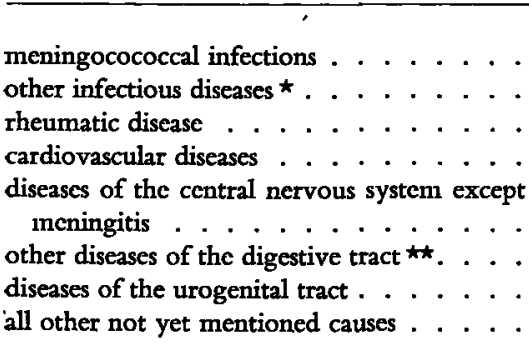 & $\begin{array}{r}27 \\
71 \\
8 \\
15 \\
36 \\
25 \\
11 \\
112\end{array}$ & $\begin{array}{l}1.7 \\
4.4 \\
0.5 \\
1.0 \\
\\
2.3 \\
1.6 \\
0.7 \\
7.0\end{array}$ & $\begin{array}{r}2.8 \\
7.4 \\
0.8 \\
1.6 \\
\\
3.7 \\
2.6 \\
\text { 1. } \\
\text { I1 } .6\end{array}$ \\
\hline
\end{tabular}

* i.e., without influenza, measles, whooping cough, diphtheria, scarlatina, meningococcal infections and dysentery

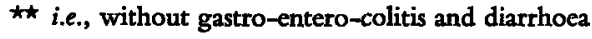

years is not valid for the older children of pre-school age. Their high diphtheria death rate in and after the war compensated for the fall of the measles and whooping cough mortality.

TABLE XXIV

Mortality in 1-year-old and 2-4-year-old children according to cause of death (1937-1939 and 1950-1952)

\begin{tabular}{|c|c|c|c|c|}
\hline \multirow{3}{*}{ cause of death } & \multicolumn{4}{|c|}{ death rate per 100,000} \\
\hline & \multicolumn{2}{|c|}{ 1937-1939 } & \multicolumn{2}{|c|}{$1950-1952$} \\
\hline & I year & $2-4$ ycars & I year & $2-4$ years \\
\hline common infectious diseases . . . . . . & $8 \mathrm{I}$ & 24 & 28 & 2I \\
\hline respiratory diseases . . . . . . . . . & 192 & 43 & 43 & 13 \\
\hline tuberculosis. . . . . . . & 45 & 23 & 9 & 6 \\
\hline intestinal discases and dysentery..... & 43 & 9 & ro & 3 \\
\hline congenital malformations. . . . & 32 & 8 & 29 & 8 \\
\hline tumours and reticuloses . . . & 8 & II & II & $\mathbf{I}_{3}$ \\
\hline violent death . . . . . . & 56 & 44 & 44 & 39 \\
\hline cause unknown . . . . & 23 & 6 & 14 & 3 \\
\hline all causes. . . . . & 567 & 217 & 256 & 129 \\
\hline
\end{tabular}


The younger members of the I-4 age group have a considerably higher mortality from diseases of the respiratory tract than the older ones, reflecting the higher incidence of these illnesses in the second year of life (DyKes).

The I-year-old children have shown a very great fall in mortality from intestinal affections during the past fifteen years (the war years included).

The total mortality of the I-year-olds has declined more since I.937-I939 than that of the 2-4-year-olds: Of all children, the I-year-olds have shown the greatest reduction of death rate.

The fall in the pre-school age mortality is duc to a marked decrease of practically all important causes of death, with the exception of congenital malformations, tumours and accidents.

Generally speaking, the fall in mortality has shown only minor differences for most of the causes of death. Therapeutic progress has been far less steady. If this had been an important factor in the decline of the mortality, this fall would not only have started later, but it would also have shown marked differences as regards the various causes of death, in accordance with the more or less favourable effect of treatment of these diseases.

The mortality figures of children of pre-school age, classified according to cause of death, therefore furnish arguments in favour of the opinion that the improvement in methods of treatment has, in gencral, been of only minor influence on the fall of the I-4 age group mortality, at any rate in comparison with the influence of the social and hygienic factors. LANCASTER, of Australia, arrives at the same conclusion in his detailed analysis of the mortality in that country.

The fall in mortality from the various causes of death at pre-school age has not becn completely identical for all of them. The significance of these causes in regard to the total pre-school age mortality has changed in the course of years. This is demonstrated in fig. 18 and table $X X$, where the mortality due to the most important of them is expressed as a percentage of the total prcschool age mortality. Thus the relative significance of these causes as regards the mortality of I-4-year-old children becomes manifest for various periods of the 2oth century.

The common infectious diseases have always played an important part in the pre-school age mortality, but this has decreased from $20 \%$ in about 1910 to $14 \%$ in $1950-1952$. Within this group, diphtheria is now the most important affection, with about as many fatal cases as measles and whooping cough together. At the beginning of the century, measles was by far the most important of the four.

The influence of tuberculosis on the mortality of children of pre-school age has become slight. At present only $4 \%$ of deaths at pre-school age are duc to 
this disease, and this figure is still decreasing rapidly. Until the second world war, it was about $10 \%$.

The mortality due to diseases of the respiratory tract (tuberculosis excluded) and influenza, still the first cause of death at the beginning of the century, has become relatively of less and less importance in regard to pre-school age mortality. About I9IO, respiratory diseases werc responsible for one third of the total pre-school age mortality, but now it is only so for one tenth.

Intestinal disturbances were of comparatively little influence some fifty years ago, and their significance has decreased even further.

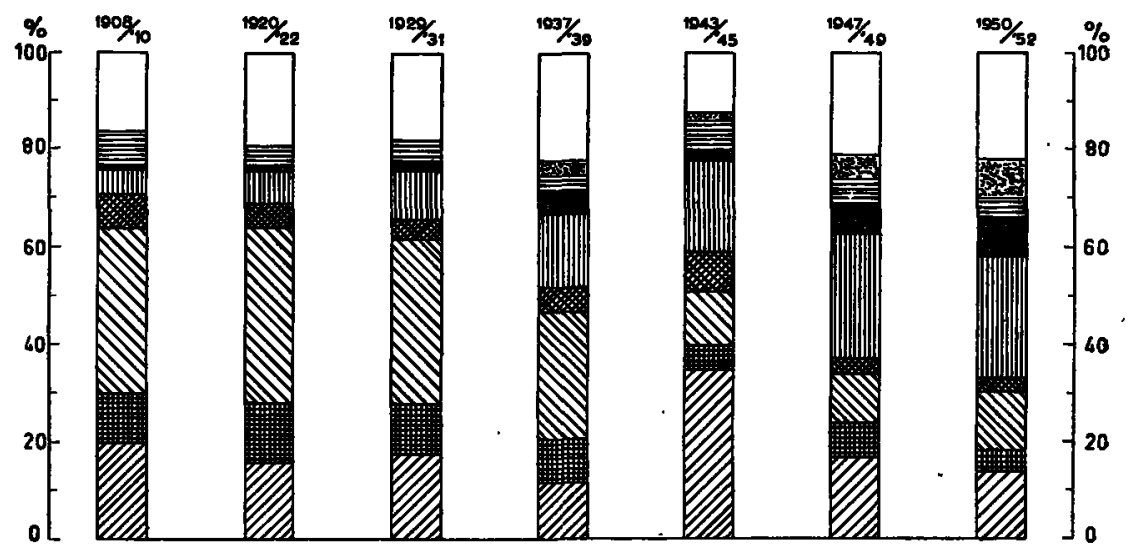

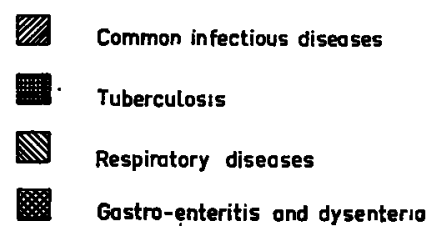

IIIII) violence
Congenital malformations

Unknown couses

Tumours and reticuloses (since 1937)

Other diseoses

Fig. 18

Main causes of death in percent of total deaths in pre-school age

Congenital malformations have become relatively of ever increasing importance for the mortality of children of pre-school age. Although there is no manifest change in the incidence of these malformations, their relative importance is increasing because the total mortality of this group of children is declining to such a great extent.

The same holds true for the mortality from accidents (violent deaths). The mortality from this cause, which is falling only slowly, has continually increased in significance in regard to the markedly reduced pre-school age mortality; at present $\mathrm{it}$ is the primary cause of death. In our times about one quarter of the total mortality of I-4-year-old children is due to accidents. 
Neoplasms and reticuloses are now an important cause of death for the I-4 age group, with $7 \%$ of the total mortality of this group. This cause of death was formerly relatively of far less importance, because the mortality due to them has probably not changed to any important extent in the course of years, in contrast to the greatly decreased total death rate of these children.

About $\varsigma \%$ of the pre-school age mortality has always been due to 'unknown and unspecified causes of death'. This constant percentage demonstrates the reliability of this method of studying the significance of the various causes of death in the $\mathrm{I}-4$ age group.

In fig. 19 and table $X X V$ a comparison is made between the two sexes. The differences between the sexes as regards the relative significance of the various causes of death, are not great (apart from the lower accident mortality in girls), although, in an absolute sense, girls have always shown a lower death rate than boys.

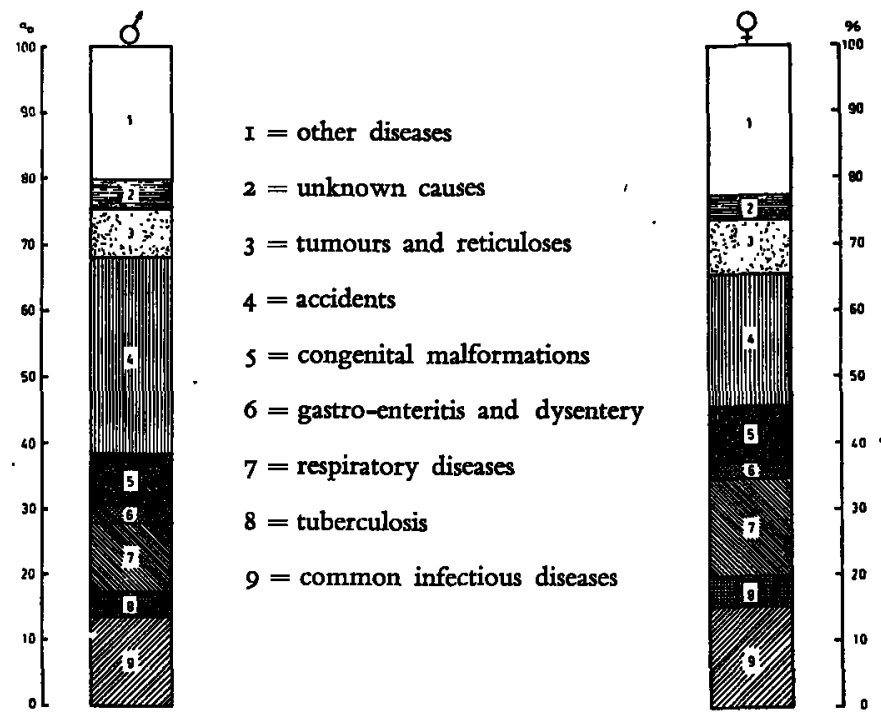

Fig. 19

Percentage distribution of deaths in pre-school children by cause and sex The Netherlands 1950-1952

The I-year-old and older pre-school age children show greater differences in relative significance of the main causes of death (fig. 20, table XXVI). Accidents and tumours and reticuloses are of less importance in I-year-old than in older children of pre-school age, but diseases of the respiratory tract and congenital malformations are comparatively of greater importance. The I-year-old children resemble more infánts of past the neonatal age as regards their pattern of causes of death. 
TABLE XXV

Pre-scho ol age mortality differentiated according to cause of death and sex (1937-1939 and 1950-1952)

\begin{tabular}{|c|c|c|c|c|c|c|c|c|}
\hline \multirow{3}{*}{ cause of death } & \multicolumn{4}{|c|}{$\begin{array}{l}\text { mortality per } x 00,000 \\
\text { of each sex }\end{array}$} & \multicolumn{4}{|c|}{$\begin{array}{c}\text { in \% of total mortality } \\
\text { of each sex }\end{array}$} \\
\hline & \multicolumn{2}{|c|}{ 1937-1939 } & \multicolumn{2}{|c|}{ I950-I952 } & \multicolumn{2}{|c|}{ I937-1939 } & \multicolumn{2}{|c|}{$1950-1952$} \\
\hline & $\delta$ & q & 0 & 우 & 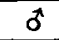 & q & 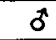 & 우 \\
\hline common infectious diseases. . . & 36.0 & 40.1 & 23.3 & 22.3 & II & I4 & I4 & IS \\
\hline respiratory diseases . . . . . . & 85.0 & $76 . I$ & 18.2 & 21.6 & 26 & 27 & II & I5 \\
\hline tuberculosis . . . . . . . & 28.2 & 28.6 & 6.5 & 6.9 & 9 & Io & 4 & 5 \\
\hline intestinal discases and dysentery. & Is.0 & II.3 & 4.7 & 3.9 & $s$ & 4 & 3 & 3 \\
\hline congenital malformations . . . & Is.3 & 12.5 & 13.6 & 12.6 & 5 & $s$ & 8 & 9 \\
\hline tumours and reticuloses . . . . & $\mathrm{x} x .6$ & 9.7 & 12.5 & $\mathrm{I} 2.2$ & 3 & 4 & 7 & 8 \\
\hline violent death. . . . . . . . . & 57.8 & 35.0 & $5 \mathbf{I} \cdot 3$ & 29.1 & 17 & 13 & 30 & 20 \\
\hline unknown causes . . . . . . . & 12.5 & 7.7 & 7.4 & 5.4 & 4 & 3 & 4 & 4 \\
\hline ......... & 330.7 & 276.8 & I73.I & $\mathrm{I}_{47.4}$ & 100 & 100 & 100 & IOO \\
\hline
\end{tabular}

Not only has mortality from the majority of causes of death markedly decreased at pre-school age, but the 'pattern' of this mortality has also changed, i.e., the relative significance of the various important diseases affecting schildren of pre-school age, has shown a considerable change in the course of the present century.
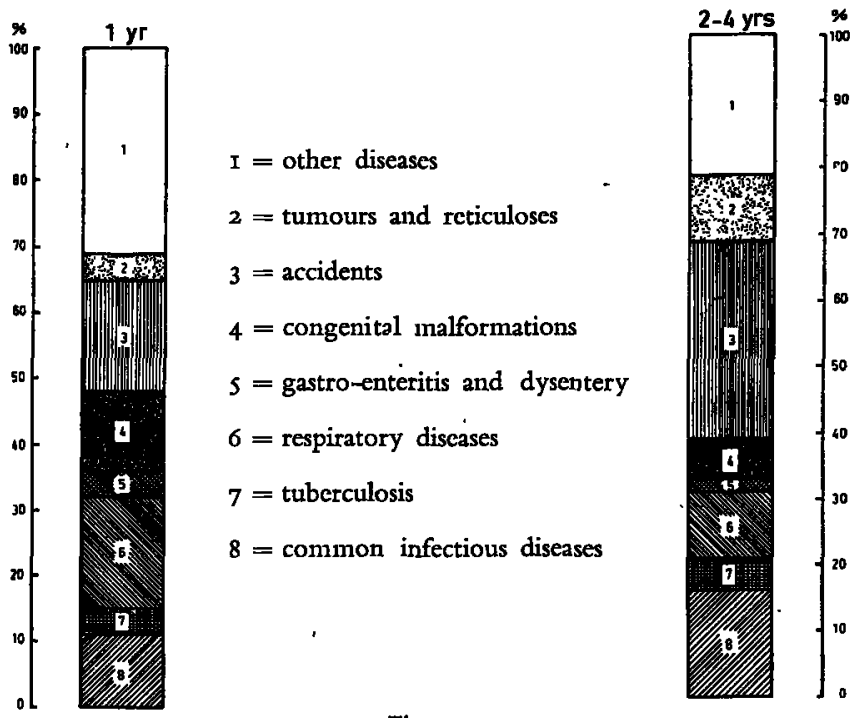

Fig. 20

Percentage distribution of deaths in pre-school age by cause and age

The Netherlands 1950-1952 
Percentage distribution of the main causes of death in 1-year-olds and 2-4-year-olds (1937-1939 and 1950-1952)

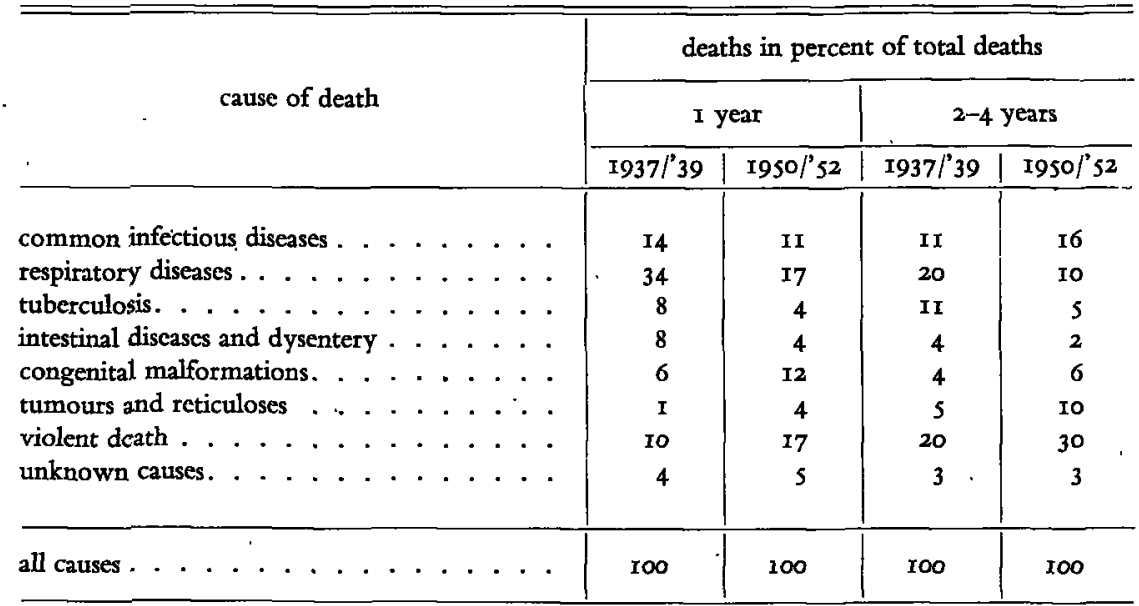

These changes, such as they occur from decade to decade, must be borne in mind by all who are engaged in combating the mortality and improving the state of health of the pre-school child, in order that the Public Health Service may remain rational and modern. The change of the sequence of the five most important causes of death is shown below, in tabular form (table $X X V I I)$.

TABLE XXVII

The five most important causes of death in children of pre-school age in the sequence of their relative significance for the mortality of this group

\begin{tabular}{|c|c|c|}
\hline I9I0 & 1930 & I950 \\
\hline $\begin{array}{l}\text { I. Diseases of the respira- } \\
\text { tory tract }\end{array}$ & $\begin{array}{l}\text { Diseases of the respira- } \\
\text { tory tract }\end{array}$ & Violent death \\
\hline $\begin{array}{l}\text { 2. Common infectious } \\
\text { diseases }\end{array}$ & $\begin{array}{l}\text { Common infectious } \\
\text { diseases }\end{array}$ & $\begin{array}{l}\text { Common infectious } \\
\text { diseases }\end{array}$ \\
\hline 3. Tuberculosis & Tuberculosis & $\begin{array}{l}\text { Diseases of the respira- } \\
\text { tory tract }\end{array}$ \\
\hline 4. Intestinal disturbances & Violent death & Tumours and reticuloses \\
\hline 5. Violent death & Intestinal disturbances & Congenital abnormalities \\
\hline
\end{tabular}

Diseases of the respiratory tract have receded from the first to the third place, while accidents have advanced from the fifth cause of death to the first one. The common infectious diseases have retained the second place. Tuberculosis and intestinal affections are no longer important causes of death; their place 
has been taken by tumours and congenital abnormalities, which have become of relative importance for the death rate of the I- 4 age group.

The influence of the wars on the mortality of children of pre-school age

The curve of the pre-school age death rate of the 2oth century shows two sharp peaks: the results of the two world wars (fig. 3).

The social and hygienic conditions were unfavourably influenced during these ,two periods. The rise of the pre-school age death rate in 1917 was relatively almost as high as in 1945, but the duration of the increased mortality was much longer in the second world war. The return to pre-war values was effected equally rapidly after both periods.

The causes of this increase of mortality in the $\mathrm{I}-4$ age group were however quite different in the two wars. Most of the 19I7 and 19I8 peak is due to diseases of the respiratory tract (influenza).

These diseases took no part in the rise of the mortality of the same group in the second world war, possibly partly thanks to sulphonamide therapy.

The same holds true for tuberculosis. The pre-school age mortality from this cause showed a marked rise in the first world war, while the corresponding figures for the second world war rose only very slightly. HoogENDOORN concluded from these facts that the increase of the total tuberculosis mortality of the second world war was not based, or only slightly so, on a greater chance of becoming infected, but rather on a marked increase of endogenous reinfections due to reduced resistance. Childhood tuberculosis, therefore, did not increase to any important extent.

On the other hand, the mortality of pre-school children due to the common infectious diseases rose only slightly during the years of the 1914-1918 war, while in the 1939-1945 war the death rate for diphtheria in this group of children was seventy times the pre-war figure. This demonstrates, in a rather painful manner, the inadequate practice of vaccination before the war.

The mortality from intestinal diseases in I-4-year-old children was only slightly increased during the first world war: the poor dietary conditions evidently no longer exerted any great influence on the mortality from these affections in children of pre-school age. In the second world war, the lack of food was accompanied by disorganization of the technical hygienic services and great mental stress on the parents, leading to a considerable increase in fatal intestinal affections and dysentery (VAN LOOKBREN CAMPAGNE).

The pre-school age mortality due to accidents did not increase in the years 1914-1918. This is in complete agreement with the facts discussed in the chapter on violent death. Care of the pre-school child at home was probably not much worse during these years, so that the number of accidents of these 
children did not increase either. The far greater disorganization of social life and the much stronger psychic and domestic difficulties during the second world war inevitably led to less adequate care for the child (Kopprus), which, inter alia, was shown by a considerable rise of the number of fatal accidents, irrespective of direct war casualties.

The accident death rate of I-4-year-old children is, perhaps more than any other cause of death, a reflection of the social conditions in the family.

Summarizing, the rise of the pre-school age mortality in the first world war was mainly due to the influenza epidemic, and also to the increased tuberculosis mortality. Although the second world war did.show an.increase of the total tuberculosis mortality, the pre-school age group was affected only to a slight degree.

Holland was taken unawares by the diphtheria epidemic of the second world war. Immunizations had been carried out only on a small scale and rarely in children of pre-school age.

In addition to diphtheria, the great number of fatal accidents contributed considerably to the rise of the pre-school age:death rate in these years; the dircct war casualties formed only a relatively low percentage of this figure. 


\section{VIOLENT DEATH (ACCIDENTS)}

Almost all causes of death that were formerly important at pre-school age are concerned more or less in the speccacular fall of the general I-4 age group death rate. The significance of 'violent death' has therefore increased relatively, and at present this cause of death occupies the first place.

For the I-4 age group, violent death is synonymous with death due to accidents...At present accidents account for a quarter of the whole pre-school age mortality, and thus they have the same quantitative significance as the four common infectious diseases and the respiratory affections together: nearly 400 deaths per year.

TABLE XXVIII

Accident death rate of children of pre-school age (The Netherlands 1908-1952 *)

\begin{tabular}{c|c|c|c}
\hline \multirow{2}{*}{ period } & $\begin{array}{c}\text { total mortality rate of } \\
\text { I-4 age group }\end{array}$ & \multicolumn{2}{|c}{ violent death } \\
\cline { 2 - 4 } & per 10,000 & per 100,000 & (3) in \% of (2) \\
\hline (I) & $(2)$ & $(3)$ & $(4)$ \\
\hline 1908-1910 & & & \\
$1920-1922$ & 138 & 64 & 5 \\
$1929-1931$ & 88 & 61 & 7 \\
$1938-1940$ & 56 & 54 & 10 \\
$1941-1942$ & 31 & 53 & 14 \\
$1943-1945$ & 37 & 88 & 15 \\
$1946-1947$ & 61 & 68 & 14 \\
$1948-1949$ & 35 & 53 & 19 \\
$1950-1952$ & 20 & 40 & 27 \\
& 16 & & 25 \\
\hline
\end{tabular}

* excl. war casualties.

Table XXVIII shows the trend of the accident death rate since the beginning of the present century, when traffic accidents were not yet of any importance. The table demonstrates how little the mortality from accidents has decreased compared with the fall of the total pre-school age death rate; this has led 
to an important relative increase of the importance of accidents as a cause of death (fig. 21). This has also been reported in other countries (SтRÖM; Martin; Craig; Clements).

It is a striking feature that the marked rise of the mortality of I-4-year-old children in the second world war has been followed by an even greater fall, so that the mortality of this group reached a level below pre-war values even before 1948. The mortality from accidents, however, which also increased markedly during the war, did not reach the pre-war level until after 1950. The disorganizing sequelae of the war were therefore still reflected in the accident death rates for a long time.

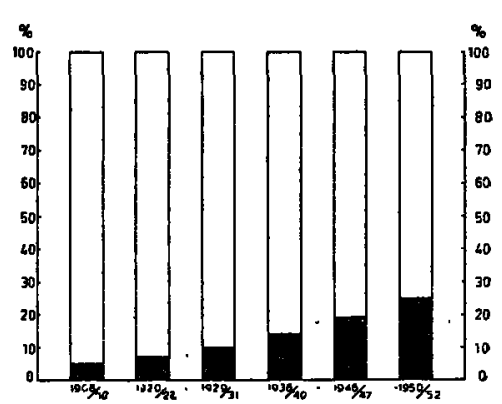

Fig. 2I

Deaths from violence in percent of total deaths at pre-school age The Netherlands I908-1952

The pre-school age mortality is to an ever increasing degree determined by the deaths due to accidents. In recent years this problem has been the centre of interest in other countries, as shown by the, by no means complete, bibliography at the end of this study. It is quite natural that in former times, when the mortality was still high due to other causes, little attention was paid to fatal accidents in children of pre-school age (Neurdenburg; SajeT). This problem still attracts relatively little interest in the Netherlands, even though a radio lecture was recently given on it (STAPERT).

Table XXIX gives some figures from various countries. Although in general a comparison of causes of death in different countries and in different periods of time is difficult, this drawback does not hold true to the same extent for the accident mortality.

The death rate due to accidents among children of pre-school age is roughly the same in various countries; only England shows exceptionally favourable figures, which also explains. the low total pre-school death rate in that country.

The fatality figures form only one aspect of the problem of violent death. Every fatal accident means many non-fatal ones, and therefore a number of cases of (permanent) disablement.

There are no Dutch statistics on the proportion between fatal and nonfatal accidents. The American literature repeatedly mentions the following figures, calculated from questionnaires: I fatal accident to every I 50 non-fatal ones, with 4 ending in permanent disablement (KrNT et al.; ROBERTs et al.). not This figure is ${ }^{P}$ valid for all age groups ${ }^{1}$, however, and therefore only gives

1 The statistics of the National Safety Council calculated, also for all age groups, one fatal case to every 100 accidents that led to disablement for at least 24 hours. 
TABLE XXIX

Accident death rate of children of pre-school age in various countries (1950)

\begin{tabular}{|c|c|c|c|}
\hline \multirow{2}{*}{ country } & \multirow{2}{*}{$\frac{\begin{array}{c}\text { total mortality rate of } \\
\text { I-4 age group }\end{array}}{\text { per 10,000 }}$} & \multicolumn{2}{|c|}{ violent death * } \\
\hline & & per 100,000 & (3) in \% of (2) \\
\hline (I) & (2) & (3) & (4) \\
\hline 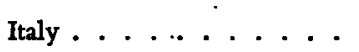 & 49 & 49 & 10 \\
\hline W. Germany .. . . . ; . & 27 & 59 & 22 \\
\hline France $\ldots \ldots \ldots$ & 24 & 33 & I4 \\
\hline$\ldots$ & 2I & so & 24 \\
\hline$\cdots \cdots$ & I9 & 5I & 27 \\
\hline$\ldots \ldots$ & I9 & 52 & 27 \\
\hline$\cdots \cdots$ & I8 & 40 & 22 \\
\hline Australia . . . . . . . & I7 & 38 & 22 \\
\hline The Netherlands. . . . . . & I7 & 45 & 26 \\
\hline U.S.A. . . . . . & $I_{4}$ & 38 & 27 \\
\hline England \& Wales & I4 & 24 & 17 \\
\hline Sweden. . . . . & I3. & 40 & $3 \mathrm{I}$ \\
\hline Denmark . . . . & I3. & 44 & 34 \\
\hline
\end{tabular}

* Annual Epidemiological and Vital Statistics part I, W.H.O., Geneva I953 (tab. 2 \& 23-4I).

** 1947-1949 annual average.

an idea of the importance of the problem. ROwNTREE found among 15,000 English 2-year-old children an accident rate of 8,000 per 100,000, every mishap for which medical aid was required being considered an 'accident'. This means, in view of the accident death rate of 40 per 100,000 (see Table $X X V I I I)$ one fatal case per 200 accidents. In Edinburgh home accidents requiring hospital treatment accounted for 20 per I,000 pre-school children in 1950 (SuILr). Colins-Winunams calculated that the fatality rate among children injured so seriously that they had to be admitted to hospital, was not even I \%. This group does not include, however, the less severely injured children who could be given outpatient treatment, and those so badly.injured that they died almost immediately.

A rough calculation on the basis of these figures shows that annually 40,000-80,000 Dutch children of pre-school age meet with an accident; $I, 000-1,500$ are more or less seriously incapacitated, and nearly 400 are fatally injured.

If the fatality rate is reduced as a result of improved treatment, a reduction in mortality may be accompanied by a less marked fall of the accident rate. The problem of accidents in the I-4 age group will, even irrespective of the in itself 
important mortality resulting from them, remain real for a long time, and will impose a great stress on individuals, family and society into the far future.

Children of pre-school age prove to be the most susceptible group as regards fatal accidents in childhood (table $X X X$ ).

TABLE XXX

Annual accident death rate according to age (The Netherlands 1950-1952)

\begin{tabular}{|c|c|c|c|}
\hline age group & & violent deaths per 100,000 & $\because \because$ \\
\hline o & & 49 * & \\
\hline $\mathbf{I}$ & & 44 & \\
\hline $2-4$ & - $\cdot$ & 39 & \\
\hline $5 \rightarrow 9$ & & 24 & \\
\hline ro-14 & & I3 & \\
\hline $\begin{array}{l}\text { I5-19 } \\
\text { all ages }\end{array}$ & & $\begin{array}{l}17 \\
36\end{array}$ & $\cdot$ \\
\hline all ag & & & \\
\hline
\end{tabular}

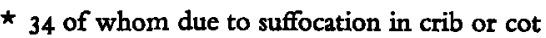

The mortality of infants due to accidents seems greater than that of children of pre-school age, but it is actually less, because in a great number of cases reported as 'suffocated in the cradle', the diagnosis is probably wrong except in rare instances of children who really died from suffocation (Werne et al.; BowDEN; BARRETT). The heading 'suffocation in crib or cot' stands for abouit two thirds of the whole accident mortality of infants.

While it could be expected that older children would show a higher mortality from accidents than younger ones, the death rate due to this cause in children of school age is barely $60 \%$ of that of children of pre-school age. The accident death rate is highest in the.second year of life. Every year about a hundred of these young children in the Netherlands pay with their lives for their first reconnoitring of the world.

The accidents leading to death in the I-4 age group can be divided into three main groups: drowning, traffic accidents and burns.

Drowning formed the largest group of fatal accidents. in the beginning of the 2oth century, and this. has remained so up to now, representing $42 \%$ of all fatalities. This means that, in spite of the increased number of road accidents, drowning is still responsible. for nearly half the total accident. mortality in children of pre-school age: This is valid for the youngest as well as for the oldest members of this group (table XXXI). 
TABLE XXXI

Accident death rate of children from 1-4 years classified according to cause, in percentages of the total accident mortality at this age

\begin{tabular}{|c|c|c|c|c|c|c|}
\hline \multirow{2}{*}{$\begin{array}{l}\text { cause of the } \\
\text { violent death }\end{array}$} & \multirow{2}{*}{ 1908-1910 } & \multirow{2}{*}{ I920-I92I } & \multirow{2}{*}{ 1938-1940* } & \multicolumn{3}{|c|}{$1950-1952$} \\
\hline & & & & I-4 yrs. & I $\dot{\text { yr. }}$. & 2-4 yrs. \\
\hline $\begin{array}{l}\text { drowning . . . . } \\
\text { traffic accidents . } \\
\text { burns and scalds . . } \\
\text { other causes. . . . }\end{array}$ & $\begin{array}{l}52 \\
29 \\
19\end{array}$ & $\begin{array}{r}46 \\
9 \\
31 \\
14\end{array}$ & $\begin{array}{l}39 \\
20 \\
24 \\
17\end{array}$ & $\begin{array}{l}42 \\
30 \\
10 \\
18\end{array}$ & $\begin{array}{r}46 \\
9 \\
15 \\
30\end{array}$ & $\begin{array}{r}42 \\
37 \\
8 \\
13\end{array}$ \\
\hline$\ldots$ & 100 & 100 & 100 & 100 & 100 & 100 \\
\hline
\end{tabular}

* excl. war casualties.

Drowning alone causes the death of more than I60 children of pre-school age per year, i.e., 2-3 times the tuberculosis death rate of this group (63 deaths). Drowning accounts for Io $\%$ of the total I-4 age group mortality in the Netherlands.

MrJN.IEFF proved in his analysis of the mortality due to drowning that in the Netherlands this figure is not primarily the result of the abundance of water in a given area, but that it is inversely proportional to the density of the population. There are therefore more cases of drowning in rural areas than in the towns, where the children have a greater chance of being saved. This explains the higher pre-school age death rate in the country $(p .38)$.

At present traffic accidents hold second place, with $30 \%$ of the total accident mortality in the I-4 age group. This second place was not reached until after the second world war. In r950-1952 the number of fatal road accidents involving children of pre-school age was about II5 annually, i.e., the same number of deaths as caused by diphtheria.

Traffic cases form only $9 \%$ of the total accident mortality in the youngest pre-school children; this is already four times as high among the older ones (table XXXI). More than balf of all fatal accidents of children of school age are caused by the traffic, but even so, the mortality due to road accidents is still higher in children of pre-school age than in those of school age, namely 12 and 10.5 per 100,000, respectively (in 1950-1952).

In the motorized country par excellence, the United States of America, the pre-school age death rate due to traffic accidents is not much higher than in the Nethierlands. In. r950 these figures were, for motor-car- accidents, II.6 per 100,000 in the U.S.A. and 9.2 per 100,000 in the Netherlands. 
Sweden and England, and also agrarian Denmark, have about the same number of fatal road accidents of pre-school children as the Netherlands (Ströм; Medical Report Denmark).

Table XXXII shows the trend of the traffic accident death rate of children of pre-school age from 1920 to 1952 inclusive, compared with the mortality due to traffic accidents at all ages. This table demonstrates that with the increase of traffic; the death rate of accidents caused by it also rises, but that it remained. practically constant for pre-school children between 1930 and 1940. The second world war caused a fall of the road accident mortality, corresponding with the decrease in traffic, except in I-4-year-old children in whom, on the contrary, a marked rise occurred. The years I945 and I946 showed the highest number of fatal traffic accidents for all age groups. Since 1947 the total mortality due to these accidents has been rising slowly again, but that of the pre-school age children is continuously falling, in spite of the ever increasing traffic.

TABLE ' XXXXII

Traffic accident death rate per 100,000 (The Netherlands)

\begin{tabular}{c|c|c}
\hline period & I-4 yrs. & all ages \\
& & \\
$1920-1922$ & 5.6 & 4.4 \\
$1931-1932$ & 10.0 & 8.9 \\
$1933-1934$ & 9.5 & 9.9 \\
$1935-1936$ & 9.4 & 10.6 \\
$1937-1938$ & 8.8 & 10.5 \\
$1939-1940$ & 9.5 & 11.3 \\
$1941-1942$ & 10.4 & 7.6 \\
$1943-1944$ & 14.7 & 8.8 \\
$1945-1946$ & 18.0 & 14.9 \\
$1947-1948$ & 15.5 & 10.9 \\
$1949-1950$ & & 11.3 \\
$1951-1952$ & 13.2 & 12.6 \\
\hline
\end{tabular}

The total number of fatal traffic accidents rises indeed with the intensification of the traffic, be it that the increase of the traffic itself exceeds that of the accompanying rise in the number of fatal accidents by a long way. The mortality due to road accidents in pre-school age children, on the other hand, proves to be not directly dependent on the intensity of. traffic, but rather on the care and supervision in the family and in general on the social and hygienic conditions, as will be discussed later.

In Switzerland also the past fifteen years have shown a slight fall of the number of fatal traffic accidents involving I-4-year-old children, in spite 
of the increase of traffic. Due to the rationing of petrol, the traffic in Switzerland. was also less intense during the war years, but this was actually accompanied by a marked fall of the traffic accident mortality among children of pre-school age (DetTuING), because the socio-hygienis and domestic conditions deteriorated but little in this neutral and prosperous country during the years 1940-1945. The U.S.A. (Accident Facts) and Sweden (StröM, personal communication) show an identical picture.

The third important cause of violent death in children of pre-school age is burns (by fire or scalding). Until recently this cause had occupied the second instead of the third place. About forty pre-school age children die from burns annually, i.e., ro $\%$ of the total accident mortality of this group. This percentage was three times as high in the years 1908-1910. The mortality from burns has been steadily decreasing since 1930 or thereabouts, the improved methods of treatment probably being also of some influence. Burns constitute Is $\%$ of the accident mortality among the younger children of pre-school age, and $8 \%$ among the older ones.

In the U.S.A. burns still form an important cause of death among I-4year-old children: relatively twice the figure for the Netherlands. In England, however, the country of open fires, the death rate due to burns is no higher than in Holland (Craig; Dietrich; Colebrook).

All other causes of violent death combined in children of I-4 years old account for only I $8 \%$ of the total accident mortality. None of them is of much importance in itself; the main ones are falls and poisoning. The latter cause accounts for (only) about ten lives of pre-school children annually; this cause requires particular attention on the part of the medical profession (FrASER).

There are far more boys than girls involved in all forms of violent death. Table XXXIII shows that this holds true for all causes, but especially for drowning.

\section{TABLE XXXIII}

Proportion of boys to girls for the various causes of violent death, in the age group 1-4 years (The Netherlands, 1950-1952)

\begin{tabular}{|c|c|}
\hline cause of death & $\mathrm{b} / \mathrm{g} \times 100$ \\
\hline 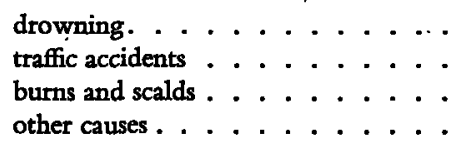 & $\begin{array}{l}216 \\
167 \\
145 \\
172\end{array}$ \\
\hline accidents $\ldots \ldots \ldots \ldots$ & 184 \\
\hline
\end{tabular}


Boys are more frequently in dangerous situations than girls, even at pre-school age, owing to their greater activity and wilder games. The mental difference in sex becomes manifest in the accident statistics at an age at which this difference would hardly yet be expected. The proportion of boys to girls as regards accident mortality is more marked among the older children of pre-school age than among the younger ones, viz., 192 and I 59 boys per Ioo girls, respectively (table XXXIV).

TABLE XXXIV

Proportion of boys to girls as regards accident mortality, in the age group 1-4 years (The Netherlands, 1908-1952)

\begin{tabular}{c|c|c|c}
\hline \multirow{2}{*}{ period } & \multicolumn{3}{|c}{ boys/girls $\times$ 100 } \\
\cline { 2 - 4 } & I yr. & $2-4$ yrs. & I-4 yrs. \\
\hline & & - & 158 \\
$1908-1910$ & - & - & 172 \\
$1920-1921$ & - & 193 & 187 \\
$1938-1940^{\star}$ & 173 & 194 & 175 \\
$1943-1945^{\star}$ & 142 & 192 & 184 \\
$1950-1952$ & 159 & & \\
\hline
\end{tabular}

The available data do not allow of an exact distinction between accidents occurring at home and out of doors. If it is accepted that cases of drowning and traffic accidents all belong to the outdoors group, and burns and other accidents to the home one, the ratio of the outdoors to the home accident mortality can be estimated fairly accurately. Table XXXV shows this ratio, classified according to sex.

\section{TABLE XXXV}

Proportion of outdoors accident mortality to home accident mortality in the age group. I-4 years, classified according to sex

\begin{tabular}{|c|c|c|c|c|c|c|c|}
\hline \multirow{3}{*}{$\begin{array}{c}\text { the Netherlands } \\
\text { period }\end{array}$} & \multicolumn{7}{|c|}{ violent death $\frac{\text { outdoors }}{\text { at home }}$} \\
\hline & \multicolumn{2}{|c|}{ I year } & \multicolumn{2}{|c|}{$2-4$ years } & \multicolumn{3}{|c|}{ I-4 years } \\
\hline & boys & girls & boys & girls & boys & girls & total \\
\hline I920-I92I & - & - & 一 & - & I. 3 & I.O & $\mathrm{T} .2$ \\
\hline I938-I940 * & 0.9 & 0.9 & $2: 2$ & I. 3 & I. 7 & 1.2 & 1.5 \\
\hline I943-I945 * & 0.5 & 0.6 & I. 5 & I.I & I.I & 0.9 & I.O \\
\hline I950-I952 & I.I & I.3 & 4.2 & 2.9 & 2.8 & 2.2 & 2.6 \\
\hline
\end{tabular}

* excl. war casualties 
A ratio of 2.6 of these outdoors and indoors accidents means that at present nearly three quarters of the fatal accidents in the pre-school age group occur out of doors. This proportional figure is not valid for other countries. In Edinburgh also about three quarters of the accidents, of I-4-year-old. children occur outdoors (Marr et al.), but in Denmark not even two thirds and in Australia and the U.S.A. the proportion is fifty-fifty (Clements). The literature gives the general impression that the mortality due to accidents at home is greater in other countries than it is in the Netherlands. .

Thirty years ago nearly $50 \%$ of the fatal accidents to Dutch I-4-year-old children occurred at home, and this was again the case during the war, as a result of the increasingly deteriorating domestic circumstances. At present the indoors mortality from fatal accidents is about a quarter of the total.

It is not entirely clear why the number of fatal accidents at home in the Netherlands differs from the corresponding figures in some other countries, which rather resemble the Dutch figures of 30 years ago. The greater frequency of female labour and the worse housing conditions in other countries may possibly afford an explanation of this phenomenon. On the other hand, the total accident mortality in I-4-year-old children in the Netherlands does not compare favourably with that in other countries.

The older children of pre-school age show a higher outdoors mortality than the younger ones, especially due to the lower number of traffic accidents in the second group. Nearly half of the accidents to I-year-old children occur at home.

As to be expected, boys predominate even more as regards the outdoors fatal accidents than the indoors ones, as compared with girls (see tables XXXIII and $X X X V)$.

The fact that formerly the ratio boys/girls as regards violent death was less marked than at present (table XXXV), is partly due to the fact that in bygone days outdoors accidents were relatively of less importance than now. The same is true for the war years.

In the years 1943-1945, the mortality of I-4-year-old children as a direct result of war action was 39 per 100,000. The boys/girls ratio was much lower than for the other accidents: about I20 boys for every 100 girls. Recklessness and 'boyishness' are evidently not important factors as regards the number of war casualties.

There is a manifest seasonal influence on the accident mortality (outdoors only?). Table XXXVI shows that in spring and summer the number of fatal accidents of pre $;$ school age children is twice that in autumn and winter, because in the first two seasons the children lead a more open-air life. 


\section{TABLE XXXVI}

Accident death rate of children of pre-school age, according to season

(The Netherlands, 1950-1952)

\begin{tabular}{|c|c|}
\hline season & annual number of fatal cases * \\
\hline 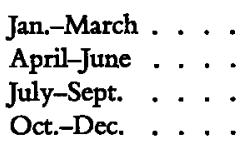 & $\begin{array}{r}68 \\
130 \\
125 \\
58\end{array}$ \\
\hline
\end{tabular}

* preliminary figures

This seasonal influence has also been described in Sweden (Hindmarsh et al.).

Contrary to expectation, table XXXVII shows that the accident death rate of the $1-\mathbf{4}$ age group.is considerably higher in the rural communities than in the towns.

\section{TABLE XXXVII}

Accident death rate of children of pre-school age in rural and urban dreas, per 100,000 children (The Netherlands, 1950-1952)

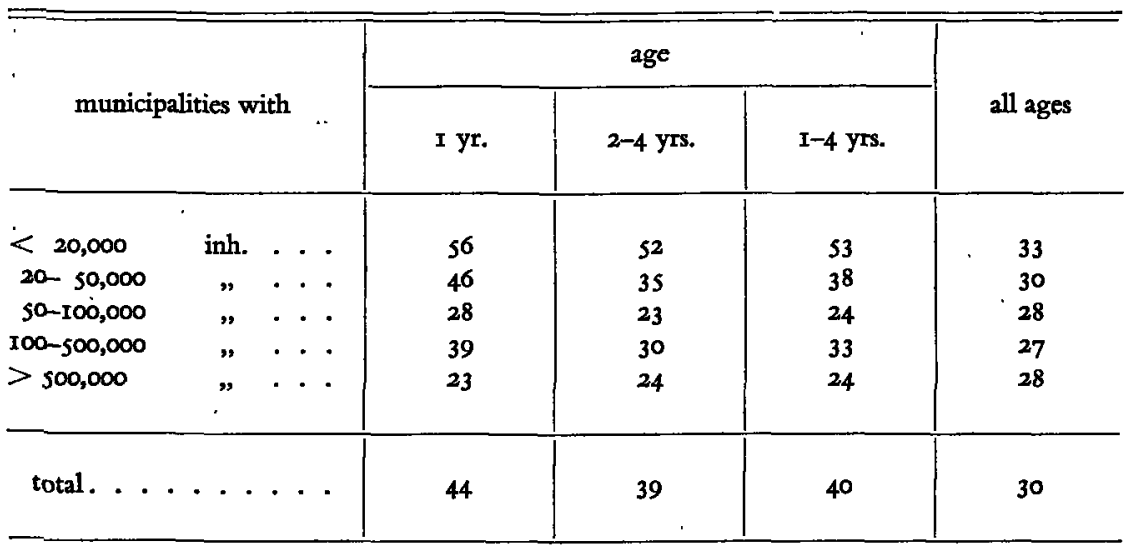

The mortality from drowning, which is considerable at pre-school age, is much higher in the country; this probably.explains the higher accident death rate in the small communities. Adults in rural and urban areas show only a slight difference in accident mortality, this being partly the result of the relative insignificance of drowning as regards older people.

'Just as a few centuries nago ignorance of cause : led medical practitioners to ascribe diseases to demons, so to-day we blame bad luck or chance for accidents. 
Accidents have specific causes, just as have the communicable diseases'. These words were written by HeLEN ROBERTs in r9s2. The analysis of the accident mortality rate should give us more knowledge about these specific causes:

Accidents in early childhood are dependent on three factors which influence each other mutually: inadequate care in the child's own milieu; the still uninhibited activity combined with ignorance of the dangers, and finally, surroundings that create many dangerous situations for the child.

The sex difference is an important factor in the distribution of the accidents, not only for older children but also for those of pre-school age. This is demonstrated by the far greater number of boys falling victims to fatal accidents than of girls, even as early as in the second year of life (table XXXIV).

Another factor of importance is the child's individual psychic structure; which may lead to a greater frequency of accidents in some children than in others: the accident-proneness. This phenomenon is-maybe somewhat too largely-attributed to psychic tensions between the child and his milieu (LANGrord et al.; KraIL). It is highly probable that the somatic condition of the child also exerts great influence. Follow-up with an extensive historytaking of a great number of children who were victims of an accident is necessary to gain more knowledge about the somato-psychic factors leading to accidents.

It is known from the literature that social conditions are of importance in the frequency of accidents in children (ROWNTREE; BrittBn; ColbBroor). Although in the Netherlands nothing is known of differences in numbers of fatal accidents in the various economic groups, the analysis of the fatality figures shows, in an indirect manner, that domestic and social relationships are also decisive factors for the incidence of accidents in I-4-year-old children. These figures give at least three indications to prove this contention.

The first indication is the ratio between the fatal accidents at home and those outdoors (table XXXV), because the number of fatal accidents at home is to a great extent dependent on domestic conditions. In about 1920 the pre-school age mortality from accidents at home was scarcely lower than that out of doors. Gradually, however, the decline of the accident mortality at home has led to a greater predominance of that in the open air. In the war years, the number of fatal accidents at home rose markedly: again and became equal to the outdoors accident mortality, although the latter also increased considerably.

The second indication is the high accident death rate of I-4-year-old children during the war years and the slow return to lower values after 1945 (table XXVIII): the social and domestic conditions were also rather unfavourable in the post-war years. 
The influence of these factors is most clearly demonstrated by the trend of the traffic accident death rate of pre-school children. In spite of the marked intensification of the traffic between 1930 and 1940, the frequency of fatal accidents in I-4-year-old children did not increase during this period, in contrast to the incidence in adults. During the. war the number of fatal accidents in adults showed a considerable fall, as a result of the marked diminution of the traffic, but the number of children of pre-school age killed in road accidents rose during this period when child care was unavoidably less adequate. The degree of care and supervision is evidently a greater-decisive factor for the number of traffic accidents in pre-school age children than the unsafety in the streets.

The prevention of accidents in this category of children should primarily be effected by improvement of the care for them. While with older children success may be expected from making them more accidentminded, prevention is synonymous with protection for the I-4-year-old children.

This improvement of the care may gradually be obtained by means of correct instruction and education of the parents. The literature gives the impression that this guidance should especially be the task of the medicalsocial workers in the family, i.e., in the Netherlands the district and home visiting nurse, the maternity home help and the mother's help. The best results can be expected from 'teaching on the spot'. Personal contact is more valuable in this guidance than the written word.

The prevention of accidents should occupy a greater place in the training and in the work of the district and home visiting nurse, maternity home help and mother's help than is the case at present, so that they are on the alert for accidents and are able to recognize potentially dangerous situations. Analysis and discussion of a recent accident in the family may prevent repetition.

It seems to be of the utmost importance that an accident is not just considered as 'bad luck'. Most certainly half the number of accidents in children and probably many more, are essentially not fortuitous, and they might therefore have been prevented. As DeNNIs says: 'It was just an accident is self-contradictory'.

We cannot enter in further detail into the prevention of accidents. The Anglo-American literature gives interesting descriptions of methods of accident prophylaxis by information and education of the public (KENT et al.; Dietrich; Colebrook; Whentiy; Jacobziner; Shaffer). Many American states have long considered the fight against accidents an essential part of the public health service. In England, a State Commission is studying the problem. of home accidents. The Netherlands have done very little in this field so far. 
-An 'epidemiological' campaign against accidents (and not only of those on the road) requires considerable study of the circumstances under which most accidents happen. Local investigations, questionnaires etc. are necessary for this purpose. There is no doubt but that the campaign against accidents is of a medical character and should be the duty of the public health service. 
CAUSES OF DEATH IN CHILDREN OF PRE-SCHOOL AGE IN THE VARIOUS PROVINCES

The mortality due to the various causes of death at pre-school age varies from province to province, as shown by table XXXVIII, which gives the present figures and those of forty years ago.

The mortality of this group due to the common infectious diseases varies in the provinces from 9 to 34 per 100,000 . Forty years ago these values also showed marked differences, but at a much higher level, viz., from I80 to 330 per 100,000. Limburg shows a remarkably high figure, for which both diphtheria and whooping cough are the responsible factors.

At present the inter-provincial differences in mortality due to respiratory diseases are not great, in contrast to the situation forty years ago. The same is true for the death rate from intestinal diseases. The formerly poor and backward Southern provinces and Drenthe had the highest death rate from these diseases forty years ago.

The number of I-4-year-old children dying of tuberculosis was, in I9IO or thereabouts, considerably higher in the densely populated Western part of the Netherlands than in the more agrarian and more sparsely populated provinces. The present tuberculosis. death rate in children of pre-school age has become too small to attach much value to regional differences, even though the low mortality in the two most thinly populated provinces, Zeeland and Drenthe, still constitutes a remarkable feature.

Accidents cause a great many deaths in the I-4 age group, and the figures for the various provinces show marked differences, just as forty years ago. Zeeland shows the lowest figures, as was already the case in about 19ro. The significance of this low pre-school age accident death rate asia standard of judgement of the care of these children has already been discussed in chapter $X$. The present high accident death rate in Friesland and Utrecht was observed even forty years ago.

The frequency of drowning, the most important cause of violent death in I-4-year-old children, is counteracted by urbanization and increase of the density of the population (MijNLIEFF). In Drenthe these factors were of less importance than elsewhere, but, contrary to expectation, the accident 


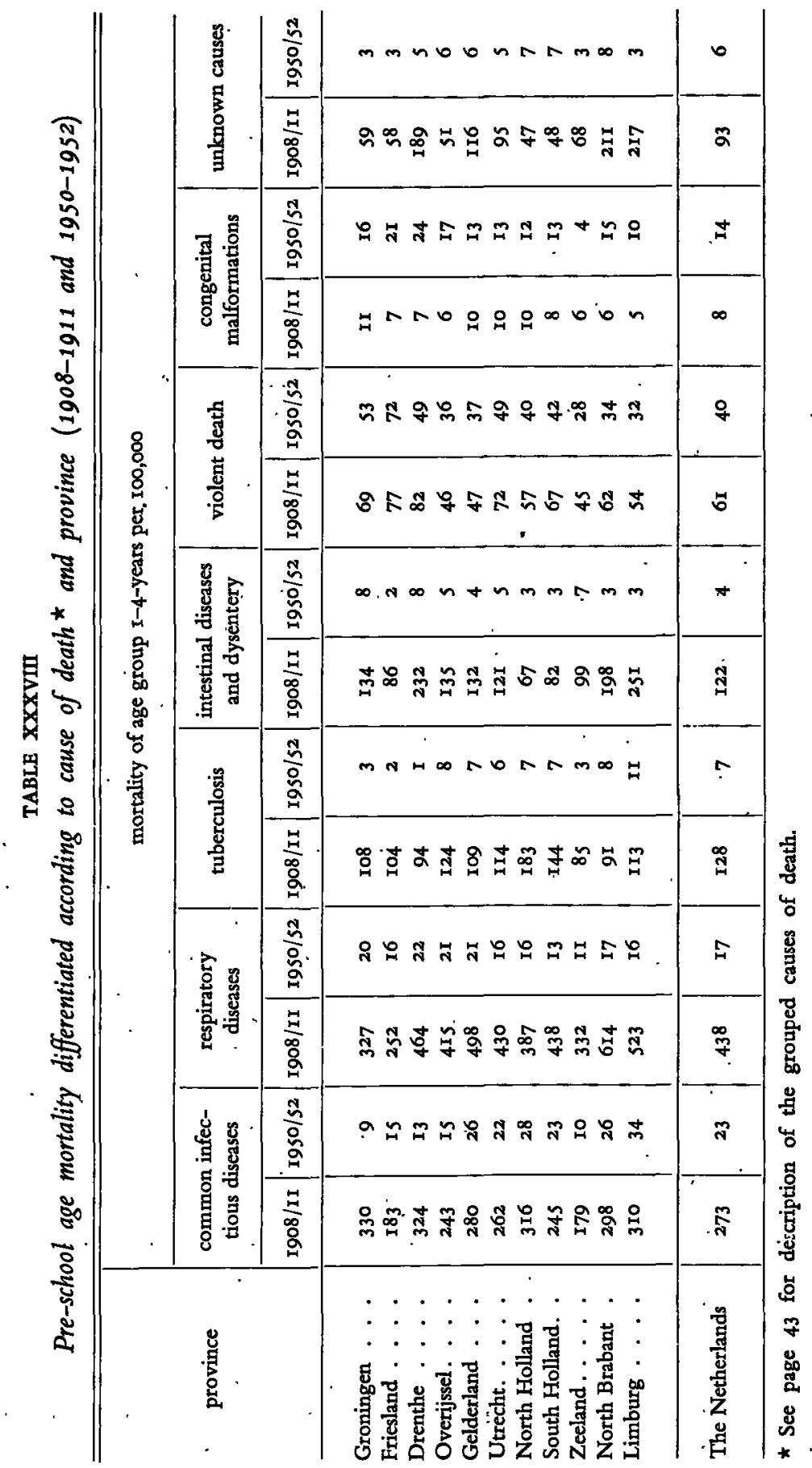


death rate has shown a considerable fall in this province during the past forty years.

There are remarkable inter-provincial differences in pre-school age mortality from congenital malformations. The Northern provinces show a high death rate from this cause, but there are only slight differences in the other provinces (excl. Zeeland).

Polman mentioned the high frequency of congenital defects (as a cause of stillbirth) in the Northern provinces. His findings agree with the higher pre-school age mortality due to congenital malformations in these areas. He carried out a more detailed analysis of this high incidence of congenital defects, and suggested that they are especially due to the influence of hereditary factors. The incidence is highest in the regions with the lowest migratory population.

Mortality statistics cannot provide information on the influence of external factors on the frequency of congenital malformations. LANCASTER has shown from the absence of a relationship between death rates from congenital malformations and epidemic disease, that epidemic disease is of relatively little influence in the production of these malformations. The deficient nutrition of the last years of the war exerted no demonstrable influence on the mortality from congenital defects. In these years West Holland actually showed lower mortality figures for congenital malformations than the Northern and Eastern provinces, which suffered far less from the famine in the 1944-1945 winter. This hunger period was probably of too short duration to result in a measurable increase in the number of congenital abnormalities.

The data of DE GROOT, who considered there was an increased number of congenital malformations in consequence of the last war winter, are not convincing. In the Netherlands, as in other countries of Europe, there has in general been little evidence of a rise of the frequency of congenital defects in a (rather short) period of deficient nutrition (see the response to question No. so in the Nederlandsch Tijdschrift voor Geneeskunde, 1954, 98, p. 1388).

As suggested above, the differences in incidence of congenital malformations in the various provinces may partly be explained by hereditary factors. These factors are most predominant in areas with a stationary population and little immigration, as is especially the case in the North-East of the Netherlands.

On the other hand, Zeeland (in the South-West), another province with stationary population, has a low mortality from congenital defects, but this may partly be due to the relatively great number of younger women among the mothers (marrying at a young age) and small families. Ingalls et al., RECORD et al., BARNET WOOLF and MURPHY found in their studies on the frequency of congenital malformations that old primiparae and multiparae 
with already many children have the greatest chance. of having a child with such an affection. SuTTER has shown that regional differences in the frequency of congenital malformations can be due to the number of consanguineous marriages, but also depend to a great extent on differences in family size.

However, the number of deaths from congenital defects in pre-school age in Zeeland is too small to warrant conclusions.

PAsma remarked on the possible coincidence of congenital defects and iodine deficiency. The geographical distribution of iodine-poor regions in the Netherlands, however, does not explain the provincial figures for the mortality from congenital abnormalities in I-4-year-old children.

The mortality from unknown or obscure causes can more or less be regarded as a criterion of medical care. This explains why, some forty years ago, the 'backward' provinces of North Brabant, Limburg and Drenthe showed a relatively high pre-school age mortality due to 'unknown causes', while the present differences between the provinces are considerably less. 


\section{CAUSES OF DEATH IN RURAL AND URBAN AREAS}

The difference in total pre-school age mortality between town and country has already been discussed in chapter VII. The present chapter deals in greater detail with this phenomenon, by analysing this difference for some important causes of death.

Table XXXIX gives a survey of the most important causes of death in I-4-year-old children, differentiated according to size of municipality.

The mortality from the common infectious diseases is still lower in rural areas than in towns, but this difference is no longer as great as forty years ago, because the isolated position of the rural areas has greatly diminished due to more intense traffic and increasing urbanization.

It is a remarkable feature that the medium-sized communities show the highest pre-school age death rate from these diseases. This is possibly the result of an unfavourable combination: more members per family than in the larger towns, and a higher density of the population than in the country. Both factors enhance the frequency of the infectious diseases at an early age. Our present small towns are probably comparable to larger towns some time ago in this respect.

In about 1910 the tuberculosis death rate of the children of pre-school age was considerably higher in the towns than in rural areas. This was especially due to the situation in the overcrowded, poorer urban districts. The significance of unsatisfactory housing conditions in the towns as regards the tuberculosis death rate has recently been convincingly demonstrated by GaLLEGo. In the Netherlands the differences between town and country in mortality from tuberculosis in the $I-4$ age group have disappeared as a result of social and hygienic measures. At present a country such as France, more backward from a hygienic point of view, still shows a higher tuberculosis death rate for pre-school age children in the towns than in rural areas (CandiotTi et al.).

The mortality of these children from diseases of the respiratory tract is somewhat higher in the country than in the towns; the reverse was the case forty years ago. 


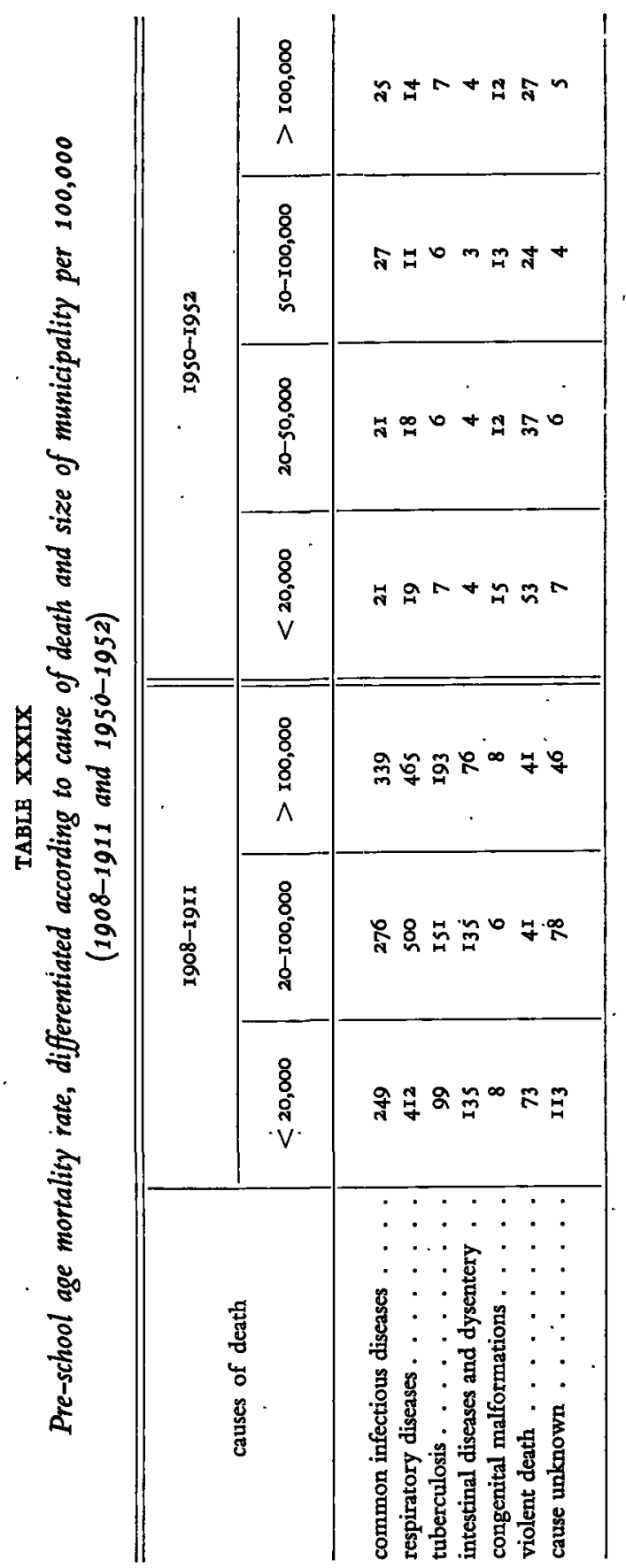

84 
Compared with the towns, the rural areas show nearly twice the number of fatal accidents in I-4-year-old children. This has not changed in the past forty years. As explained in chapter $X$, this difference between urban and rural areas is mainly based on the much greater chances of drowning in the country.

Intestinal diseases form nowadays only a relatively rare cause of death in children of pre-school age; they were of a greater frequency about the year I9ro, when the rural areas showed higher fatality figures for intestinal diseases than the towns, due to poor hygienic conditions.

Nowadays the mortality from congenital malformations is higher in the country than in the towns. As discussed on $p .81$, the highest. incidence of these malformations is found in certain rural. areas. with a stationary population and often also large families. The pre-school age mortality from congenital abnormalities in the country is thus slightly higher than in the towns, without this being characteristic for all rural districts. These differences between town and country were not demonstrable about the year I9Io, but this may. be due.to the fact that in those days diagnosis made outside the towns were often incomplete.

This is also demonstrated by the fact that, especially formerly, the rural areas showed a considerably greater frequency of deaths of pre-school children without the cause of death being accurately stated.

As already mentioned on $p .23$, the seasonal influences on the I-4 age group mortality in the country are only slight compared with the situation in the towns. This regional difference in seasonal influence cannot be differentiated according to the causes of death, because of the lack of data. The higher summer mortality from accidents and the lower winter mortality from infectious diseases, however, explain why the rural areas show no winter peak in the pre-school age mortality, while there is a manifest peak in the towns. 
XIII

\section{MORTALITY OF CHILDREN OF PRE-SCHOOL AGE, ECONOMIC CONDITIONS AND SIZE OF FAMILY}

The prosperity factor has always been a main centre of interest among the many that influence the death rate. In the years following the first world war, the influence of economic conditions on the pre-school age mortality was studied by SAJET in Amsterdam. He used the number of inhabitants per dwelling.as a standard of measurement of prosperity. There were considerable differences as regards death-rate between the I-4-year-old children in the poorer and the more well-to-do districts of the town, and these differences were even greater than among the infants. About 1920 the infant mortality in the popular quarters was approximately twice as high as in the well-off districts, but the mortality of children of pre-school age was four times as high. SAJET and VAN GELDEREN had already proved in their earlier publications that the mortality from measles and whooping cough, in those times the most important causes of death for I-4-year-old children, was considerably higher in poor families than in the wealthier milieux.

There are no other Dutch studies on the relationship between pre-school age mortality and prosperity. METHORST, in his analysis of the juvenile mortality in connection with prosperity, did not separate children below five into infants and children of pre-school age. The death rate of these children is practically determined by the mortality of infants, and gives little indication of the I-4-age group mortality. Economic conditions formed an important factor for children under five at the time of METHORST's investigation (1927 and earlier). His data justify the further deduction that this influence of prosperity on mortality was also manifest in children over five.

Based on the figures of the I947 census, VAN DEN BRINK analysed the mortality of children younger than six years according to the occupation. of the parents. This analysis clearly proves that at present prosperity is still an important factor for the mortality of these children, but to a less marked degree than in former days. However, this investigation also has the drawback that the mortality of children under six, if taken together as one group, is almost completely determined by the mortality of infants.

GALE stated that in England, at any rate before the second world war, 
economic conditions exerted a great influence on the pre-school age mortality; this was particularly true for the common infectious diseases.

- These studies have demonstrated that the importance of the prosperity factor in regard to the pre-school age mortality decreases with the fall of the pre-school age death rate and the general juvenile mortality, together with improvement of the general standard of living. This probably also holds true for the influence of prosperity on the juvenile morbidity rate. DoRothy Holland, in the American National Health Survey of 1938, found that the frequency of infectious diseases, tuberculosis and accidents was considerably lower in children from well-to-do families than in those from poorer ones. The studies of Dougras and RownTres on the morbidity in England after the second world war also show a difference in the incidence of disease in infants and young children of pre-school age in poor and wealthy families but this influence of prosperity is hardly noticeable in the recent morbidity studies of Drkes et al. in young pre-school children of Luton (England).

When an analysis of mortality or morbidity no longer shows any influence of the economic conditions, the method of determining the prosperity of the groups under consideration becomes of significance. A closer differentiation might have yielded differences according to prosperity. On the other hand, however, this is an indication of the decreasing significance of the prosperity factor, because this influence would only be demonstrable by means of more subtle statistical methods. Not so long ago a rough classification according to social class was sufficient to show marked differences in mortality.

The importance of economic conditions in regard to child mortality cannot be determined accurately if the size of the family is not considered separately, because in general the size of the family is also dependent on the economic conditions, and conversely. Studies on the relationship between prosperity and child mortality only rarely take this fact into account.

METHORST's investigation of the mortality of children under five makes a distinction between the factors 'prosperity' and 'number of children'. The mortality of these children proved to be influenced both by size of the family, and economic conditions. In small families the mortality of children under five was lower than in large families, also within the same social classes. Conversely, a marked influence of the economic conditions was demonstrable in families of the same size. At the time of the investigation (round about 1925) the poorer 'families were therefore, for these two reasons, in a more unfavourable position as regards the mortality of young children than the more well-to-do families, viz., both due to lower prosperity and the on an average larger families. The influence of the size of the family had disappeared among the older children; at any rate, it was no longer demonstrable in their mortality rates. The external factors increase. to such an extent for these older children that the family size no longer influences the death-rates. 
Relatively little is known of the significance of the size of the family in regard to pre-school age mortality. Recently-Lowe demonstrated that, during the first three years of life, the influence of number of children on the frequency of common infectious diseases, pneumonia and intestinal affections (and thus on the mortalicy from these causes) is greater than that of prosperity and housing conditions.

It is a well-known fact that the frequency of common infectious diseases at an early age, and thus the mortality, is higher the greater the number of children in a family. This is not without significance for the total pre-school age mortality, because these diseases are still an important cause of death at this age. The care of the I-4-year-old child in a large family, especially if its economic and housing conditions are bad, will often (and almost unavoidably) be less good than in a small one. Care and supervision are of special importance for the accident mortality, at present the most important cause of death in children of pre-school age. The study of Douglas demonstrated a clear relationship between overcrowding and mortality of young children. A relationship between pre-school age mortality and family size would therefore be readily acceptable, but of course this does not imply that large families and high pre-school age mortality are always coincident.

The following pages are an analysis of the present relationship between prosperity and family size, and pre-school age mortality.

This analysis had to be limited to the mortality of children of pre-school age in the cities of Amsterdam and The Hague in I952 and 1953. Data covering other towns are not available.

The following (non-personal) data werc obtained from both towns:

(a) A subdivision into districts, and the number of I-4-year-old children in these districts, as at December 3Ist, 1952, i.e., right in the middle of the period under consideration.

(b) The number of $\mathrm{I}-4$-year-olds that had died, differentiated according to age, address, occupation of father or mother, and position in the sequence of births in the family.

(c) The number of legitimate children, born alive in 1951, differentiated according to the occupation of the father or mother, address and birth rank.

It was therefore possible to determine directly the mortality of I-4-year-old children in proportion to the total number of this group. in the district.in which they were living.

An indirect method had to be followed for the differentiation of the preschool age mortality according to the occupation of the parents.and size of the family, because these data were not obtainable for all living children. It was 
assumed that the distribution of the occupations over the fathers. of newborn children in $195 \mathrm{r}$. was the same as that over the fathers of children of preschool age in I952 and 1953. This supposition seems justified, because the grosss distribution of occupations in the families with small children will not have changed to any important extent during these two years. A second assumption was that the division according to number of children per family in which a child was born in 195I, was still the same for the pre-school age children in I952 and I953. This presumption only leads to errors if, in these few years, there were an important difference in the increase of the number of children in the various social groups, in which case the difference in family size between fertile families and less fertile ones would have increased slightly in the period of one or two years between the birth of a child in I95I and the death of a pre-school age child in 1952 or 1953. The differences in number of children per family in the various prosperity groups in Amsterdam and The Hague proved to be insignificantly small, however (see table XLII).

In this way it is possible to analyse the pre-school age mortality according to occupation and size of the family. This has been carried out for the two cities separately.

In 1952 and 1953, I76 children of pre-school age died in Amsterdam; this corresponds to an annual death rate of 14.6 per 10,000.

In order to study the mortality differentiated according to the various neighbourhoods, the 70 districts were divided into three groups: poor, mixed. and well-to-do. These terms were chosen for convenience's sake. This classification was based on the data of De WolfF and MEERDINK's study on the number of inhabitants of the various districts of Amsterdam who received a State loan in 1946 and 1947 , on account of their low income. The 'poor' group comprises the quarters in which at least $25 \%$ of the inhabitants received a State loan, and the 'well-to-do' group the districts in which less than ro $\%$ needed this. The 'mixed' group comprises the other neighbourhoods, where between Io and $25 \%$ of the inhabitants received a State loan.

The results of this arrangement are given in table $X L$. Four districts are left out of consideration, because they had changed so much in character since 1947 (due to the many new houses built there) that it was impossible to include them in the analysis.

The number of I-4-year-old children that died is small, so that a statistical elaboration is necessary to find out whether the differences found, if any, are significant or whether they can be explained by a chance factor. The values found are always compared with the figures to be expected if there were no difference in death rate between the groups. If the latter is really the case, the deaths will be distributed over the groups under consideration in the same proportion as the total number of pre-school age children. When the distri- 
bution of these children is not known (as in the division according to social classes and family size), it is deduced from the distribution of the newborn children two years previously on the strength of the presumptions mentioned above. In order to avoid a seeming exactness, we did not calculate the preschool age mortality per 10,000 differentiated according to occupation and size of the family, but we just compared the observed and expected number of deaths.

The Chi-square test can then be used to determine whether a significant difference exists between the values found and those expected ${ }^{1}$. If there is actually a significant difference, this means that the groups under consideration show a difference in death rate that cannot be attributed to chance but must. be real.

TABLE XL

Mortality of children of pre-school age according to districts in Amsterdam (1952-1953)

\begin{tabular}{|c|c|c|c|c|}
\hline districts & $\%$ state loan 1947 & $\begin{array}{l}\text { number of I-4- } \\
\text { year-old children }\end{array}$ & died in $1952-1953$ & $\begin{array}{c}\text { annual mortality } \\
\text { per } 10,000\end{array}$ \\
\hline $\begin{array}{l}\text { well-to-do . } \ldots \\
\text { mixed } \ldots \ldots \ldots \\
\text { poor. } \\
\text { new districts } \\
\text { address unknown }\end{array}$ & $\begin{array}{l}\text { less than ro } \% \\
\text { Io-25 \% } \\
\text { more than } 25 \% \\
- \\
-\end{array}$ & $\begin{array}{r}9,404 \\
28,267 \\
19,457 \\
3,165 \\
-\end{array}$ & $\begin{array}{r}25 \\
75 \\
67 \\
5 \\
4\end{array}$ & $\begin{array}{l}13.3 \\
13.3 \\
17.2 \\
- \\
-\end{array}$ \\
\hline · & well-to-do & - mixed & poor & total \\
\hline $\begin{array}{l}\text { values found ... } \\
\text { values expected . }\end{array}$ & $\begin{array}{r}25 \\
28\end{array}$ & $\begin{array}{l}75 \\
82\end{array}$ & $\begin{array}{l}67 \\
57\end{array}$ & $\begin{array}{l}167 \\
167\end{array}$ \\
\hline
\end{tabular}

$\dot{\gamma}_{0}^{2}=2.78 ; 0.30>P>0.20$

The higher mortality found in the poor neighbourhoods does not differ significantly from the expected mortality if the chances of dying were the same-in the three.groups of districts. In other words, in this manner differences in pre-school age mortalicy, dependent on the economic conditions, cannot be demonstrated with certainty.

The districts of Amsterdam have also been divided into groups according

I The tables give rounded-off figures; more accurate values were used for the calculation of the Chi-square test. 
to other methods, and their pre-school age mortality compared. In the article of $D_{B}$ WoLirF and MEERDINK, referred to above, the districts are also differentiated according to the number of inhabitants per room. In this way, family size, sharing the house and overcrowding have been important factors in the grouping of the districts, in addition to prosperity.

Table XLI shows the results of this division.

TABLE XLI

Mortality of children of pre-school age according to districts in Amsterdam

\begin{tabular}{|c|c|c|c|c|}
\hline districts & $\begin{array}{l}\text { number of house- } \\
\text { mates per room }\end{array}$ & $\begin{array}{l}\text { number of } 1-4- \\
\text { year-old children }\end{array}$ & died in $1952-1953$ & $\begin{array}{c}\text { annual mortality } \\
\text { per } 10,000\end{array}$ \\
\hline $\begin{array}{l}\text { well-to-do . . . } \\
\text { mixed . . . . . } \\
\text { poor. . . . . . } \\
\text { new districts . . . } \\
\text { address unknown . }\end{array}$ & $\begin{array}{l}\text { less than } 0.75 \\
0.75-0.85 \\
\text { more than } 0.85 \\
-\end{array}$ & $\begin{array}{c}14,215 \\
31,642 \\
11,271 \\
3,165 \\
-\end{array}$ & $\begin{array}{r}36 \\
77 \\
54 \\
5 \\
4\end{array}$ & $\begin{array}{l}12.7 \\
12.2 \\
25.0 \\
- \\
-\end{array}$ \\
\hline \multicolumn{4}{|c|}{ - } & $\cdot$ \\
\hline . & well-to-do & mixed & poor & total \\
\hline $\begin{array}{l}\text { values found . . } \\
\text { values expected . . }\end{array}$ & $\begin{array}{l}36 \\
40\end{array}$ & $\begin{array}{l}77 \\
9 \mathrm{r}\end{array}$ & $\begin{array}{l}54 \\
36\end{array}$ & $\begin{array}{l}167 \\
167\end{array}$ \\
\hline
\end{tabular}

$\chi^{2}=12.12 \quad P>0.0 I$

The values found show a highly significant difference from those expected on the presumption that there was no difference in death rate between the three groups. The higher mortality of pre-school age children in the 'poor' districts is therefore real. The combination of various factors leading to overpopulation causes a higher-mortality of I-4-year-old children. However, not only the more unfavourable economic conditions must be considered responsible for this.

DE WOLFF and MEBRDink also found a (weak) correlation between overpopulation and total mortality, and no association between prosperity and total death rate, if the prosperity factor wäs"dedüced from the extent to which State loans were given. The infant mortality of 1946-I949 did not reveal any correlation between town districts and mortality, notwithstanding the fact that, according to a later study, the infants from the various prosperity groups in Amsterdam did show marked differences in mortality. 
The pre-school age mortality of $1952 / 19.53$ was analysed. according to social. classes, on the basis of the distribution of the occupations over the fathers (or mothers) of the newborn children in I95I. Three social classes were chosen, with all the drawbacks inherent to every differentiation according to occupation.

Class I: owners of larger industrial firms; other owners of larger firms, not mentioned in classes II or III; managers, etc.; higher administrative personnel; higher officials; the clergy; university professors and secondary school teachers; captains, engineers and mates of sea-going vessels; regular army officers; elementary school teachers; professional people

Class II: owners of agricultural enterprises; owners of shops and heads of branch establishments; owners of inland vessels; lower administrative personnel; lower officials; commercial travellers, representatives and insurance agents; police and fire brigade personnel and military men below the rank of commissioned officer; nursing staff; shop assistants and other employees

Class III: owners of small enterprises; all labourers; motor-car drivers and waggoners; domestic staff; personnel of hotels, cafés and restaurants.

These three social classes were condensed from the existing classification into smaller professional groups in such a way that not only the sharpest possible division into three classes was obtained, but that it was also possible to classify the stated occupations of the fathers of deceased children in the correct group. It was necessary to include the group of owners of small enterprises in the third prosperity group, because a great many of these people are heads of one-man businesses, and are practically to be regarded as members of the working class. The differences between the first social class and the third one thus become sharper rather than less definite, because this group of semiindependent workers occupies an unfavourable position from a social and economic point of view. This is also shown by DE WolfF and MeERDINK's study, who observed a relatively high infant mortality in their group of semiindependent people, practically as high as that of the lowest prosperity group.

For completeness's sake; table XLII shows the distribution of family sizes and social classes over the legitimate newborn children in 195I; this distribution served as basis for the following calculation of the pre-school age mortality.

This table shows that the three social classes in Amsterdam show only slight differences as regards the size of the families with young children. Large families are relatively rare. In class II, with many young marriages, the number of small families is somewhat higher than in the two other groups, but the difference is small. At present birth control is evidently practised by all population groups in the large towns, so that the great differences originally existing between the more well-to-do and the poorer people as regards the number of children, are disappearing.

Table XLIII gives the pre-school age mortality in the three social classes 
TABLE XIII

Legitimate newborn children, according to social class and birth rank (Amsterdam 195i)

\begin{tabular}{|c|c|c|c|c|c|c|c|c|c|c|}
\hline \multirow{3}{*}{ birth rank } & \multicolumn{6}{|c|}{ social class } & \multirow{3}{*}{\begin{tabular}{|l}
$\begin{array}{c}\text { without } \\
\text { occupa- } \\
\text { tion }\end{array}$ \\
number
\end{tabular}} & \multirow{2}{*}{\multicolumn{2}{|c|}{$\begin{array}{l}\text { total, excl. } \\
\text { without } \\
\text { occupation }\end{array}$}} & \multirow{3}{*}{$\frac{\begin{array}{c}\text { total } \\
:\end{array}}{\text { number }}$} \\
\hline & \multicolumn{2}{|l|}{ I } & \multicolumn{2}{|l|}{ II } & \multicolumn{2}{|l|}{ III } & & & & \\
\hline & number & $\%$ & number & $\%$ & number & $\%$ & & number & $\%$ & \\
\hline $\begin{array}{l}\text { I and } 2 \ldots \ldots \\
3 \text { to } 5 . \ldots . \\
\text { higher than } 5 .\end{array}$ & $\begin{array}{r}901 \\
478 \\
69\end{array}$ & $\begin{array}{r}62 \\
33 \\
5\end{array}$ & $\begin{array}{r}2,939 . \\
1,122 \\
198\end{array}$ & $\begin{array}{r}69 \\
26 \\
5\end{array}$ & $\begin{array}{r}5,324 \\
2,458 \\
547\end{array}$ & $\begin{array}{r}64 \\
30 \\
6\end{array}$ & $=$ & $\begin{array}{r}9,164 \\
4,058 \\
814\end{array}$ & $\begin{array}{r}65 \\
29 \\
6\end{array}$ & $\frac{-}{-}$ \\
\hline total .... & $\mathrm{I}, 44^{8}$ & roo & 4,259 & 100 & 8,329 & 100 & 183 & $\mathrm{r} 4,036$ & 100 & $\begin{array}{l}\text { I4,2199 } \\
\end{array}$ \\
\hline
\end{tabular}

compared with the values expected if there were no difference in death rate between these economic groups.

TABLE XIIII

Mortality of children of pre-school age according to social class (Amsterdam 1952/1953)

\begin{tabular}{|c|c|c|c|c|}
\hline . & \multicolumn{4}{|c|}{ social class } \\
\hline & . I I & . II & III- & total \\
\hline number of deaths found . . . . . & 22 & 39 & 97 & 158 \\
\hline number of deaths expected $\ldots \ldots$ & I6 & 48 & 94 & rs8 \\
\hline
\end{tabular}

$\chi^{2}=3.64 ; \quad 0.20>P>0.10$

Of nine pre-school age children who had died, the fathers' occupations were unknown. Illegitimate children were not included in the analysis.

Table XLIII shows that the mortality observed does not differ significantly from the figures expected if there were no difference in death rate: It is thus again impossible to demonstrate differences in mortality depending on the economic conditions.

Although it was already known (table $X L I I)$ that the three social classes show only minor differences as regards the number of children, the pre-school age mortality was determined separately, differentiated according to social class and size of the family (number of birth): see table XLIV. 
Number of deaths among children of pre-school age according to social class and size of the family (Amsterdam 1952/1953)

\begin{tabular}{|c|c|c|c|c|c|}
\hline \multirow{2}{*}{$\begin{array}{l}\text { social } \\
\text { class }\end{array}$} & & \multicolumn{4}{|c|}{ birth rank of the deceased I-4-year-old children } \\
\hline & & $\mathbf{I}-\mathbf{2}$ & $3-5$ & higher than 5 & total \\
\hline I & $\begin{array}{l}\text { number of deaths found } \\
\text { number of deaths expected }\end{array}$ & $\begin{array}{l}13 \\
14\end{array}$ & $\begin{array}{l}6 \\
7\end{array}$ & $\begin{array}{l}3 \\
\mathbf{I}\end{array}$ & $\begin{array}{l}22 \\
22\end{array}$ \\
\hline II & $\begin{array}{l}\text { number of deaths found } \\
\text { number of deaths expected }\end{array}$ & $\begin{array}{l}26 \\
27\end{array}$ & $\begin{array}{l}\text { II } \\
\text { I0 }\end{array}$ & $\begin{array}{l}2 \\
2\end{array}$ & $\begin{array}{l}39 \\
39\end{array}$ \\
\hline III & $\begin{array}{l}\text { number of deaths found } \\
\text { number of deaths expected }\end{array}$ & $\begin{array}{l}55 \\
62\end{array}$ & $\begin{array}{l}29 \\
29\end{array}$ & $\begin{array}{r}13 \\
6\end{array}$ & $\begin{array}{l}97 \\
97\end{array}$ \\
\hline total & $\begin{array}{l}\text { number of deaths found } \\
\text { number of deaths expected }\end{array}$ & $\begin{array}{r}94 \\
103\end{array}$ & $\begin{array}{l}46 \\
46\end{array}$ & $\begin{array}{r}18 \\
9\end{array}$ & $\begin{array}{l}158 \\
158\end{array}$ \\
\hline
\end{tabular}

$\chi^{2}$ in prosperity class III $=7.61 \quad 0.05>P>0.02$ (almost $=0.02$ )

$\chi^{3}$ in all prosperity classes together $=9.24 \quad P=0.01$

Table XLIV proves that the large families had a higher mortality than expected on the presumption that there would be no difference in chances of dying according to size of the family, while the small families showed a lower mortality than expected. The greater chance of dying in large families is significant. In a further subdivision into social classes, this difference proves only to exist (or is at any rate demonstrable) in the lowest group, where it is also significant though not great.

Reviewing the results of the investigation into the pre-school age mortality in Amsterdam: it. is. impossible to demonstrate a significant influence of the prosperity factor, either if this factor is determined by a differentiation into poorer or richer districts, or if the fathers' occupations are the criteria of prosperity. The influence of the size of the family is only demonstrable in the lowest prosperity group. There is also a correlation between overcrowded dwellings and pre-school age mortality, without it being possible to state to what extent sharing the house, bad houses, low prosperity and great number of children are responsible for this relationship. It is probable that the combination of these four (or more) unfavourable factors, which come markedly to the fore if the districts are grouped according to density of population, has led to demonstrable differences in the mortality of $\mathrm{I}-4$-year-old children. 
The pre:school age mortality in The Hague was analysed essentially in the same manner as in Amsterdam. The somewhat different classification into occupations applicable to this city, and the fact that the division into districts was less suitable for our purpose, made it impossible to elaborate the data of both cities in one analysis.

The Hague is divided into forty districts, which, however, are of a less homogeneous character than in Amsterdam. It was moreover impossible to divide these districts according to objective data on prosperity and number of people per room, as was the case in Amsterdam.

The differentiation into three classes is therefore only based on the general impression of prosperity made by the various districts. It is not difficult to classify a number of neighbourhoods as well-to-do and poor districts. The other districts, constituting an intermediate group, form in reality a residual group, and are indicated as such. This residual group has assumed great proportions because of the heterogeneous structure of the districts of The Hague and the necessity of making the contrast between poor and well-off as sharp as possible.

The distribution of the number of I-4-year-old children over the various districts was also known for The Hague, as was the address of the pre-school children that had died, so that a direct determination of the mortality according to districts was possible. The total number of deceased children of preschool age in I952 and 1953 was Ios. Table XLV gives the distribution of them over the various prosperity groups.

TABLE XLV

Mortality of children of pre-school age in The Hague, according to districts (1952/1953)

\begin{tabular}{c|c|c|c}
\hline districts & $\begin{array}{c}\text { number of } \\
\text { I-4-year-old children }\end{array}$ & $\begin{array}{c}\text { deceased I-4-year-old } \\
\text { children }\end{array}$ & $\begin{array}{c}\text { annual mortality } \\
\text { per I0,000 }\end{array}$ \\
\hline well-to-do . . . . & 6,059 & 16 & I3.2 \\
poor . . . . . . & 14,684 & 33 & II.3 \\
residual group. . . & 24,62 II.4 & 56 & II.6 \\
\hline
\end{tabular}

This table shows the differences in pre-school age mortality in the three groups of districts to be small and insignificant. Although the arrangement in districts is only a rough reflection of the prosperity conditions, the contrast in prosperity between well-off and poor neighbourhoods is still great, because 
of the large.residual group: The large-scale sharing of houses cannot eliminate this difference in prosperity between the two extreme groups.

By this method it is therefore not possible to demonstrate any differences in pre-school age mortality dependent on economic conditions.

The analysis of this mortality according to the fathers' occupation and size of the family was carried out in an identical manner to that in Amsterdam, but the classification of the occupations. was different. For The Hague also it was assumed that the distribution of the occupations and family sizes over the I-4-year-old children in 1952/1953 corresponded with that of the infants of I95I. The data on the fathers' occupations and the number of births in the family (as an indication of the size of the family) were known for the legitimate newborn children of I9SI and for the I-4-year-old children that died in 1952 and 1953. In the following tables a comparison is again made of the actual number of deceased children of pre-school. age with the expected number if there were no difference in pre-school age death rate according to size of the family and occupation of the father.

There are four occupational groups, of necessity different to those in Amsterdam.

Class I: directors; managers; professional people; administrative personnel; officials; university professors; teachers of secondary and elementary schools; the clergy; regular army officers; higher fire brigade and police personnel; commercial travellers and representatives.

Class II: people working on own account in commerce, industry, traffic and agrarian enterprises.

Class III : lower police and fire brigade personnel; shipping and air traffic personnel; nursing staff; shop assistants and other employees.

Class IV : all labourers.

Table XLVI gives the distribution of the newborn infants in 1951 over these four social classes and three groups according to size of the family (number of births in the family), used as a basis for the calculation of the pre-school age mortality.

TABLE XLVI

Legitimate newborn children, according to social class and birthrank (The Hague 1951)

\begin{tabular}{|c|c|c|c|c|c|c|c|c|c|c|}
\hline \multirow{3}{*}{ birth rank } & \multicolumn{10}{|c|}{ social class } \\
\hline & \multicolumn{2}{|l|}{ I } & \multicolumn{2}{|l|}{ II } & \multicolumn{2}{|l|}{ III } & \multicolumn{2}{|l|}{ IV } & \multicolumn{2}{|c|}{ total. } \\
\hline & number & $\%$ & number & $\%$ & number & $\%$ & number & $\%$ & number & $\%$ \\
\hline I to $2 \ldots \ldots$ & 2,344 & 63 & 500 & 49 & 730 & 66 & 2,823 & 59 & 6,397 & 60 \\
\hline 3 to $5 \ldots$ & 968 & 26 & 378 & 37 & 332 & 30 & $I, 53 I$ & 32 & 3,209 & 30 \\
\hline higher than 5 . . & 409 & II & I 43 & I4 & 43 & 4. & $43 I$ & 9 & $I, 026$ & IO \\
\hline total . . . . . & 3,721 & 100 & I,02I & IOO & I,IO5 & 100 & 4,785 & 100 & 10,632 & 100 \\
\hline
\end{tabular}


The Hague also shows little difference in family size between the various social groups. The somewhat greater frequency of small families in group III and of large families in group II is connected with the average age of the parents in these groups, which will be higher than the average in group II and lower in group III.

Table XLVII shows the distribution of the pre-school age mortality according to social classes, compared with the distribution expected if there were no difference in death rate.

TABLE XIVII

Mortality of children of pre-school age according to social class (The Hague 1952/19̈53)

\begin{tabular}{|c|c|c|c|c|c|}
\hline & \multicolumn{5}{|c|}{ social class } \\
\hline & I & II & III & IV & total * \\
\hline number of deaths found . . . . & 30 & 12 & 9 & 53 & IO4 \\
\hline number of deaths expected. . . & 36 & Io & II & 47 & I04 \\
\hline
\end{tabular}

$\chi^{2}=2.65 ; \quad 0.50>P>0.40$

$\star$ excl. one without any occupation

Although this table suggests that social class I shows less and class IV more deaths than would be expected with equal chances of dying, these differences are not significant, even if groups I and IV only are compared (0.20 > P $>0.10)$.

Table XLVIII gives a further subdivision of the social classes according to size of the family (birth rank).

This table demonstrates that the actual number of deaths differentiated. according to size of the family, is more favourable for the smaller families and less favourable for the larger families, compared with the figures found if there had not.been a difference in chance of dying between the pre-school age children in small and in large families. In other words, the chances of dying of I-4-year-old children increase significantly as the families become larger. The table shows that this is especially true for the lowest social class (workers), which șhows a significant difference between large and small families, indicating the more unfavourable hygienic conditions under.which the pre-school children are living in relatively large and poor families.

The factor 'size of the family' seems also of importance in the classes II and III, but the figures are too small to allow of certain conclusions. Influence of the size of the family is not demonstrable in the highest social class. .. . . '.... 
TABLE XIVIII

Mortality of children of pre-school age according to social class and size of the family (The Hague 1952/1953)

\begin{tabular}{|c|c|c|c|c|c|}
\hline \multirow{2}{*}{$\begin{array}{l}\text { social } \\
\text { class }\end{array}$} & & \multicolumn{4}{|c|}{ birth rank of the deceased I-4-year-old children } \\
\hline & & I-2 & $3-5$ & higher than 5 & total * \\
\hline I & $\begin{array}{l}\text { number of deaths found } \\
\text { number of deaths expected }\end{array}$ & $\begin{array}{l}18 \\
19\end{array}$ & $\begin{array}{l}9 \\
8\end{array}$ & $\begin{array}{l}3 \\
3\end{array}$ & $\begin{array}{l}30 \\
30\end{array}$ \\
\hline II & $\begin{array}{l}\text { number of deaths found } \\
\text { number of deaths expected }\end{array}$ & $\begin{array}{l}2 \\
6\end{array}$ & $\begin{array}{l}6 \\
4\end{array}$ & $\begin{array}{l}4 \\
2\end{array}$ & $\begin{array}{l}12 \\
12\end{array}$ \\
\hline III & $\begin{array}{l}\text { number of deaths found } \\
\text { number of deaths expected }\end{array}$ & $\begin{array}{l}3 \\
6\end{array}$ & $\begin{array}{l}5 \\
3\end{array}$ & $\begin{array}{l}\mathbf{I} \\
0\end{array}$ & $\begin{array}{l}9 \\
9\end{array}$ \\
\hline IV & $\begin{array}{l}\text { number of deaths found } \\
\text { number of deaths expected }\end{array}$ & $\begin{array}{l}22 \\
3 \mathrm{I}\end{array}$ & $\begin{array}{l}24 \\
16\end{array}$ & $\begin{array}{l}6 \\
5\end{array}$ & $\begin{array}{l}52 \\
52\end{array}$ \\
\hline total & $\begin{array}{l}\text { number of deaths found } \\
\text { number of deaths expected }\end{array}$ & $\begin{array}{l}45 \\
62\end{array}$ & $\begin{array}{l}44 \\
3 \mathrm{I}\end{array}$ & $\begin{array}{l}14 \\
10\end{array}$ & $\begin{array}{l}\text { ro3 } \\
\text { I03 }\end{array}$ \\
\hline
\end{tabular}

social class IV : $\chi^{2}=10.22 ; \quad P<0.01$

all social classes: $\chi^{2}=11.20 ; \quad P<0.01$

* excl. one without occupation and one illegitimately born

Summarizing, we may say that the results of the analysis of the pre-school age mortality in The Hague agree with those in Amsterdam, in spite of the fact that both the division into districts and the classification of the occupations were somewhat different. This agreement greatly enhances the reliability of the conclusion that, with the present low death rate of these children and under relatively favourable soeial conditions, prosperity is no longer of great importance for the mortality of children of pre-school age in two large cities of the Netherlands. The influence of the size of the family, however, is still demonstrable.

Should, therefore, the conclusion be drawn that prosperity has lost all significance? This is improbable. The prosperity of the family will undoubtedly be of great influence on the general state of health of the I-4-year-old children, but this influence is no longer so great that it exerts a clear effect on the death rate. It is however by no means impossible that some influence of the prosperity factor. on pre-school age mortality may be demonstrable with more refined. methods and more extensive material.

The prosperity groups used in these analyses are most certainly not complete, but it can be said with a fair degree of certainty that prosperity has lost much in importance for the pre-school age mortality. This prosperity factor could easily be 
demonstrated, also with a rough analysis, in the older literature, dating from a time when the pre-school age death rate was high (see the discussion in the first pages of this chapter).

It is still an open question whether these facts are to be observed outside the large towns as well, but it is probable that in these areas also the influence of the prosperity factor on the mortality of I-4-year-old children has greatly decreased, partially due to the levelling out of the differences in prosperity in the rural areas that has begun to take place in recent years. This is also of importance. The influence of prosperity on the (pre-school age) mortality decreases in proportion to the levelling out of the differences in prosperity in a country. The general rise of the standard of living, especially of the lowest groups, has been one of the most important among the complex of socio-economic improvements.

DE WOLFF and MEERDINK's study showed that there were still great differences in the infant mortality in Amsterdam between 1946 and 1950, differentiated according to social class. This discrepancy between infant and pre-school age mortality has already come to the fore in our discussion of the low mortality of I-4-year-old children in Zeeland, be it on other grounds. Unfortunately the Amsterdam analysis (DE WolfF and MeERDINK) did not make a distinction according to parity, which is of importance in regard to the infant mortality. The choice of the period of investigation also was not quite favourable, because it included the years 1946 and I947, when the infant mortality was still unusually high as a result of post-war conditions.

SAJET, also in Amsterdam, observed in the years following the first world war that the mortality of children of pre-school age is influenced to a greater degree by the prosperity factor than that of infants. Children of pre-school age have therefore shown more distinctly a levelling out of the influence of prosperity on the death rate than infants, apart from the influence of family size which was not analysed by SAJET. This fact is in agreement with the conclusion, drawn in chapter II on the strength of the trend of the total pre-school age mortality, that I-4-year-old children have benefited even more from social and hygienic progress than infants.

The size of the family is apparently such an important factor as regards the state of health of the pre-school child that its influence is even reflected in the death rate, in any case for the lower prosperity groups. The more well-to-do families did not show any significant difference in mortality according to the number of children, and, although 'non-significant' does not automatically mean 'non-existing', our figures still suggest that if there is any difference in mortality between large and small families of the higher social groups, this is of little importance. Prosperity can compensate for the disadvantages connected with a large family. 
An influence of the family size on the pre-school age mortality is found even in large towns, where the number of families with many children is relatively low. Although there are no corresponding data from the rural areas, this influence is probably not less in the country. The low mortality in Zeeland already has led to the conclusion that the size of the family is of greater importance in regard to low pre-school age mortality than prosperity.

It is easier to demonstrate the existence of this influence of the family size than to explain how the large family exerts an unfavourable influence on the pre-school age mortality. It is true that the prosperity factor has largely been eliminated in this calculation, but there are still many other factors interwoven with the family size, such as housing conditions, age of the parents, general adjustment and mentality, etc. Probably, however, the degree of care for the I-4-year-old child is an important factor, as already discussed earlier. Care and supervision are so important for the present low pre-school age mortality that less adequate care may influence the death rate to a great extent. It is clear that housing conditions are also important in this respect. Table XLI demonstrates that the overcrowded dwellings in Amsterdam show a significantly higher pre-school age mortality than the other houses.

The distinction made in this analysis between prosperity and size of the family is somewhat artificial. In reality, the combination of a large family with poverty is not only a very frequent, but also very important factor for the state of health and mortality of I-4-year-old children. Conversely, in former times the influence of poverty will have been less in the smaller families than in the larger ones (Zeeland).

Under present social conditions and with the low pre-school age death rate, prosperity has (in Amsterdam and The Hague) no longer any manifest influence on the mortality of I-4-year-old children, however the prosperity factor was determined.

The size of the family still constitutes an important factor for the chance of dying of a pre-school child, at any tate in the lower prosperity groups. 


\section{NUMBER OP PRE-SCHOOL CHILDREN D.YING IN HOSPITAL}

At present by far the larger part of the population of the. Netherlands live within a short distance of a hospital, while general practitioners are easily available in practically all parts of the country. The number of persons who die without receiving medical help is therefore negligible.

The frequency of hospital admission of ill patients is a different matter, however. The number of seriously ill children of pre-school age sent to hospital in order to undergo the most efficient treatment, can be determined indirectly by a comparison of the numbers of these children dying in hospital and at home.

The proportion of the number of I-4-year-old children who died in hospital to the total number of deceased pre-school age children, is a reflection of the efficiency of the medical aid and the degree to which use is made of the specialist services available in the whole country. It should be borne in mind that this admission percentage gives a too optimistic picture of the extent to which critically ill pre-school children are admitted, because a number of them reach hospital too late or even moribund.

Only in a very limited number of cases of serious disease with a hopeless prognosis it is perhaps justifiable to leave the child at home or to discharge him from hospital to let him die at home. The question whether a child can still be saved or death be postponed by specialist treatment, can, in principle, almost never be answered in the negative beforehand, and therefore this question should not influence the indications for admission. In the light of modern therapeutic possibilities, TeN BOKKEL HuININK's dictum is even more true than formerly, also as regards pre-school children: 'a child is not dead until he is really dead'.

In many cases of death at home, the seriousness of the disease has been underestimated or not recognized in time.

The Central Bureau for Statistics provided us with data on the place of death (hospital or at home) of all pre-school age children who died from certain diseases in 1948 and 1949. These data have been elaborated and summarized 
in table XLIX. There are no more recent data available, because after 1949 this Bureau did not keep separate records of the cases with fatal outcome inside and outside hospital.

Table XLIX shows that nearly half the deaths from the common infectious diseases in I-4-year-old children in 1948 and 1949 took place at home. This figure was lower in the towns than in rural areas. The fact of admission or non-admission is, even in the Netherlands, still also dependent on the regional density of doctors and hospitals.

It is a remarkable feature that, in Limburg, nearly $75 \%$ of the pre-school age children who die from infectious diseases do so in hospital, while this province shows high mortality rates for these diseases (table XXXVIII). Zeeland has both a low percentage of I-4-year-old children who die in hospital and a low total pre-school age death rate.

Of the fatal tuberculosis cases $70-80 \%$ died in hospital, without marked differences according to province or size of municipality.

Respiratory diseases and influenza have even more unfavourable figures than the common infectious diseases. Only $40 \%$ of the deceased pre-school age children died in hospital, and these figures did not exceed $50 \%$ even in the towns!

For diarrhoea, enteritis and dysentery : about half of the I-4-year-old children falling victims to them died at home!

Only $40 \%$ of the pre-school age children dying from congenital defects were admitted to hospital. This percentage says less than that of the other diseases, because it probably includes quite a number with a hopeless prognosis. and sudden death (cardiac defects). This is even more true for the violent deaths, because timely hospital admission is often impossible in these cases. That in rural areas less I-4-year-old children die in hospital than in the towns, is partially the consequence of the higher mortality from drowning in these regions.

$80 \%$ of the children of pre-school age succumbing to an unknown or unstated cause, died at home. The chance that a child dies without a diagnosis being made (previously or afterwards) is of course smaller in hospital than at home.

Apart from accidents, common infectious diseases and respiratory affections are quantitatively the most important causes of death. The data on the hospital admission of pre-school age children who died from these diseases are therefore subjected to closer scrutiny.

Of the I03 children of pre-school age who died from measles in 1948 and I949, only 36 , i.e., one third, died in hospital. Whooping cough accounted for 168 victims in these years; Ior, or about $60 \%$, died in hospital. Of the 320 diphtheria victims 204, i.e., also about $60 \%$, died in hospital.

Although in general the family doctor has more time to decide on hospital 


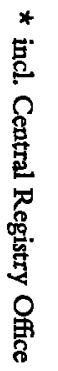




admission when dealing with whooping cough pneumonia than in case of measles pneumonia, and, in the first disease, the exhausted parents will probably exert greater pressure to have the child admitted, these figures still show that an unfavourable course in measles is more frequently not recognized, or too late, than in whooping cough and diphtheria.

The opportunities of admission to hospital are favourable for the pre-school age children living in the three largest towns of Holland. Yet $30 \%$ of the I-4-year-old children of Amsterdam, Rotterdam and The Hague falling victims to the commion infectious diseases died at home, while this figure was over $60 \%$ for diseases of the respiratory tract! This is an unsatisfactory figure for towns with special hospitals for children and large children's wards in general hospitals.

Table $L$ gives a comparison of the percentages of $\mathrm{I}$-year-old and 2-4-yearold children of pre-school age who died in hospital, with the total number of deaths for the years 1948 and 1949.

TABLE L

Proportion of pre-school age children who died in hospital, in percentages of all preschool age deaths, differentiated according to age and cause, in 1948 and 1949

\begin{tabular}{|c|c|c|}
\hline \multirow{2}{*}{ disease } & \multicolumn{2}{|c|}{ percentage } \\
\hline & I-year-olds & 2-4-year-olds \\
\hline $\begin{array}{l}\text { measles and whooping cough } \ldots \ldots \ldots \\
\text { diphtheria } \ldots \ldots \\
\text { respiratory diseases } \ldots \ldots \ldots\end{array}$ diarrhoea, enteritis and dysentery $\ldots \ldots \ldots$ & $\begin{array}{l}54 \\
59 \\
44 \\
60\end{array}$ & $\begin{array}{l}42 \\
68 \\
32 \\
30\end{array}$ \\
\hline
\end{tabular}

If the main cause of the relatively low percentage of hospitalized pre-school age children were the result of failure to recognize or of too late recognition of a serious disease or complication by the family doctor, it is to be expected that this would occur more frequently in younger than in older children of this group, diagnosis as a rule being more difficult in the younger children than in the older ones. The reverse is however the case: the older pre-school age children are less frequently admitted (apart from cases of diphtheria). This rather suggests a tardy recognition of the necessity to send a seriously ill child (irrespective of the diagnosis) to hospital; this necessity will be felt earlier when dealing with very young than with somewhat older children.

- The fact that in measles more of the victims die at home than in whooping cough, also indicates that the serious cases of measles, especially the older children of pre-school age, are in general not sent to hospital often enough. 
The data pertaining to hospital admission of deceased I-4-year-old children, lead to the conclusion that there is an urgent need for sending more seriously ill children of this group to hospital, where they can be given the greatest chance of recovery. Careful and regular observation of an increasingly ill child is a pre-requisite in order to recognize a grave condition in time. The considerable fall of the pre-school age mortality has led to a decreasing opportunity for general practitioners to acquire experience with seriously ill pre-school age children, because such cases become increasingly rare. The overcrowding of children's wards with observation cases and chronic patients sometimes leads to the refusal to admit a seriously but not alarmingly ill child. This may discourage general practitioners from asking for admission of an ill child, even if this would be granted in an emergency case.

General practitioners and hospitals should cooperate, in order that every seriously ill child may profit from the best therapeutic possibilities offered by modern medicine in a hospital. One should also be aware of the potential danger still attached to many so-called harmless diseases, for example mcasles, also for older children of pre-school age.

At present family doctors have only rarely'to deal with a disease with fatal outcome in a I-4-year-old child, and they probably rely very much upon the modern drugs. The statistics show, however, that many of these children still die without having had a chance of hospital treatment.

It is a regrettable fact that the Central Bureau for Statistics cannot afford data on the mortality inside and outside hospital for the years after 1949. It is therefore impossible to find out to what extent the considerably enlarged hospital capacity of recent years has caused an improvement in the rate of hospital admissions of seriously ill children of pre-school age. 


\section{$\mathrm{XV}$}

\section{LITERATURE}

There are not many special studies dealing with pre-school age mortality, in contrast with the relatively numerous treatises on infant mortality. Only in a wider connection, in investigations concerning the total child mortality, are data on pre-school age mortality to be found in the literature.

The fact that the pre-school age mortality rate has been relatively low as compared with the infant death rate, has probably been the reason why there has been little interest in the mortality of I-4-year-old children, although, as a standard of measurement of social and hygienic conditions, the latter is perhaps even more sensitive than the infant mortality, giving better and quicker indications of changes in these conditions. The analysis of pre-school age mortality is moreover less complicated than that of infants, as the causes of death are more clearly defined and diagnosis is simpler. One should, for example, only think of 'causes of death' such as prematurity, congenital debility, birth trauma, etc., which serve as true reservoirs in the. statistics of . infant mortality, in which they still appear very frequently.

The small interest as regards the mortality of I-4-year-old children is a symptom of the relatively small attention which social medicine in general pays to this group.

The only extensive publication on pre-school age mortality known to us in the Netherlands is the important study by SAJET, who analysed this subject in the nineteen twenties in Amsterdam. The most important facts of his interesting paper are the great differences in mortality and morbidity found in pre-school age children belonging to various social classes. These differences proved to be even greater than in infants. One of the causes of the lower pre-school age mortality in groups of higher economic prosperity was the lower incidence of common infectious diseases at a young age, as already described by SAJET et al. in other studies.

The pre-school child congresses of the Netherlands Society for Social Medicine (1929, 1932 and 1938) drew attention to the defective, care of the I-4-year age group. GoRTRR pointed out that the fall in the mortality of this group had been considerable, in spite of the lack of any organized care of the pre-school child. 
MoL belicved that the fall in pre-school age mortality must be attributed to a persistent effect of the infant welfare centres, which are of high educational value. This is, however, not the main cause, because the marked fall in preschool age mortality already started in a period when there was still no question of organized infant care, and the pre-school age mortality has always been lowest in Zeeland, where there were only very few infant welfare centres.

In I935 METHORST published a study on the mortality of infants and children of pre-school age in connection with economic prosperity and the size of the family. The juvenile mortality increased both as a result of lower prosperity and larger families. In these families the child - mortality remained higher than in smaller ones, even after elimination of the prosperity factor.

Neurdenburg (1936) described, in a short statistical paper, the fall in child mortality since 1869 . This reduction had been considerable for all juvenile age groups. The mortality lines converge towards a low level, a decisive proof that infant care does not lead to postponement of unavoidable death, as was formerly sometimes thought on the basis of 'survival of the fittest' theories,

Various papers have been published on the influence of the second world war on child mortality in the Netherlands, but mainly on that of infants (NeURDenBURG). VAN LOOKEREN CAMPAGNe emphasized the marked increase of mortality, including that of children of pre-school age, from intestinal diseases and dysentery.

KopPIUs, in his inaugurational lecture, pointed to the significance of family care as regards morbidity and mortality in young children. In addition to worse hygienic conditions, -hunger, cold, etc., he emphasized as a cause of the rise of the juvenile death rate during the war, decreased care of the child, as an unavoidable result of the psychic tensions under which the mothers lived during that period and during the excitement after the liberation.

VAN DEN BRINK, when elaborating the results of the latest census.(1947), also studied the mortality of children younger than six, which is, naturally, mainly determined by the mortality of infants and only to a small extent by that of children of pre-school age. He also pointed out the great differences in child mortality according to prosperity, still clearly demonstrable as regards children born in recent years, though not to such a high degree as in the first decades of the present century. Mentioning the extreme cases only: the mortality of children under six per 100 marriages (with children) contracted between I944 and 1946 (until May 3 Ist, I947), was: for professional people 3-4, for the working classes 6-9. The corresponding figures previous to I9I4 were: 19-20 for the first group, 70-109 for the second group! The influence of the size of the family is interwoven with this prosperity factor, and these two factors cannot be separated properly from one another. 
VAN. DEN BRINK considers a direct relationship between high child mortality and large families unlikely, which, therefore, does not agree with the actuai findings of METHORST. VAN DEN BRINK believes that the child mortality in small families is unfavourably influenced by the greater frequency of older primiparae, with their higher infant mortality. This, however, forms a problem in itself, without connection with the mortality of children of pre-school age.

LowE's recent investigation also confirms the existence of a direct relationship between size of family and disease and death in the first years of life.

Pre-school age was the subject of an investigation by the League of Nations (193I). This investigation laid special emphasis on the relationship between living in confined surroundings under bad housing conditions, and the high mortality from common infectious diseases. The great importance of accidents in pre-school age is not done justice to in the report. The plea for more frequent and quicker admission to hospital of seriously ill I-4-year-old children seems to have lost little of its force. All the same, when reading the report twenty years after its publication, we get a clear picture of how radically the problems of diseases in pre-school age have changed, together. with the fall in pre-school age mortality. The significance and consequences of this development are often insufficiently realized.

The literature of other countries contains more publications on the mortality of children over one year than the Dutch literature. A clear survey of the child mortality in England between 1840 and 1940 has been given by GALE. This author points out that the mortality of children of pre-school and school age was already markedly falling long before the infant mortality started to decline. In his opinion the juvenile mortality showed a manifest fall as early as in the 18th century, but industrialization and urbanization interrupted this process for a long period. Wrckes believes the same. The slums have been true churchyards, especially for children of pre-school age. The juvenile mortality (apart from infants) did not begin to fall again until the disappearance of widespread epidemics such as of smallpox and cholera, and of famines, and the birth of technical hygiene.

Economic conditions were closely connected with pre-school age mortality, especially as regards death from common infectious diseases. SAJET's data from Amsterdam about the year 1920 are confirmed by those of GALE in England in the nineteen thirties. In which way social conditions influence the death rate is still insufficiently known, as GaLE pointed out.

CAMMOCK and Miller, in their recent investigation, consider the marked fall of the mortality of children older than one year (which reduction is 
considerably greater than that of infant mortality) the most striking characteristic of juvenile mortality.

More concise surveys were given by CraIg in Aberdeen (I95I) and MaIR and TAIT in Edinburgh (1953). The first author considers the development of medical care an important factor in the decline of pre-school age mortality. We cannot share this opinion; it does not explain, for example, the reduction of the I-4-year age group mortality in the last quarter of the Igth and the first quarter of the 2oth century. MaIR and TAIT lay more emphasis on improvements in social conditions, and justly so, in our opinion.

Martin's publication on the childhood mortality in England is remarkable, because, in 1945, he forecasted a $50 \%$ reduction of the pre-school age mortality in the very near future, due to a decrease of accident mortality and the practical disappearance of diphtheria. Within a few years, this forecast was confirmed. Holland has not yet progressed so far in this respect; diphtheria still has many victims among I-4-year-old children, and there is as yet no manifest fall in the number of fatal accidents in this group.

The juvenile mortality in Sweden has been analysed by SтRÖM. It is a striking feature that in this country also the great reduction in pre-school age mortality began about the year 1870,just as in England and the Netherlands.

The Children's Bureau in the United States regularly publishes data on the trend of childhood mortality in that country. Short considerations on juvenile mortality are also to be found in the publications of the Metropolitan Life Insurance Company. Closer analysis of childhood mortality, however, is not available. Time and again emphasis is placed on the present important causes of death for children older than one: accidents and tumours. Accident mortality in children and the measures to overcome it form the subject of many American publications. All recent articles on juvenile mortality emphasize the enormous fall in the death rate and the changes in the mortality pattern accompanying it; for example the ever increasing importance of accident mortality.

It is, however, impossible to find any explanation in the literature for the fact that the mortality of children of pre-school age falls more rapidly than that of other children, and which factors in particular are active in the reduction of the I-4-age group death rate. Modern methods of treatment are repeatedly regarded as belonging to the most important factors. This is however contrary to the fact that the great decline of pre-school age mortality started as early as about 1870 . The uniformity of the fall in mortality from most of the causes of death, irrespective of whether they responded to specific treatment or not, also pleads against the opinion that the reduction of the pre-school age mortality is mainly due to medical measures. Better economic conditions, improved nutrition and other such general factors afford a better explanation. There are even indications that young children have derived less benefit from 
chemotherapy and antibiotics than adults. Of late years the mortality from measles and especially whooping cough in Glasgow infants has decreased far more than the pneumonia mortality, in spite of the effective treatment of the latter disease. The sulphonamides have shown less effect in these children than in adults (ANDERSON). The investigation carried out by VERA NORRIS also points into this direction (page 50).

The picture of the state of health of pre-school children, as may be deduced from the mortality of I-4-year-old children, is incomplete without accurate morbidity statistics.

Investigations into the frequency of disease in children have been carried out in other countries than the Netherlands, but none of these have, so far, yielded reliable statistics.

There are various theoretical possibilities of evolving morbidity statistics of young children of pre-school age:

(a) By questionnaires, in which a large number of persons are requested to mention the diseases occuring in the family during the past year. An example of such an investigation is the National Health Survey in the U.S.A. of 1938, which included 2,500,000 persons and has been described by BRTTten and Dorothy Holland. This method has the great drawback that it is not only dependent on the memory of the participants, so that there is probably a considerable amount of 'under-reporting', but it is even more important that the degree of under-reporting is dependent on social class, age, intelligence, etc. The National Health Survey has only yielded a rough picture of the morbidity incidence in children in the U.S.A. More than $50 \%$ of the diseases in pre-school children are the common infectious diseases; next in frequency are respiratory affections. Chronic diseases and disturbances of the digestive tract are relatively of little importance; otitis and accidents occur more often. Pre-school age children and young children of school age are ill two to three times as frequently as older children and adults, but the average duration of illness is shorter. Boys are more often ill than girls. An important factor was the marked influence of prosperity on the incidence of diseases, especially as regards infectious diseases, accidents and tuberculosis.

(b) A second method of morbidity study in young children is the taking of their history as regards disease at the beginning of the school age, as done, for example, by BransBy for the common infectious diseases and by SAJET for whooping cough. Here also the investigator is dependent on the memory of those interrogated.

(c) Another method is the follow-up of a group of newborn children over a period of some years by regular home visiting. Such investigations have 
been carried out, after the second world war, by DyKes et al. in Luton (England) and by Douglas and. Rowntrer.

These investigations are fairly accurate. They clearly bring the great significance of common infectious diseases at pre-school age to the fore. The respiratory affections are also still very frequent in young children of preschool age, but they rapidly lose in importance as the children become older. Compared with these two groups of diseases, all other affections are of low frequency, but accidents have probably been given far too little attention in the investigations.

It is remarkable that the Luton study did not show a clear influence of the prosperity factor, in contrast to the findings of Douglas.

This is possibly the result of statistical imperfections in the choice of the social groups. All the same, it is of importance that in the Luton study no differences were found in mortality between the social classes, becauise formerly, even with a rough division into social groups, great differences in morbidity and mortality were always found. The influence of the prosperity factor alone has probably lost greatly in importance, now the death rate has reached such a low level. Douglas believes that the main causes of higher morbidity in poorer families should be sought for in overcrowding and less care on the part of the mother.

(d) Experts in the field of morbidity investigation in England recommend, as a good method, the study of the diseases in a limited number of families, followed-up accurately for a long period, so that many aspects of illness can be studied. Such an investigation has been organized with great care by SPENCE and MiLLer in Newcastle, but so far it has not yet led to a survey of morbidity in I-4-year-old children, because this method is very timeconsuming. One of the things that have become clear is that certain infections persistently circulating among members of the family (especially by staphylococci and streptococci) exert a great influence on the morbidity of pre-school age children. The importance of these familial infections is also manifest 'in DiNGLe's study in Cleveland, 'carried out more or less in the same way as in Newcastle, but on a smaller scale. The pre-school children suffer most from familial infections; they are more frequently ill than other groups with the same chances of infection. After the fourth year of life the diseases of the respiratory tract especially decrease in frequency due to increasing resistance and the development of relative immunity. These findings are corroborated by the investigations of Downes.

(e) A fifth method of morbidity investigation is the study of hospital admissions. These, however, concern only a selected group of more serious patients, the selection of which group varies from place to place. Hospital files, therefore, cannot give a.good survey of the frequency of disease. 
$\because$ On the other. hand, it is possible to trace the great changes in the incidence and nature of serious diseases in children during the past decades in these hospital files. Davison pointed this out, inter alia, and proved that at present the 'children's wards are often filled with patients with tumours, reticuloses and congenital defects, while admissions for tuberculosis and acute infectious diseases are increasingly rare..The whole aspect of clinical paediatrics is showing a rapid and radical change.

$(f)$ The files of the general practitioners ought to form a good source for morbidity investigation. Unfortunately, the recent Dutch investigations of BUMA and VAN DeEN do not allow of conclusions on morbidity in children of pre-school age, because these authors did not make a distinction according to age.

We have dealt in somewhat greater detail with the investigations of morbidity in I-4-year-old children, because these, theoretically, might give a better picture of diseases at pre-school age than the mortality statistics.

It appears, however, also from the general opinion. of the investigators themselves, that there are practically no good surveys of morbidity, and that the existing studies show such serious errors that they only allow of very general conclusions. These studies are moreover so intricate and time-consuming that there exist only a small number of them, comparison with figures from other regions and former years being impossible.

On the other hand, the mortality statistics have long given. reliable and comparable figures, reflecting disease and health. Properly speaking, we are still dependent on these statistics to gain knowledge about morbidity and state of health of pre-school children, and the changes that have occurred in them. 


\section{XVI \\ PRE-SCHOOL AGE MORTALITY IN \\ VARIOUS COUNTRIES}

The World Health Organization has very actively continued the work of the League of Nations in the field of medical and demographic statistics. The data on pre-school age mortality in various countries have largely been taken from its Vital Statistics and Epidemiological Reports.

The reliability of such material, obtained from a great number of countries, is, quite naturally, subject to considerable discussion. It is an established fact that there is no question of trustworthy statistics in the so-called underdeveloped countries. The death rates mentioned in these regions are in general too low, because many deaths are not recorded. With improving registration this 'under-reporting' disappears, and the mortality figures become more complete. In this way a fall of mortality may seem less marked than it really is.

This chapter deals mainly with a number of 'developed' countries, the mortality statistics of which have been reliable for a long time. Small deviations are moreover of little importance in comparison with the enormous changes in pre-school age mortality. We agree with PASCUA that there is no reason to discard this precious material, collected painstakingly, out of an exaggerated desire for accuracy and statistic al nihilism. The changes of mortality have moreover been very constant, unidirectional and according to expectation, and, from a statistical point of view, the I-4-year age group forms one of the most reliable groups as regards the accuracy of notification of causes of death.

Graph 22 gives the trend of the pre-school age mortality for a number of European countries. This curve is taken from a WHO report and supplemented with more recent data.

For clearness' sake, the war years have been omitted. These periods show only an interruption of the fall of pre-school age mortality; after the war this decline has continued steadily, often even at a somewhat accelerated rate.

The curve gives rise to three general conclusions:

(x) The mortality of I-4-year-old children has markedly decreased in all these countries during the past so years. A certain tendency to levelling out of the differences between the countries becomes manifest in a con- 
vergence of the lines. This means that the countries with initially a higher pre-school age mortality are making up for their arrears.

(2) The Netherlands occupy a medium position among the Western countries as regards pre-school age mortality. While the infant death ratc has been one of the lowest in the world for a long time, the pre-school age mortality is not so favourable.

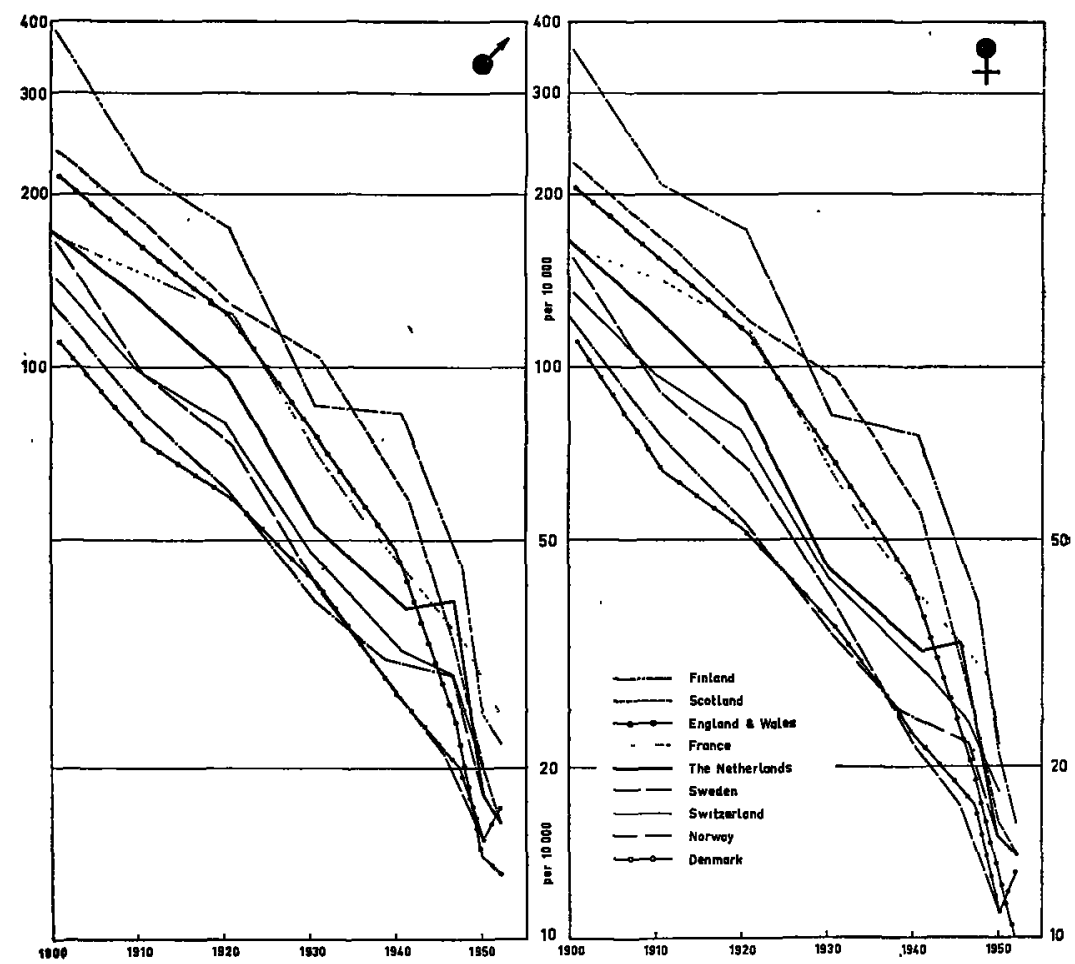

Fig. 22

Mortality of I-4-ycar-old children in some European countries, 1900-1952

(3) In all these countries the mortality of girls has fallen to a greater extent than that of boys, so that the difference in mortality of the two sexes is. increasing relatively.

Table LI gives a comparison of the fall of mortality of various age groups. between 1900 and 1950. The mortality of children of pre-school age has declined more than that of any other juvenile group in practically all the countries considered. The fact that the I-4-age group derives most benefit from the factors leading to a reduction of mortality, is therefore a general phenomenon. The lowest mortality is always found among the (older) children 


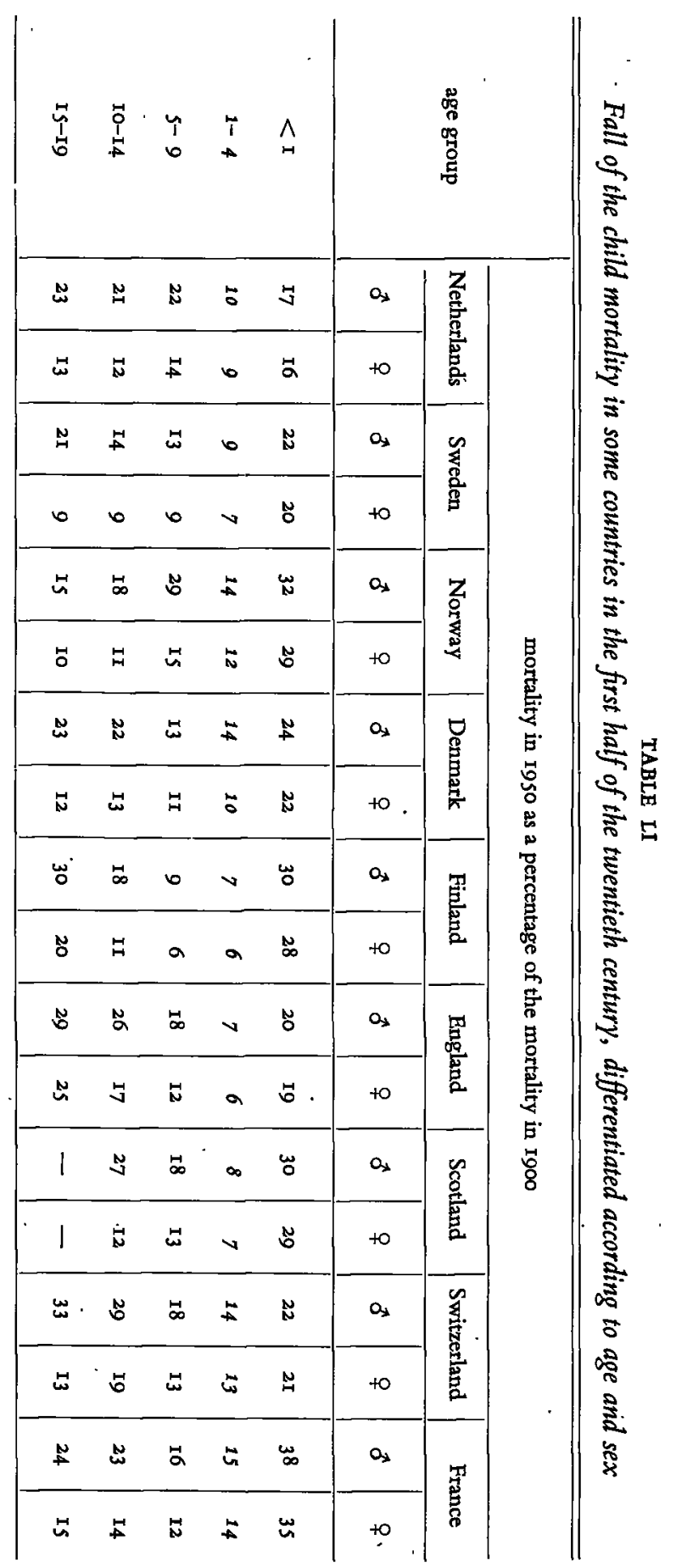


of school age. The higher the pre-school age mortality, the greater its proportion to the total mortality. This is shown in table $L I$, which takes the differences in age structure of the population into account. These differences have partially been eliminated by the presumption that, in all countries mentioned, the number of I-4-year-old children forms the same proportion to the whole population as in the Netherlands.

TABLE LII

Significance of the pre-school age mortality for the total mortality in various countries ${ }^{*}, 1950$

\begin{tabular}{|c|c|c|}
\hline countries & $\begin{array}{l}\text { pre-school age mortality } \\
\text { per 10,000 }\end{array}$ & $\begin{array}{l}\text { pre-school age mortality in } \\
\text { percentage of the total mortality }\end{array}$ \\
\hline 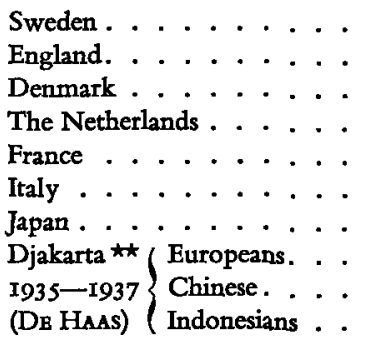 & $\begin{array}{r}13 \\
13 \\
13 \\
16 \\
24 \\
49 \\
93 \\
80 \\
220 \\
760\end{array}$ & $\begin{array}{r}\text { I. } \\
\text { r.I } \\
\text { I.4 } \\
2.1 \\
\text { I. } \\
4.8 \\
8.2 \\
7.0 \\
14.6 \\
14.6 \\
21.8\end{array}$ \\
\hline
\end{tabular}

$\star$ after correction of the differences in proportion of the $\mathrm{I}-4$ age groups to the whole populations

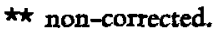

Comparison of mortality according to cause of death in various countries is more difficult, because registration and nomenclature are not the same everywhere.

As PASCUA says: '... the task of analysing international statistics on causes of death for a relatively long period of time is a rather unwieldy and thorny one, full of all sorts of difficulties. Logically therefore some air of relativity should float above all numerical statements and conclusions made on the subjects ... . However, it would appear that, generally, changes expressed in well-marked trends will possess a definite meaning and should be invested with an inferential 'value'.

This chapter only discussess the present pre-school age mortality differentiated according to cause of death, which considerably enhances the reliability.

Table LIII gives a picture of the differences in pre-school age mortality according to cause of death in a number of countries in the period 1948-1950.

In order not to be swamped with figures, the figures of table $L I I I$ have been replaced by o signs in table $L I V$, indicating whether in the countries mentioned the mortality from a cause of death is high, medium or low. In this way the not too favourable place of the Netherlands is clearly shown. 


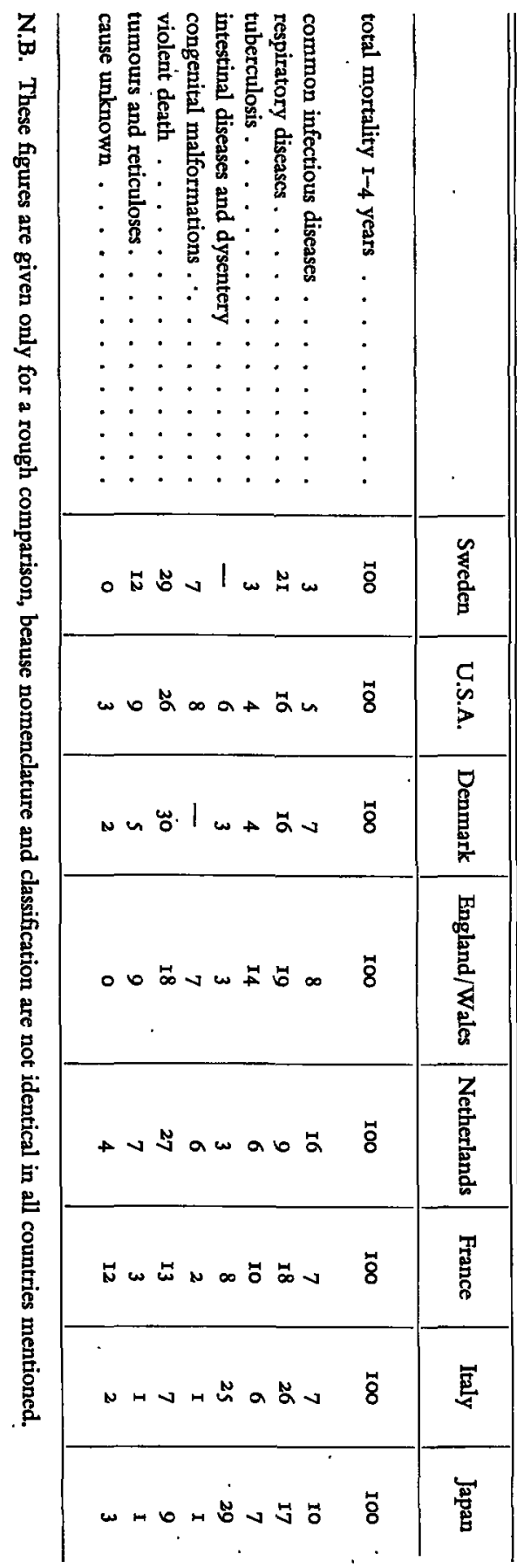

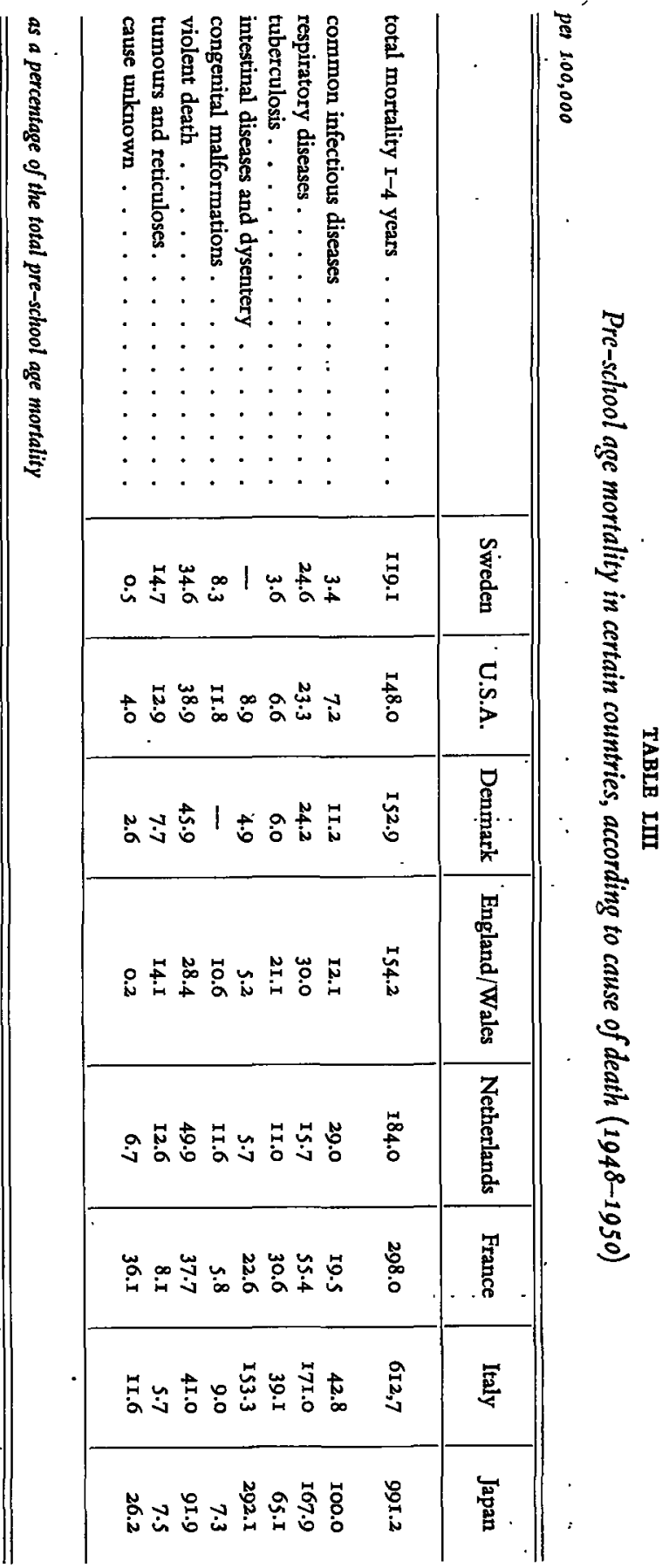


TABLE LIV

Pre-school age mortality in certain countries according to cause of death (1948-1950)

\begin{tabular}{|c|c|c|c|c|c|c|}
\hline cause of death & Sweden & U.S.A. & Denmark & England \& Wales & Netherlands & France \\
\hline $\begin{array}{l}\text { conimon infectious } \\
\text { diseases . . . . } \\
\text { respiratory diseases . } \\
\text { tuberculosis . . . } \\
\text { intestinal diseases. } \\
\text { congenital malfor- } \\
\text { mations. . . . } \\
\text { tumours and reticu- } \\
\text { loses . . . . } \\
\text { violent death . . }\end{array}$ & $\begin{array}{c}0 \\
000 \\
0 \\
0 \\
0 \\
\infty \\
0000\end{array}$ & $\begin{array}{c}0 \\
000 \\
0 \\
0 \\
\infty \\
\infty \\
\infty \\
\infty\end{array}$ & $\begin{array}{c}\infty 0 \\
000 \\
0 \\
0 \\
0 \\
0 \\
00000\end{array}$ & $\begin{array}{c}\infty 0 \\
\infty 00 \\
000 \\
0 \\
00 \\
00 \\
000\end{array}$ & $\begin{array}{c}\infty 00 \\
\infty \\
\infty \\
0 \\
\infty \\
1 \infty \\
00000\end{array}$ & $\begin{array}{c}00 \\
00000 \\
0000 \\
000 \\
0 \\
0 \\
0000\end{array}$ \\
\hline
\end{tabular}

Explanation of symbols:
$0 \quad$ < I0 fer 100,000
$00 \quad 10-20$ per 100,000
$000 \quad 20-30$ per 100,000
$0000 \quad 30-40$ per 100,000
$00000>40$ per 100,000

Sweden, a country with traditionally low juvenile death rates, shows a remarkably low mortality from common infectious diseases in the I-4-age group, mainly because diphtheria has practically disappeared in that country (without immunization).

On the other hand, the mortality from respiratory diseases is considerably higher than in Holland.

In 1948-1950, the mortality from tuberculosis had fallen to a very low level in Sweden. The Netherlands did not reach this low level until I950 (without mass B.C.G. vaccination!). The accident death rate is clearly lower than in the Netherlands.

The juvenile mortality in Sweden has been analysed by SтRöм. The preschool age mortality of that country in the 2oth century shows quite the same trend as in Holland, apart from the mortality from infectious diseases, cspecially diphtheria, which has decreased to a greater degree in the first country.

England and Wales have a lower I-4 age group mortality than the Netherlands, largely due to the low accident mortality, which is the lowest in Europe.

The mortality from the common infectious diseases of childhood is lower than in Holland due to the low diphtheria mortality. This is the result of the immunization campaign in the ninetecn forties. On the other hand, a considerably greater number of children of pre-school age died from diseases of the respiratory tract and of tuberculosis between 1948 and 1950.

The analysis of the juvenile mortality in England by GaLe shows that 
that country has more than made up for its arrears as regards the pre-school age death reate. The mortality from infectious diseases especially has declined more than in the Netherlands.

The mortality of I-4-year-old children in the U.S.A. (1950) is lower than in Holland, due to the smaller number of deaths from the common infectious diseases and tuberculosis.

It is a remarkable fact that, even in 1949, there was a great difference in pre-school age mortality between whites and negroes, in spite of the low total pre-school age death rate. The figures for white and negro children of pre-school age are: 13.7 per I0,000 for the first group, and no less than 23.9 per Io,000 for the second group. There are especially great differences as regards deaths due to tuberculosis and respiratory diseases (RoBinson; STuART; BufkIN; and other authors). The differences in prosperity are the main cause, just as in general marked so-called racial differences in (juvenile) mortality are based on this factor (De HaAs).

In France the mortality of the I- 4 age group is about $\mathrm{I}^{1} / 2$ times as high as in the Netherlands. Tuberculosis especially accounts for many deaths at this age. The mortality from infectious diseases and respiratory affections is also higher than in Holland, but the accident death rate is somewhat lower. The mortality from intestinal affections is much higher in France, also due to the worse hygienic conditions.

In a less developed country, Italy, the pre-school age mortality is three times as high as in the Netherlands. Apart from the many deaths due to tuberculosis and respiratory diseases, there is a strikingly high number of fatalities due to intestinal diseases, almost 30 times as high among the Italian I-4-year-old children as among the Dutch ones. The much higher Italian pre-school age mortality is therefore mainly manifest in the very high intestinal diseases death rate. This may partially be due to the worse hygienic conditions, but an even more important factor is probably the worse general state of health of the Italian children, in particular as regards the nutritional condition. This is the reason why tuberculosis and respiratory diseases also claim so many victims. In the warmer climate of Italy the significance of dysentery as regards preschool age mortality is probably very great, just as in the tropics (see De HaAs).

Japan shows the influence of low prosperity on pre-school age mortality even to a greater extent. In that country the mortality of these children is about $S$ times as high as in Holland. Even if it is taken into account that the statistics of causes of death in the undcrdeveloped countries are less reliable, the very high mortality from intestinal diseases, dysentery included, constitutes here a striking feature. It accounts for more than one third of all Japanese. cases of death among the I-4 age group. The mortality: from common 
infectious diseases, respiratory affections and tuberculosis also is much higher among the Japanese children of pre-school age.

Compared with the Dutch figures of about 1920 (table XX), when the preschool age death rate was about as high as the present Japanese figures, intestinal diseases and dysentery are now of far greater importance in Japan. With the same high pre-school age death rate, the pattern of causes of death is quite different. It is of importance to bear this difference and its background in mind if efforts are made to reduce the juvenile mortality in underdeveloped countries.

Table LIII shows the pattcrn of causes of death for the I-4 age group in the countries discussed, i.e., the relative significance of the various causes as regards the total mortality at this age. The table demonstrates that, roughly speaking, this pattern is fairly uniform for the pre-school age children of all 'developed' countries.

An exception is especially made of the mortality from diphtheria ${ }^{1}$, tuberculosis and accidents, which vary considerably in the different countries, and for which Holland does not show up very well. If the Dutch children of preschool age were to have the same low tuberculosis mortality as in Sweden and the same low diphtheria and accident mortality as in England, the total pre-school age mortality in the Netherlands would be $20-25 \%$ less than at present; in other words: the total I-4 age death rate would be the same as in Sweden, and as in the province of Zeeland in the Netherlands themselves.

The higher figures in the Netherlands as compared with other Western countries cannot be attributed to lower prosperity. It is possible that large families form a factor of some importance as regards the higher pre-school age mortality.

In the underdeveloped countries the pattern of causes of death is quite different: the respiratory diseases, common infectious diseases and especially intestinal affections and dysentery predominate to such a degree that the mortality from accidents, congenital defects, tumours and reticuloses is only of slight relative importance. This is mainly the result of the bad general state of health and nutritional condition of the I-4-year-old children in these countries.

The fall of the pre-school age mortality has indeed.been very great. Round about 1900 this mortality was still higher than $\mathrm{I} \%$ everywhere in Europe, areas with $4 \%$ mortality being not at all rare. At present in all countries of Northern and Western Europe the pre-school age death rate is between ro and 25 per 10,000 i.e., $0.10-0.25 \%$. This mortality has been reduced to less than one tenth of the original values in numerous countries during the past

1 not separately mentioned 
5o years. Far higher values are, however, still being found in the less privileged part of the world, and this is still by far the greater part. Reliable data are lacking, but it is, for example, known how high the pre-school age mortality was among Indonesians in pre-war Batavia (now Djakarta) about r935: approximately $7-8 \%$, or 25 times as high as in the Netherlands at the same time and many times higher than that of European children of the same age group in Batavia itself (DE HAAS).

Even though, as is well known, there is a great difference in infant mortality between these tropical regions and the Western countries, the difference in mortality of children of pre-school age is often even greater. In the same way as the latter children derive most benefit from improvement of social circumstances, they suffer, conversely, also most under extreme poverty and malnutrition in the underdeveloped areas. Recently OOMEN demonstrated that serious malnutrition was most frequent and most manifest among the. I-3year-old children of the working classes in Djakarta, and thus arrived at the same conclusions as DE HAAS some twenty. years earlier. 


\section{XVII \\ A GLANCE INTO THE FUTURE}

Table $L V$ gives the pre-school age mortality in the provinces and:large towns in 195I/I952. In the city of Utrecht and in the province of Zeeland, this mortality has declined to values considerably lower (up to $30 \%$ ) than the average for the Netherlands as a whole.

TABLE LV

Pre-school age mortality in the provinces and four largest towns in 1951-1952

\begin{tabular}{|c|c|}
\hline provinces & $\begin{array}{l}\text { I-4 age group mortality } \\
\text { per 10,000 }\end{array}$ \\
\hline Groningen . . . . . & I4. I \\
\hline Friesland . . . . . . & 17.0 \\
\hline Drenthe ....... & 20.1 \\
\hline Overijssel. . . . . . . & I5.7 \\
\hline Gelderland . . . . . & I6.7 \\
\hline Utrecht . & I6.7 \\
\hline North Holland . . . . & Is.7 \\
\hline South Holland . . . . & I5.6 \\
\hline Zeeland . . . . . . & II.O \\
\hline North Brabant . . . . & 15.7 \\
\hline Limburg . . . . . . & 16.5 \\
\hline \multicolumn{2}{|l|}{ towns } \\
\hline Amsterdam . . . . . & 14.9 \\
\hline Rotterdam . . . . . . & 14.I \\
\hline The Hague . . . . . . & 14.2 \\
\hline Utrecht $\ldots \ldots$ & I2.9 \\
\hline
\end{tabular}

In general, local death minima indicate the rates to be reached in the whole country within a fairly short time (De HAAs). The province of Zeeland has been such a region with a local minimum for a long time past. The expectation is therefore warranted that, within a few years, the total pre-school age mortality of Holland will fall to II per Io,00o (the present value in Zeeland). This is by no means a strikingly low level, because at present other West 
European countries such as the Scandinavian countries and England show a I-4 age death rate of about II per 10,000 (fig. 22), without any signs that the tendency to fall is decreasing.

The curve representing the mortality of children of pre-school age has shown a remarkably steady decline, with a somewhat increasing gradient, for a long time (fig. 3). This fall of mortality is the result of a complex of factors, influencing one another mutually and cumulatively.

The very fact that there is a complex of causal factors gives this fall a certain 'inertia of change' (TAYLOR), catastrophic situations (e.g., a war) being necessary to bring the fall of the mortality to a sudden end. The effect of this 'inertia of change' is the stronger because the great majority of causes of death are involved in the marked fall of mortality. A considerable reduction of the fatality figures for one particular disease due to a modern drug therefore results in only a slight acceleration of this tendency to fall, or in none at all.

The constancy of the decline of the pre-school age mortality and its slight variability justify an estimation of this mortality ten years ahead, by extrapolation of the curve, in the same way as done by TAYLOR for the infant mortality.

This can, naturally, only be done with the reserve that no catastrophic events will happen in the meantime. In this way the $\mathrm{I}-4$ age group mortality of I96s can be estimated at about 7 per 10,000, half the present figure at this agc.

There are only four important causes of death that have not participated in the fall of the pre-school age mortality in recent years. These are: diphtheria, congenital defects, tumours (leukaemia included), and accidents. It is possible to combat diphtheria effectively, and the accident mortality can also be reduced by sufficient attention to this problem.

From a conscrvative point of view, based on the death rates between 1900 and I950, violent death, tumours and reticuloses, and congenital abnormalities can be regarded as the so-called 'hard core' of pre-school age mortality, because the mortality from these causes has decreased so little. For the same reason, neonatal mortality is considered the 'hard core' of infant mortality.

At present tumours and reticuloses, congenital defects and violent death combined take about 650 lives of $\mathrm{I}-4$-year-old children annually, i.e., about 70 per 100,000.

Death from tuberculosis, intestinal diseases and (with general immunization) diphtheria and whooping cough, may be practically eliminated within to years. Measles and respiratory diseases combined will account for less than io deaths per 100,000 children of pre-school age, if the fall continues-at the same rate. The group of 'other causes of death' will, with a continued fall of mortality, account for about to per 100,000 pre-school age children.

According to this calculation the total pre-school age mortality of I965 will 
amount to about 90-100 per 100,000, i.e., 9-10 per 10,000, as against 16 per 10,000 in the period I950/1952.

Extrapolation of the pre-school age mortality curve as it has been up to now leads to an expected death rate of about 7 per I0,000. It is highly probable that the 'hard core' of pre-school age mortality will prove not so hard, as is also the case for neonatal mortality (DE HAAs). Even at present- this 'hard core' of pre-school age mortality is considerably smaller in some provinces than the average in the whole country. In the province of Zeeland, for example, in 1950/1952, the pre-school age mortality from tumours and reticuloses, congenital malformations. and accidents together, was only about 50 per 100,000 as against nearly 70 per 100,000 in the whole country.

In I952 England.and Wales had a death rate of less than 50 per 100,000 from. these causes.

The presumption that these causes of death will remain forming a permanent 'hard core' of pre-school age mortality is therefore too conservative, and is already being disproved by the facts.

After the reduction to one-tenth in the first half of the present century, another reduction of pre-school age mortality of half the present figure is to be expected in the next IO-IS years, provided that the Netherlands are not stricken by a new catastrophe, social and hygienic conditions remain developing in a favourable sense, and details of pre-school age mortality are combated by planned measures. Thus another 700 children of $1-4$ years old will be spared annually, which is only a reflection of a far greater decline of disease and suffering.

Social and clinical paediatrics will show quite another aspect in the near future, as appears from the percentual distribution of the pre-school age mortality roughly to be expected for I965. Only about 700 children of the approximately 800,000 then constituting the pre-school age group will die annually. Of these 700 children, about $300(=40-45 \%)$ will die from an accident, about Ioo (= nearly $1.5 \%$ ) from tumours and reticuloses and about I30 (= nearly $20 \%$ ) from congenital malformations, so that $75 \%$ of the pre-school age death rate will be due to these three causes.

All other causes of death together will account for only about I70 (= 25\%) deaths in the I-4 age group annually, i.e., approximately the same number succumbing to diphtheria alone in the past years. Even though these figures are no more than rough estimations, the general tendency is unmistakable. It can be expected with fair certainty that the aspect of paediatrics will change even further than it has done up to now. 


\section{SUMMARY}

To determine the state of health or disease of a large group of children, use can be made of data on development, morbidity and mortality. The changes that have occurred in the course of years are of special importance. There are, however, no Dutch figures on the development of children of pre-school age, comparison with former times thus being impossible. Direct determination of the disease factors by means of extensive morbidity statistics has also not been feasible so far, although interesting efforts in this direction have been. made, especially in England in recent years.

We are therefore still forced to use the mortality rates, although these figures do not reflect all aspects of the general state of health of a group of the population. Study of the mortality statistics over long periods, however, not only discloses the trend of the mortality, but also reflects the state of health or disease to a greater degree than is often realized and may help to illuminate the highway social medicine is to follow.

This paper gives an analysis of the mortality of I-4-year-old children, based mainly on the official mortality statistics.

The death rates constitute a collection of facts which, by systematical arrangement and tracing of correlations, yields a better comprehension of the factors determining the death rate. The analytical working method necessarily leads to separate consideration of these many factors. It should, however, be borne in mind that all factors form a 'causal and meaningful unity', one factor serving in no case as the sole explanation for the differences in death rate.

Those studying child mortality have, in general, confined themselves to the mortality of infants, probably because this is quantitatively of the greatest importance and appeals most to the imagination. The literature on infant mortality has thus become very extensive, in contrast to the small number of publications on mortality of children of pre-school age.

If, however, the trend of juvenile mortality of the past hundred years is studied, it is not the infant mortality that has declined most, but the pre-school age mortality, although there has been practically nothing in the nature of special social-medical care as regards the I-4 age group. 
In other countries than the Netherlands the fall of the pre-school age mortality has also exceeded that of any other age group.

The mortality of the I-4 age group in the Netherlands has been reduced to less than one tenth of its original value during the past fifty years. During this period it has declined in a remarkably steady way from nearly 2 per hundred to I.S per thousand. At the beginning of the present century nearly ro,000 Dutch children between I and 4 years died annually, but at present this figure does not reach even $\mathrm{I}, 500$, whereas this number would have been nearly 20,000 if the death rate had remained the same during these 50 years. The difference between these figures is greater than the total number of pre-school children in the city of Utrecht.

The death rate of pre-school children is however still considerably higher than that of older children, and equal to that of 40 -years-olds.

The mortality of I-4-year-old children is probably. a better and more sensitive criterion of social and hygienic conditions than the infant death rate which is generally used for this purpose. This is conceivable because, especially in former times, the infant mortality was markedly influenced by the method of feeding the child, this method being not directly dependent on the social conditions. The dietary habits are also of the utmost importance for the state of health of the child of pre-school age, but the latter's nutrition, on the other hand, is directly related to social conditions. Improved nutrition is only one cause of the decline of the death rate, but an important one.

The contention that the pre-school age mortality is a more sensitive criterion of social and hygienic conditions than the infant mortality is supported by the facts that the mortality of I-4-year-old children has fallen more than that of any other age group, that this decline started earlier than the fall of the infant mortality, and that the pre-school age mortality curves showed higher peaks during the war years.

In the I-4-year age group, the I-ycar-olds have the greatest chance of dying, but the difference in mortality between the younger and older members of this group is decreasing. One of the reasons for this levelling out is the fact that the accident mortality shows only a slight decline as regards this age group. The mortality from accidents among older children of pre-school age is relatively higher than among the younger ones. The mortality from most causes of death, however, has decreased in young pre-school age children even more than among the older ones, so that the I-year-olds have shown the greatest fall of mortality of all juvenile age groups.

The mortality of boys has always exceeded that of girls, even if this excess mortality of boys is not so constant (at any rate in the I-4 age group) as is often thought. In the course of the, present century the excess mortality of 
boys has increased together with the decline of the total pre-school age mortality, and this holds true for practically all countries. This is partially based on the increasing importance of accident mortality as the total pre-school age. mortality decreases. On the other hand, the sex ratio in the mortality from various causes of death is by no means constant.

In recent years the Netherlands have shown a tendency for the excess mortality of boys to fall among the youngest pre-school children. It must be accepted, on the evidence of the death rates, that the boys form in reality the weak sex, and thus the girls initially benefit more from the improvements in social and hygienic conditions. The boys do not begin to make up for their arrears until the pre-school age death rate has fallen to a low value. This catching up of the boys, however, is masked by the increasing importance of accidents as cause of death.

The mortality of children' of pre-school age has always been higher in winter than in summer. The winter peak has remained relatively the same, in spite of the increasing importance of the accident mortality, which is especially high in summer, and notwithstanding the improved methods of treatment of the diseases causing this peak. Winter continues to exert an adverse effect on mortality so long as there is no compensation for its influence.

At the beginning of the 2oth century the towns had a higher pre-school age mortality than the rural areas. At present the reverse is the case: the accident death rate is higher in the country than in the towns. Disregarding the mortality due to accidents, there is no longer any difference between rural and urban areas as regards the total mortality of I-4-year-old children.

The total pre-school age mortality in the various Dutch provinces showed rather wide variations in former times, but at present most of the differences have been levelled out. The low pre-school age mortality in Zeeland however, which has existed for 50 years or even longer, continues to be a striking feature. Greater attention is paid to the pre-school age mortality of this province, because it may be expected that such a constantly low death rate might yield indications shedding more light on the backgrounds of the I-4-age group mortality.

The social and hygienic factors in Zeeland have not compared favourably with those in other provinces, especially in former times. They do not explain the low pre-school age death rate.

The comparatively small size of the families is probably of influence on the low pre-school age mortality in Zeeland. There are in addition various in- 
dications of a relatively good care for the I-4-year-old child in the Zeeland families, probably associated with the character of the population of this province, even though the latter statement cannot be proved with certainty. The fact that the at one time very high infant mortality in Zeeland has fallen to one of the lowest in the Netherlands - more rapidly than in the other provinces - and in spite of the fact that medical care and the social and economic conditions offer no adequate explanation of this rapid fall, strongly suggests the existence of good care for the children in Zeeland. Good maternal care can exert a greater influence on the infant death rate the lower this becomes, and it accelerates the fall of the infant mortality. The low infant mortality in Zeeland proves in particular to be based on a low post-natal mortality, which is in agreement with the idea that maternal care is of predominant importance.

The low accident mortality in the Zeeland children of pre-school age also points to relatively good child care in this province, because the accident death rate depends to a great extent on care and supervision.

The constantly low pre-school age mortality in Zeeland seems best explained by a favourable combination of good care for the I-4-year-old children. with relatively small families. Compared with these factors, the less intensive medical care and hygienic conditions are only of minor importance for this age group.

Although the figures concerning total pre-school age mortality already give a good idea of the great changes in the trend of the pre-school age mortality, a better understanding of the backgrounds necessitates a closer consideration of the mortality from the various causes of death at pre-school age.

Only the most important causes of death can be dealt with. The statistical conception 'cause of death' largely corresponds with the clinical one, but it is clear that the real cause of dying of a pre-school age child should often be sought for in the general state of health of the child when he is stricken by his last disease. This general condition is of greater importance than the cause of death itself, especially if the mortality figures are still high.

This also explains why the fall of the juvenile mortality concerns by far the majority of diseases, more or less independent of improvements in.methods of treatment and the degree of medical care.

Disregarding this dual conception of 'cause of death', the statistics of causes of death in the Netherlands can be regarded as reliable if groups of diseases are studied and only great changes are taken into consideration. Changes in nomenclature do not cause any great difficulty in the study of pre-school age mortality. 
The mortality from the common infectious diseases has decreased markedly, but not to the extent which might have been possible, and such as has.been the case in various countries. Diphtheria still takes a great number of lives of I-4-year-old children, which might have been saved by more frequent immunization at an early age. This also holds true for.whooping cough.

The trend of the mortality from tuberculosis in children of pre-school age (and in children in general) has shown an impressive fall since 1945, continuing steadily. This decline is very likely the result of the anti-tuberculosis campaign in the Netherlands, together with the relatively low pre-war level of tuberculosis mortality. Modern methods of treatment are probably of less importance than prophylactic measures. The marked decrease of tuberculosis is most manifest in childhood.

The course of the pneumonia mortality, which has also shown a marked reduction since 1945, is different from that of tuberculosis in so far as the fall was checked after several years. This can be explained by the fact that the fight against tuberculosis has primarily been preventive, and that against pneumonia curative. The latter method is less effective.

The death rate from tumours and reticuloses in the $\mathrm{I}-\mathbf{4}$ age group is remaining practically constant.

Intestinal diseases have not been of great importance as regards the pre-school age mortality in the Netherlands in the 2oth century. At present this cause of death is still of great importance in the I-4 age group in underdeveloped countries, even where the total pre-school age mortality is not higher than in the Netherlands some thirty years ago.

The mortality from congenital malformations in 1-4-year-old children has remained practically constant in the past fifty years. To form a judgement on the frequency of serious. congenital abnormalities, the death rate from these affections in pre-school age children is generally a better standard of measurement than the corresponding figures in infants.

At present accidents have become the most important cause of death in children of pre-school age, accounting for.one quarter of the total pre-school age mortality. The number of I-4-year-old children falling victims to accidents is the same as to common infectious diseases and respiratory affections combined. Drowning causes $40 \%$ of the fatal accidents in the I-4-age group, traffic accidents $30 \%$ and burns $10 \%$. At present traffic accidents alone take as many lives of children of pre-school age annually as diphtheria.

The analysis of the accident mortality in pre-school age children clearly shows the great influence of maternal care on the accident frequency. Even as regards road accidents these factors are of higher importance than the density of the traffic. 
.There is a manifest difference between the sexes in the accident rates in young children. The accident mortality of boys is considerably higher than that of girls as early as in the second year of life.

In analogy with the non-Dutch literature, the number of .I-4-year-old Dutch children needing medical help because of an accident can be estimated at 40,000-80,000 per year, I,000-I,500 remaining more or less. disabled and nearly 400 dying.

In combating this important cause of death and of disablement, the factor of care and supervision in the family must be made the central one, so that education and instruction of the mothers is of great significance. The social workers in the family, such as home-visiting nurse, maternity home help, etc., have an important task in this respect. So far little attention has been paid in the Netherlands to measures against accidents, at any rate as regards children, although it should be an important branch of child hygiene.

The fall of the pre-school age mortality has been accompanied by a relative change of importance of the main causes of death. The mortality from most caiuses of death has decreased markedly, but that due to congenital defects, tumours and reticuloses, and accidents only to a slight degree or not at all. The importance of these causes of death has thus increased considerably, at present forming $40 \%$ of the total pre-school age mortality. The changes in the pattern of causes of death reflect the great changes in paediatrics of recent years. An at one time formidable enemy such as tuberculosis. is at present hardly a problem at pre-school age, but another enemy, accidents, urgently requires measures.

The peaks in the pre-school age mortality curve during the two world wars have been about equally high, but they were based on quite different causes. During the 1914-1918 war the increase in pre-school age mortality was largely due to the influenza epidemic and respiratory diseases. The marked rise of the pre-school age mortality in the second world war was caused by diphtheria, by intestinal diseases and accidents. The considerable increase of the mortality from accidents. clearly illustrate the importance. of maternal care, which was, almost unavoidably, diminished during the years of occupation.

The formerly great differences in mortality from most causes of death between the various provinces and between urban and rural areas, have greatly diminished in importance. Regional differences in size of the family exert an influence on the mortality from common infectious diseases, although to a lesser degree than in former times. The higher frequency of congenital defects 
in the North-Eastern parts of the Netherlands, as already described for infants, is also manifest in the higher death rate from this cause among the children of pre-school age.

There is a great difference between rural and urban areas as regards the preschool age mortality from accidents, probably resulting from a higher chance of drowning in the country, leading to an accident death rate in I-4-year-old children nearly twice that in the towns.

Schematically, a fall of the mortality may be the result of:

(I) A decrease of the fatality of the diseases by:

(a) better methods of treatment,

(b) increase of resistance in the widest sense of the word.

(2) A fall of the morbidity.

The analysis of the mortality from the most important causes of death in pre-school age children shows that in general the significance of social-hygienic and demographic factors has been far greater than that of direct medical and therapeutic measures.

Increase of resistance and reduction of the frequency of disease (or a shift to higher age groups) have been of greater importance as regards the decline of the pre-school age mortality than the improved therapeutic possibilities. The young children have probably benefited only late and to an insufficient degree from the progress of medical science. It took, for instance, a long time before the introduction of the sulphonamides had a perceptible influence on the trend of the mortality in I-4-year-old children. The possibilities of combating diphtheria and whooping cough (immunization) are not utilized to the maximum extent by any means.

Studying the infant mortality in the province of Limburg, Starmans has pointed out that general social and hygienic conditions, local customs and educational level determine the infant mortality rate, independent of the availability of.medical assistance.

The number of children of pre-school age dying without having had a chance of hospital treatment, is still considerable in the Netherlands. It was possible to determine this number accurately for the period 1948/1949: nearly half of the I-4-year-old children falling victims to a common infectious disease, respiratory affection or intestinal disease, died at home. The figures suggest that too often the seriousness of a disease with an unfavourable course was not recognized in time, or that the indications for hospital admission were not made wide enough, even in areas with special children's hospitals or children's wards available at a short distance. More children would derive benefit from the advance in medical skill if there were a greater inclination and possibly also a 
greater opportunity for admission to hospital, in addition to more rapid recognition of an unfavourable course. It was unfortunately impossible to find out whether the great increase of the number of children's beds of late years. has already brought about an improvement in the admission rate of seriously ill children.

The trend of the pre-school age mortality of the past 100 years, the practically uniform fall of the mortality from most causes of death, the low pre-school age mortality in Zeeland, the still existing winter peak, are all indications that the progress of curative medicine has been only of secondary importance as regards the fall of the pre-school age mortality, compared with the social and hygienic factors. Of this complex of factors the following may be mentioned: the increase of the general standard of living, better nutrition, better hygienic habits, prophylactic medical measures and health education, and the fall of the birth rate.

A separate investigation has been carried out into the present influence of size of the family and prosperity on the mortality of I-4-year-old children. During the years 1952 and I953 this mortality was analysed in the cities of Amsterdam and The Hague, according to fathers' occupations, family size and district of residence. Prosperity, with fathers' occupations and district of residence as criteria, proved to have no demonstrable effect on the pre-school age death rate in these two cities. On the other hand, there was a clear influence of the size of the family, especially in the lower income groups; the pre-school age mortality in large families was significantly greater than in small ones. In the overpopulated quarters of Amsterdam the pre-school age mortality was higher than in the less densely populated areas, probably due to the unfavourable combination of low prosperity and large families.

The special significance of these results is that the formerly repeatedly observed differences in mortality among pre-school children based on prosperity have, if not disappeared, at least decreased to such an extent that they can only be demonstrated by means of refined statistical methods, while, on the contrary, the size of the family is still a factor of importance. It is not certain in which way family size exerts its influence, but the degree of child care is probably of high importance in this respect. The results of the analysis in Amsterdam and The Hague agree well with the conclusions based on the analysis of the low pre-school age mortality in Zeeland.

Comparison of the pre-school age mortality in the Netherlands with that in other Western countries proves that Holland does not show up particularly well, although the Dutch health statistics generally show favourable figures. 
There is a clear tendency to levelling out of the differences in pre-school age mortality in the various European countries.

A closer analysis shows that the relatively high pre-school age mortality in the Netherlands as compared with various other countries, is based on a rather high mortality from accidents and common infectious diseases, in particular diphtheria. For the rest the patterns of causes of death in the 'developed' countries are fairly uniform. The underdeveloped countries show a far higher mortality from infectious.diseases in young children, and the mortality from intestinal affections is still alarmingly high in these areas, while it has nearly disappeared in the more developed countries.

The estimation of the level of the pre-school age mortality in the coming years is based on the trend of the pre-school age mortality in recent years and the lower death. rate already reached in some areas and countries. The expectation is warranted that within Io to I 5 years the pre-school age mortality will decrease to. 8-Io per I0,000, i.e., to nearly half the present values.

Accidents, congenital defects, tumours and reticuloses together will then account for $75 \%$ of the total pre-school age mortality, all other causes of death combined for only $25 \%$. There is however still much to be done in the social medical field, in order that this expectation may be realized.

The recent markedly changed aspect of paediatrics will change again considerably within a few years. It is to be expected that serious diseases will become relatively rare in children of pre-school age (and older ones), so that 'health promotion' may completely take the place of the by then obsolete defensive attitude against disease and death. 


\section{REFERENCES}

Accident facts. National Safety Council. Chicago. 1953.

Accidents in the home; report of the standing interdepartmental Committee on accidents in the home. Loindon, r9s3.

ANDERson, O. W., Infant mortality and patterns of living. Child (Wash.) (I953), 17: 122.

Anderson, T., Respiratory infections in childhood; a study of family contacts. Proc. roy. soc. Med. (1953), 46: 59 .

BARRETT, A. M., Sudden death in infancy. In: Recent advances in paediatrics, London, r954, p. 30I.

Begaafdheidsonderzoek en intelligentiespreiding; methoden en uitkomsten van het medisch en psychologisch onderzoek bij de keuring voor de militaire dienstplicht. Utrecht, I95I.

Bouman, P, J., Geschiedenis van de Zeeuwse landbouw. Wageningen, 1946.

BOWDEN, K. M., Overlaying of infants. Med. J. Aust. (1952), 39: 609.

BransBy, E. R., Previous experience of the common infectious diseases, of immunization and of tonsillectomy in a group of school children. Monthly Bull. Minist. Hlth (Lond.) (1952), 11: 105.

BRINK, T. VAN DEN, Eerste resultaten van een statistische analyse van de loop der geboortecijfers in Nederland. Amsterdam, r949. (Inst. soc. onderzoek v. h. Nederl. volk: Commissie geboorteonderzoek; 2).

.Brtrten, R. H., Illness and accidents among persons living under different housing conditions; data based on the National Health Survey. Publ. Hlth Rep. (Wash.) (194I), 56: 609.

Britren, R. H., The incidence of pneumonia as recorded in the National Health Survey. Publ. Hlth Rep. (Wash.) (1942), 57: 1479.

- Bufrin, J. H., and Davison, W. C., Childhood cancer (tumour, leukemia and Hodgkin's disease). J. Pediat. (1953), 42: 612.

Buma, J. T., De huisarts en zijn patient; grondslagen van het medisch denken en handelen, Amsterdam, 1950.

Cammock, R. M., and MmLRR, F. J. W., Trend of mortality in childhood with special reference to tuberculosis on Tyneside. Lancet (I9SI), 2: 764 .

Candrotri, Ch., et Moing, M., Mortalité urbaine et rurale en France en 1928, I933 et I947. Paris, 1953. (Monographie de l'Institut National d'Hygiène; 3).

Charts on infant, childhood and maternal mortality, 1949. (Children's Bureau Statistical Series; 9).

Childhood mortality. In: A study of child health services in Maryland. Baltimore, I95o.

Claments, F. W., The mortality from violence in childhood in Australia. Med. J. Aust. (I952), 39: 654.

Colrbroor, L., The prevention of burning accidents in England and America. Bull. N. Y. Acad.

. Med. (I95I), 27: 425.

Colbrrook, L., and Colrbrook, V., The prevention of burns and scalds; review of 1000 cases. Lancet (1949), 2: I8r.

Collnss-Winuams, C., Accidents in children. Canad. Med. Ass. J. (I95I), 65: 53I.

Comparability of statistics of causes of death according to the fifth and sixth revisions of the international list. W. H. O. Geneva, 1952.

Craig, J., Mortality in young children in the City of Aberdeen during the fifty years 1900-1949. Arch. Dis. Childh. (I95I), 26: 399.

Davison, W. C., The pediatric shift. J. Pediat. (1952), 40: 536.

DerR, K. J. vaN, Arbeidsanalyse in een plattelandspraktijk. Thesis Groningen, r952. 
Degenaar, J., Gegevens over de sterfte aan mazelen en kinkhoest in Nederland. Thesis. Amsterdam, 1947.

Dennis, J. M., and Kaiser, A. D., Are home accidents in children preventable? Study of $49 \mathrm{r}$ cases. Pediatrics (1954), 13: 568.

Detruivg, J., Der Unfalltod im Kindesalter, speziell im motorisierten Straszenverkehr. Schweiz. med. Wschr. (1952), 82: 377 .

Dirtrich, H. F., Clinical application of the theory of accident prevention in childhood. Amer. J. publ. Hlth (1952), 42: 849.

Dincle, J. H., et al. A study of illness in a group. of Cleveland families. Amer. J. Hyg. (I953), 58: $16,3 \mathrm{I}, 4 \mathrm{I}, \mathrm{I} 74$.

Douglas, J. W. B., Health and survival of infants in different social classes; a national survey. Lancet (I95I), 2: 440.

Downes, J., Change with age in susceptibility to minor respiratory illness. Milbank mem. Fd. Quart. (1953), 30: 211.

Dykes, R. M., Illness in infancy; a comparative study of infant sickness and infant mortality in Luton. Luton, I95o.

Dykns, R. M., Grundy, F., and Lewis-Faning, E., Ilness during the first five years of life (Luton inquiry). Brit. J. prev. soc. Med. (I953), 7: 31 .

Fraser, M. S., Accidental poisoning. Practitioner (1954), 172 : 649.

GALE, A. H., A century of changes in the mortality and incidence of the principal infections in childhood. Arch. Dis. Child. (1945), 20: I.

Gallego, Barcina F., Tuberculosis en Polanco. Abstracted in: Tuberculosis Index (1953), 8 : 719.

Gauld, W. R., Innes, J., and Robinson, H. N., A survey of 647 cases of leukaemia, I938-'5I. Brit. med. J. (I953), 1 : 585 .

Gorter, E., Over sterftecijfers van kinderen van I-4 jaar in Nederland. Maandschr. Kindergeneesk. (1938), 8: 69 .

Groot, J. DE, Over den invloed welke de laatste oorlogsmaanden gehad hebben op de ontwikkeling der kinderen, geboren in en na deze periode, mede in verband met het toenemen van het aantal aangeboren misvormingen. T. soc. Geneesk. (1947), 25: I17..

HAAs, J. H. DE, Mortality according to age groups in Batavia especially amongst children. Indian J. Pediat.' (I939), 6: 23 I.

.HAAs, J. H. DE, The development of paediatric work at Batavia. J. Malaya Branch Brit. med. Ass. (1940), $4: 34$

HAAS, J. H. DE, Kindervoeding van embryo tot adolescent. Voeding (I95I), $12: 41$ I.

HAAS, J. H. DE, Perinatal mortality and maternity home help in the Netherlands. Neo-natal studies (1954), 3: $7 \mathrm{I}$.

HaAs, J. H. DE, De snelle daling der kindertuberculose. T. soc. Geneeskunde, in print.

Hindmarsh, J., Mrin, G., and Melin, K. A., Accidents in childhood. Acta chir. scand. (I946), 94: 483 .

HolinND, D. F., The disabling diseases of childhood; their characteristics and medical care as observed in 500,000 children in 83 cities canvassed in the National Health Survey, 1935-I936. Publ. Hlth Rep. (Wash.) (I940), 55: I35.

HoogendoonN, D., Over de diphtherie in Nederland; epidemiologie en prophylaxe. Leiden, í948. (Verhandelingen van het Ned. Inst. v. Praeventieve Geneeskunde; II).

Hoogendoorn, D., Wat kunnen wij verwachten van het B.C.G.? Maandschr. Kindergeneesk. (I952), $20: 369$.

HoogendoORn, D., De inentingen tegen diphtherie en de propaganda hiervoor. Ned. T. Geneesk. (I954), 98 : 1806.

Ingails, T. H., PuGH, T. F., and MCMnhon, B., Incidence of anencephalus, spina bifida and hydrocephalus related to birth rank and maternal age. Brit. J. prev. soc. Med. (1954), 8 : I7.

JACOBZiner, H., Home safety and accident prevention in a child health conference. Amer. J. publ. Hilth (1954), $44: 83$.

Kent, F. S., and Persemng, M., Home accident prevention activity. Publ. Hlth Rep. (Wash.) (I952), 67: 54I.

KNAPPER, CzN, N., Een kwart eeuw zuigelingenzorg in Nederland. Amsterdam, 1935. 
KopruUs, P. W., Kinderen in oorlogstijd; openbare les. Groningen, I946.

Krall, V., Personality characteristics of accident repeating children. J. abnorm. soc. Psychol. (I953), 48 : 99.

Kropvraagstuk in Nederland; uitg. door den Voorzitter van den Gezondheidsraad. I932.

KüGLE, M., Medizinalstatistische Betrachtungen über die Sterblichkeit der Kleinkinder, inbesondere der Kriegsjahrgänge. Thesis München, 1928.

LANCASTER, H. O., The measurement of mortality in Australia. Med. J. Aust. (I95I), $38: 389$.

LanCaster, H. O., Mortality from congenital malformations in Australia. Med. J. Aust. (I95I), 38: 318.

LANCAster, H. O., The mortality in Australia from acute infective disease. Med. J. Aust. (r952), 39: 175 .

LANCAstrer, H. O., The mortality in Australia from influenza and from diseases of the respiratory system. Med. J. Aust. (1953), 40: 672.

LANGFord, W. S., GIIDER, R., WuKIN, V. N., Pilot study of childhood accidents, New York City; preliminary report. Pediatrics (1953), 11: 405 .

LogaN, W. P. D; Mortality in England and Wales 1848-1947; a survey of the changing causes of death during the past 100 years. Population studies (I950), $3: \mathrm{x}_{32}$.

Lookzren Campagne, J. van, en Wiers, H. F., Kinderziekten in bezettingstijd. In: Medische ervaringen in Nederland tijdens de bezetting r940-1945, p. 277.

LORBER, J., The mortality from childhood tuberculosis in Sheffield; possible causes of its decline. Brit. med. J. (I953), 2 : II22.

Lowe, C. R., and MCKeOWN, TH., Incidence of infectious disease in the first three years of life, related to social circumstances. Brit. J. soc. prev. Med. (1954), 8 : 24.

MaIR, J. M., and TarT, H. P., Child deaths in Edinburgh, I90I-'51. Edinburgh med. J. (1953), 60: 212 .

Many drownings among young children. Statist. Bull. Metrop. Life Insur. Co. (I953),.34/7 : 9.

MartIN, W. J., Mortality in childhood during I920-'38. Brit. med. J. (I945), 1 : 363.

Medical report 1951, Denmark. København, I953.

Mrertrens, P. J., en VRIES, A. DE, Nederlandse volkskarakters. Kampen, 1938.

Methorst, H. W., Onderzoek naar nataliteit in verband met welstand en kindersterfte in 4 steden en I03 plattelandsgemeenten in Nederland. Mens en Maatschappij (I935), 11: 25 I.

Mor, C., Hygiënische en medisch-hygiënische voorzorg en geneeskundig schooltoezicht op de bewaarschool. T. soc. Geneesk. (1932), 10: 104.

MURPHY, D. P., Maternal age at the conception of the congenitally malformed child. Amer.J. Dis. Child. (1936), 51 : 1007.

MuNLIBF, C. J., De sterfte door verdrinking (na dertig jaren). Samaritaan (1935), $9: 380,442$.

Neurdenburg, M. G., Doodsoorzaak en statistiek. Amsterdam, 1929.

Neurdenburg, M. G., De daling van de zuigelingensterfte en van het geboortecijfer. Maandschr. Kindergeneesk. (1935), 7: 285 .

Neurdenburg, M. G., De groote daling van de jeugdsterfte. T. soc. Geneesk. (1936), 14 : I.

Nburdenburg, M. G., Algemeene statistiek der mortaliteit en der morbiditeit. In: Medische ervaringen in Nederland tijdens de bezetting I940-I945, p. 32I.

Nifuwenhulze, J. P. van, Actieve bestrijding der diphtherie. Thesis Amsterdam, 1949.

Noordam, A. L., Diphtherie in Amsterdam, Thesis Amsterdam, I948.

NORRIs, V., Review of 8,000 cases of pneumonia admitted to Dudley Road Hospital, Birmingham (1934-'38 and 1944-'48). Brit. J. prev. soc. Med. (I953), $7:$ II2.

OOMEN, H. A. P. C., Het uitwendige patroon van wanvoeding bij kleuters te Djakarta. Ned. T. Geneesk. (1954), 98 : I686.

Panel discussion. Amer. J. Publ. Hlth (1950), 40: 513.

Pascua, M., Evolution of mortality in Europe during the $20 t h$ century. Epidem. vital Statist. Rep. (I950), $3: 30$.

Pascun, M., Evolution of mortality in Europe during the 2oth century; typhoid fevers, scarlet fever, whooping cough, diphtheria, measles, malaria, smallpox, typhus. Epidem. vital Statist. Rep. (I95I), $4: 36$. 
Pasma, F., De endemische krop en haar gevolgen in den Z.O. hoek van Friesland. Thesis Utrecht, 1947.

Piưmirs, I. C.., Ec. Stat. Ber. (1943).

Polman, A., Monstruositeit en andere vormgebreken als oorzaak van doodgeboorte. T. soc. Geneesk. (I947), 25 : 69.

Polman, A., Aangeboren vormgebreken als oorzaak van doodgeboorte. Ibid.: 395 .

Polman, A., Ontwikkeling en huidige stand van de sterfte in Nederland en Belgiê. 's-Gravenhage, I95I.

Rapport du Comité-Rapporteur pour la protection de la mère, l'hygiène de la première enfance et de l'enfance d'âge préscolaire. Organ. Hyg., Société des Nations. Genève, I93I.

RzCoRD, R. G., and MCKвоwN, Tн., Congenital malformations of the central nervous system. Brit. J. soc. Med. (1949), 3: 183; (I950), 4: 26.

Roberts, H. L., Gordon, J. E., and Frore, A., Epidemiological techniques in home accident prevention. Publ. Hlth Rep. (Wash.) (I950), 67: 547.

Robinson, V. G., The flowers between. Monthly Bull. Indiana State Board'of Hlth. (I95I), p. 82.

RowNTreE, G., Accidents among children under two years of age. J. Hyg. (Lond.), (1950), 48 : 150.

RuYs, A. Cr., Een vermaning uit buitenlandse cijfers. Ned. T. Geneesk. (1954), 98 : I I04.

SAJET, B. H., Eenige statistische gegevens omtrent,kleuters (aantal, morbiditeit, mortaliteit). Amsterdam, 1929. (Statistische meded. v. h. Bureau Statistiek Gemeente Amsterdam; 84).

SajeT, B. H., en van GrLDERen, J., Sterfte aan mazelen in Amsterdam (in de jaren 1909, I910 en I9II). Amsterdam 1916. (Demogr. en hyg. stat. meded. v. h. Bureau Statistiek Gemeente Amsterdam; 48).

SAJET, B. H., en van GerdiRen, J., Kinkhoest; een medisch-statistische studie. Amsterdam, 'r9I9. (Demogr. en hyg. stat. meded. v. h. Bureau Statistiek Gemeente Amsterdam; 53).

SAlter, R. H., en Falkenburg, PH., De kindersterfte in Nederland I88I-I905: Amsterdam, 1907. (Demogr. en hyg. stat. meded. v. h. Bureau Statistiek Gemeente Amsterdam; r9).

Schoutrn, J., I200 accouchementen ten plattelande. Ned. T. Verlosk. (I903), 14: 79.

SEILRR, H. E., Home accidents. Practitioner (I954), $172 ; 628$.

Shafper, T. E., Accident prevention. In: Pediatric Clinics of North America, May 1954, p. 421.

SpencB, J., Walton, W. S., MilirR, F. J. W., A thousand families in Newcastle-upon-Tyne. London, etc., I954.

StapRRT, H. H. C., Gevaren die kleuters bedreigen. T. soc. Geneesk. (1953), 31 : 389.

Starmans, J. H., Verloskunde en kindersterfte in Limburg. Masstricht, I930.

StrigrngA-Kouws, S. E., Zeeuws Vlaanderen. Thesis Leiden, 1950.

STocks, P., Fifty years of progress as shown by vital statistics. Brit. med. J. (1950), 1 : 54 .

STRóm, J., Dödlighet och dödsorsaker hos spädbarn och småbarn mellan I och 5 år i Sverige frår I9II-1945. Nord. Mèd. (1949), 41 : 915 .

StUART, H. C., Mortality among infants and children and progress in reduction of rates from certain causes. J. Pediat. (1939), $15: 266$.

Studies in morbidity in childhood; discussion by Dr F. J.W. Miller, Dr R. M. Dykes, and Dr J. W. B. Douglas. Proc. roy. Soc. Med. (1952), 45 : 116.

SutTrB, S. et Tabar, L., Fréquence et nature des anomalies dans les familles cosanguines. Population (1954), 9: 425 .

Tasman, A., Voorbehoedende entingen tegen diphtherie, kinkhoest en tetanus. Kath. Gezondheidszorg (I953), 22: 334 .

TAYIOR, W., The changing pattern of mortality in England and Wales. Brit. J. prev. soc. Med. (1954), 8: 1 .

Tromson, D., Whooping cough; a review. Monthly Bull. Minist. Filth (Lond.) (1953), 12 : 92.

Vooxs, A. C. DE, De geboortedaling in Noordbrabant; bijdrage tot een demografische indeeling. $T$. Aardr. Genootsch. (1936), $53: 173$.

Vooys, A. C. DE, Enkele aantekeningen over het bevolkingsvraagstuk in Zeeland. T. Aardr. Genootsch. (194I), 58: 883 .

VooYs, A. C. DE, Differentiëring van het geboortecijfer in Nederland. Geogr. T. (1949), $2: 196$.

Vooys, A. C. DE, De sterfte in Nederland in het midden der Ige eeuw; een demogeografische studie. T. Aardr. Genootsch. (I9SI), 68: 233. 
WERNE, J., and GaRROw, I., Sudden deaths of infants allegedly due to mechanical suffocation. Amer. J. publ. Hlth (1947), $37: 675$.

Wheatly, G. M., Arena, J. M., and Kotter, R. H., Prevention of accidents in childhood; round table discussion. Pediatrics (1952), 9: 237.

WICKEs, I. G., A history of infant feeding. Arch. Dis. Childh. (I953), $28: 4 \mathrm{I} 6$.

Wolff, P. DE., et MEERdink, J., La mortalité a Amsterdam selon les quartiers. Population (1952), 7: 639 .

Wolfr, P. DE., et MrerdinK, J., La mortalité infantile a Amsterdam selon les groupes sociaux. Population (1954), 9: 293.

Woorf, B., Vital statistics of stillbirth and neonatal deaths. Brit. med. Bull. (1946/47), 4: 170 .

Zuigelingenstatistiek van de in 1936 geboren kinderen, die onder toezicht stonden van de Gemeentelijke Consultatiebureau's voor zuigelingen. (Meded. Med. Statist. Bureau, G.G. en G.D. Amsterdam; 42) T. soc. Geneesk. (1938), 15: 167.

Sources of statistical data:

Staatkundig en Staathuishoudkundig jaarboekje 1849-1884.

Statistisch jaarboekje voor het Koninkrijk der Nederlanden I85I-I856.

Statistisch jaarboek voor het Koninkrijk der Nederlanden I857-I868.

Statistische bescheiden voor het Koninkrijk der Nederlanden I867-1876.

Statistiek van den loop der bevolking van Nederland 1878-1882.

Vijfjarig overzicht van de sterfte naar leeftijd en oorzaken des doods 1875-1879; I895-I899.

Statistiek van de sterfte naar de leeftijd en oorzaken van de dood I900-'42

Sterfte naar doodsoorzaken, leeftijden en geslacht. C.B.S. 1943-I952.

Maandelijkse mededelingen van de Geneeskundige Hoofdinspectie v. d. Volksgezondheid I95I, I952, I953. In: T. soc. Geneesk.

Maandschrift van het Centraal Bureau voor de Statistiek, 1946-I952.

Maandstatistiek van de bevolking, I953.

Epidemiological and vital statistics report, World Health Organisation. (I950), 3: 63; (I95I)

4: 197 ; (I952), $5: 470 ;$ (1953), $6: 348$.

Inkomensverdeling I950. C.B.S., I954.

Berekeningen omtrent de toekomstige loop der bevolking. C.B.S. 1951.

I2e Volkstelling, serie A deel 4. Utrecht, I95r. 
XXIII. Dr P. WALLER-FETTER, Onderzoekingen over de neutralisatie- en haemagglutinatieremmingsreactie bij enige virusinfecties. . . . . . . . . . . . .

XXIV. Dr J. B. Wilterdink, Hepatitis infectiosa, een epidemiologische studie . . . . . . . . . . . ,, , 6.50

XXV. W. Winsemius, E. R. B. Janssen-van der Schoot W. F. Donath, A. DE WaART, Vitamine C en geestelijke

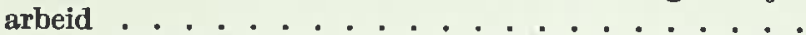

XXVI. Dr J. F. PH. Hers, The histopathologie of the respiratory tract in human influenza . . . . . . . . geb. , 17.50

XXVII. Dr Lie KhINg Ting, Onderzoekingen over het kweken van Mycobacterium tuberculosis in het bebroede kippenei ing. ,, 13. -

XXVIII. Dr H. H. van Gelderen, Pre-school child mortality in the Netherlands . . . . . . . . . . . . . . , , 9.-

\section{ONDERZOEKINGEN EN MEDEDELINGEN UIT HET NEDERLANDS} INSTITUUT VOOR PRAEVENTIEVE GENEESKUNDE

In deze serie zijn verschenen:

I. Dr J. D. Veruinde, Manifestations névraxiques et histopathologiques, obtenues chez des lapins inoculés par voie souscutanée avec la neurovaccine et le virus de l'herpes

niet in de handel

II. Ong Sion Guan, Over een positieve reactie van BordetWassermann, verkregen met een serum tegen longweefsel en een vaccine-immuunserum . . . . . . . niet in de handel

III. E. Gorter, De splitsing van eiwitten . . . . . . niet in de handel

IV. De personeelsleiding in de onderneming . . . . . . . ing.f 5.-

V. Het maatschappelijk werk in de bedrijven . . . . . . . , , , 2.-

VI. Studies on the antigenic composition of human influenza virus A strains. . . . . . . . . . . . . . . . . , , 4.-

VII. Prof. Dr A. Polman, Over consanguine huwelijken in Nederland. . . . . . . . . . . . . ,, , 2.-

VIII. Prof. Dr A. Polman, Geografische en confessionele invloeden bij de huwelijkskeuze in Nederland . . . . . , , 2.50

IX. Dr L. M. Brans, Studies on the antigenic composition of influenza virus B-strains . . . . . . . . . , , 5.-

X. M. C. J. Baronesse Mackay, Tumor cerebri en ontwikkelingsstoornissen . . . . . . . . . . . .

XI. Prof. Dr J. D. Verirnde, C. A. G. Nass, Dr O. Maks'TeNIEKs en A. C. HEKKER, Voorlopige resultaten van de vaccinatie tegen influenza. . . . . . . . niet in de handel

XII. Dr W. Winsemius, Enkele beschouwingen aangaande voorlichting en propaganda op gezondheidsgebied . . . ing. $f \quad 2.50$

XIII. Dr C. Den Hartog, C. A. G. Nass en F. W. Frets, Onderzoek naar de voeding van de Leidse studenten . . . . . , , , 4.- 